\title{
Acto-myosin based mechano-sensitivity of cells - comparing human mesenchymal stem cells and differentiated cells
}

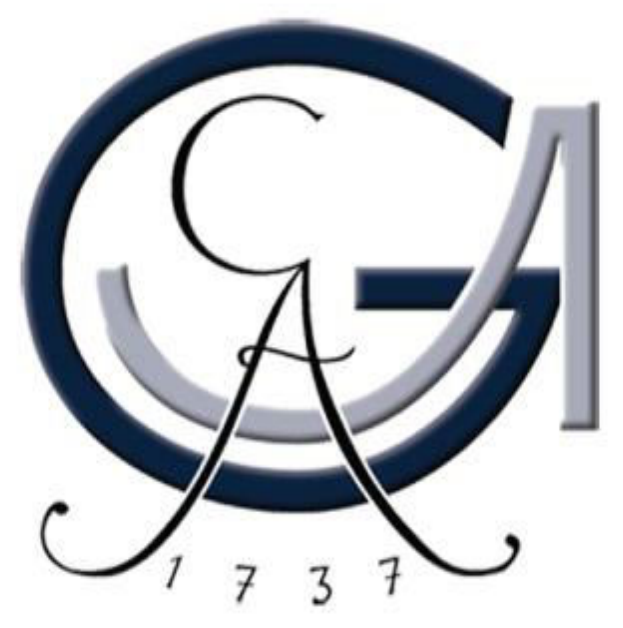

By Galina Kudryasheva 



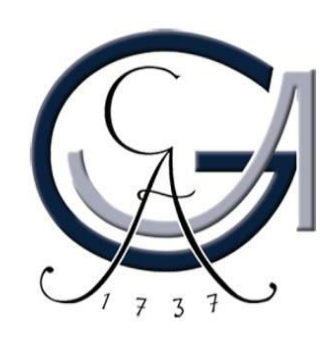

\title{
Acto-myosin based mechano-sensitivity of cells - comparing human mesenchymal stem cells and differentiated cells
}

\author{
Dissertation \\ for the award of the degree \\ "Doctor rerum naturalium" \\ of the Georg-August-Universität Göttingen \\ within the doctoral program \\ Physics of Biological and Complex Systems \\ of the Göttingen Graduate School for Neurosciences, Biophysics, and \\ Molecular Biosciences (GGNB) \\ of the Georg-August University School of Science (GAUSS)
}

submitted by

\section{Galina Kudryasheva}

from Krasnoyarsk, Russia

Göttingen 2017 


\section{Thesis Committee}

Dr. Florian Rehfeldt

( $3^{\text {rd }}$ Institute of Physics - Biophysics, University of Göttingen)

Prof. Tim Salditt

(Institute for X-Ray Physics, University of Göttingen)

Prof. Annette Zippelius

(Institute for Theoretical Physics, University of Göttingen)

\section{Members of the Examination Board}

$1^{\text {st }}$ Referee: Dr. Florian Rehfeldt

( $3^{\text {rd }}$ Institute of Physics - Biophysics, University of Göttingen)

$2^{\text {nd }}$ Referee: Prof. Tim Salditt

(Institute for X-Ray Physics, University of Göttingen)

\section{Further members of the Examination Board}

Dr. Dieter Klopfenstein

$3^{\text {rd }}$ Institute of Physics, University of Göttingen

Dr. Alexander Egner

Optical Nanoscopy, Laser-Laboratorium Göttingen e.V.

Prof. Stefan Klumpp

Institute for Nonlinear Dynamics, University of Göttingen

Prof. Annette Zippelius

(Institute for Theoretical Physics, University of Göttingen)

Date and place of the oral examination:

16.03.2017 


\section{Affidavit}

I herewith declare that I have produced this dissertation without the prohibited assistance of third parties and without making use of aids other than those specified; notions taken over directly or indirectly from other sources have been identified as such. This dissertation has not previously been presented in identical or similar form to any other German or foreign examination board.

The thesis work was conducted from July 2013 to February 2017 under the supervision of Dr. Florian Rehfeldt at the Third Institute of Physics - Biophysics.

Galina Kudryasheva Göttingen, February ${ }^{3 \text { rd }}, 2017$ 



\section{Abstract}

Within the last decades it was discovered that the cellular microenvironment plays an important role in cellular processes and cell fate can be directed by mechanical properties of the extracellular matrix (ECM), which can have various elasicities. Cells can sense mechanical properties of their surrounding with contractile acto-myosin stress fibers through focal adhesions and generate force throughout the cell. Human mesenchymal stem cells (hMSCs) are a striking example for mechano-sensing and transduction. They can differentiate into various cell lines by plating them on substrates with different elasticities for several days up to weeks. Interestingly, morphological changes of the acto-myosin fibers and the global cell shape appear already within the first 24 hours of culture.

In this thesis, we compare morphological changes of hMSCs, which were chemically and mechanically driven towards differentiation into muscle cells. We present that both, chemical preculture (in addition of dexamethasone or transforming growth factor $\beta 1$ ) and mechanical preculture (seeding on elastic substrate with muscle-like rigidity) changes stem cell morphology, measured by the cell area and aspect ratio. I found that the morphology of these treated cells is close to muscle cell's shape. Moreover, after a week of culture on muscle-like rigidity hMSCs did not lose their ability to readapt to new environment.

Furthermore, we investigate spreading mechanics of various already committed cell types on elastic substrates. We found that cell spread area on a 2D surface monotonically increases with the substrate elasticity independent of cell type and size, which is in good agreement to recently stated theoretical predictions. Though the extracted parameters from the theoretical predictions differ between the cell lines, we confirm that the spreading process is not cell type specific. The presented results support the importance of non-muscle myosin II's (NMMII) for cellular mechano-sensing and -transduction. We show that addition of low concentrations of the NMMII inhibitor blebbistatin affects cell morphology only on soft substrates. This mild blebbistatin treatment facilitates cell spreading on soft substrates and prevents formation of focal adhesions, whereas cellular morphology on stiff substrates is not affected. The results suggest a model emphasizing the importance of contractile forces in the acto-myosin cortex during cell spreading. 


\section{Table of contents}

Chapter 1 Introduction

Chapter 2 Biological Background

2.1. Cellular mechano-sensing 8

2.2. Cell spreading 9

2.3. Inhibition of myosin motor activity 10

2.4. Human mesenchymal stem cells 11

2.5. Theoretical model of cell-substrate interactions 13

$\begin{array}{ll}\text { Chapter } 3 \text { Experimental Methods } & 16\end{array}$

3.1. Cell culture 16

3.2. Chemical induction of hMSCs into muscle 16

3.3. Blebbistatin treatment 17

3.4. Gel preparation 17

3.5. Probing visco-elasticity 19

3.5.1. Atomic force microscopy 19

3.5.1. Rheology 22

3.5.3. Comparison of PAA gel elasticity using rheometry and 25 atomic force microscopy

3.6. Immunostaining 26

3.7. Fluorescence microscopy 27

3.8. Image analysis 28

3.8.1. Area and aspect ratio analysis 28

3.8.2. Focal adhesion analysis $\quad 29$

3.8.3. Protein expression analysis using immunofluorescence $\quad 30$

3.9. Filament sensor $\quad 32$

3.10. Extraction of the effective cell elasticity from the model 32

3.11. Optical trap 34

Chapter 4 Chemical and mechanical induction of hMSCs 35

4.1. Introduction 35

4.2. Chemical induction 36

4.2.1. Effects of dexamethasone and hydrocortisone on stem cell 36 
differentiation

4.2.2. Effects of long and short culture in transforming growth factor $\beta 1$ on stem cell differentiation

4.3. Mechanical induction of hMSCs on gels with muscle-like rigidity 42

4.4. Myogenin expression in muscle-induced hMSCs and committed myoblasts

4.5. Summary and discussion

Chapter 5 Mechanics of hMSCs and committed cells

5.1. Spreading mechanics on elastic substrates 51

5.2. Cellular spreading dynamics 54

5.3. Applying the theoretical model on cellular spreading 56

5.4. Myosin II inhibition 62

5.4.1. Inhibition of the myosin activity in SAOS-2 cells 62

5.4.2. Inhibition of the myosin activity in hMSCs 64

$\begin{array}{ll}\text { 5.4.3. Dynamics of myosin inhibition } & 67\end{array}$

5.4.4. Quantification of myosin localization 70

5.4.5. Analysis of focal adhesions 72

5.5. Probing visco-elastic characteristics of blebbistatin treated cells $\quad 75$ by Atomic Force Microscopy (AFM)

5.6. Summary and discussion 78

Chapter 6 Outlook $\quad 82$

$\begin{array}{ll}\text { Conclusions } & 85\end{array}$

$\begin{array}{lr}\text { Appendices } & 87\end{array}$

$\begin{array}{ll}\text { List of references } & 101\end{array}$

$\begin{array}{ll}\text { Acknowledgements } & 110\end{array}$

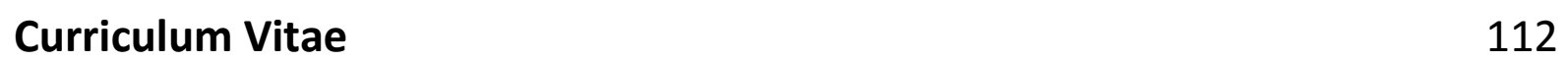




\section{Chapter 1. Introduction}

Biophysics is a comparably young discipline, particularly the field of cellular mechanics. The first physical and medical studies of biological systems focused on electrical and chemical signaling, but only within the last three decades scientists found the importance of mechanical sensing and signaling. From a physicist's point of view cells are highly complex and inhomogeneous many-particle bodies and detailed models which describe their behavior are still in progress. Due to this complexity, typical experiments measure and evaluate only a limited set of parameters. That is why coarse-grained approaches became popular regarding the description of biological matter. Even more, in living beings, cells rarely occur as single objects but mostly in clusters leading to the formation of various types of tissues. The human body, for instance, consists of tissues with different mechanical properties. The stiffness of these tissues varies from very stiff as bone consisted of osteoblast (Young's modulus $E>30 \mathrm{kPa}$ ) to very soft as brain consisting of neurons (Young's modulus $E 0.1-1 \mathrm{kPa}$ ) down to complex fluids like blood consisting of hemocytes $(1,2)$.

It is crucial to understand the mechanical properties of single cells and their dynamics to e.g. understand diseases like cancer tumor spreading which is based on the enhanced motility of cells. On the other hand it is a tempting vision to control cell and tissue growth in order to be capable of healing damaged organs or even engineer tissues with new properties.

During tissue formation cells attach to each other, build cell-cell connections, or interact with each other indirectly via a molecular framework being present within between the cells. In fact, most of the cell types in our body are adherent cells, which do not grow in suspension, but have to attach to a solid substrate for instance to the extracellular matrix (ECM) which provides cell-specific ligands. The attachment process happens by forming adhesion points, which connect the cell's internal cytoskeleton to the attached surface. One component of the cytoskeleton are so called stress fibers (SF), consisting of cross-linked actin bundles. These stress-fibers interconnect the focal adhesion within the cell. Myosin motors are a second key player of the stress fibers. They can attach to actin filaments, crosslink them. Moreover, they can produce contractile stress inside the cell (3). Interestingly, SFs are coupled to the nucleus (4) and the stress is transmitted to it. By the stress the nucleus 
could be compressed, which has profound effects on gene transcription and influences nuclear structure and function $(1,5,6)$.

Beyond this active force generation, cells are capable of sensing the stiffness of their surroundings. This plays the role of a feedback loop and so the mechanical properties of the material the cell attaches to can impact cellular morphology (7). That means cellular microenvironment plays an important role in the cell's fate, i.e. its protein expression levels, its shape and function depends on the mechanical properties of the surrounding. Human mesenchymal stem cells (hMSCs) are a prominent example for that. They provide the evidence that differentiation is not only regulated by the stem cell's genetics or the chemical environment, but also by the mechanics of the microenvironment. In vitro assays gels with defined stiffness and covered with according ligands mimicked the ECM. When placing hMSCs on mimicked ECM, it can differentiate them towards the tissue type with a similar intrinsic elasticity (1). Already after one week of culture cells express specific markers showing their commitment towards neuronal, muscular or bone lineages depending on the stiffness they were placed on. Interestingly, this differentiation process can be stopped just by blocking myosin motor activity (1).

Cells adapt their shape according to the surrounding and these changes in cellular morphology be seen already after 24 hours of culture on different substrates $(1,8)$. One can characterize cells by their structural differences, such as cell size and shape as well as the alignment of the SFs. That is why in this work we measured the cell morphology, which serves as an early marker for microenvironment adaptation. A recently proposed theoretical model describes the relation between cell shape and the stiffness of the underlying two-dimensional substrate and was experimentally proven on the example of hMSCs (9). The model predicts the monotonic increase of the cell spread area with the matrix elasticity. As a follow up investigation on this finding, we targeted on the question if this model also holds true for already differentiated hMSCs. Even more, we checked the model's validity for committed cells. Besides these examinations, the presented work focuses on getting a better understanding of the spreading process depending on the elasticity of the mimicked ECM. Additionally, it reveals the importance of myosin II motors in the complex interplay of acto-myosin stress fibers and focal adhesions in their response to the ECM elasticity. 
The thesis is structured as follows:

In chapter $4 \mathrm{I}$ will show analysis and comparison of morphological changes of hMSCs, where differentiation towards muscle cells is promoted chemically and mechanically. I will demonstrate that both chemical and mechanical induction changes cellular susceptibility to the matrix.

Then, chapter 5 presents the investigation of spreading behavior of already committed cells and experimentally validate the suggested theoretical model (9). Then I will use the model as a tool to extract cellular elasticities. In the chapter 5 I will also show that the model prediction is not cell type specific, i.e. hold true for many different cell lines.

In order to get a more detailed insight into the role of acto-myosin activity during the spreading and mechano-sensing process, we use the specific myosin inhibitor, blebbistatin, to measure effects on cell morphology. In particular, I will show in the chapter 5 , that low concentrations of blebbistatin alters cell spread area on soft substrates. This finding leads to suggesting a model emphasizing the role of contractile forces of the acto-myosin cortex during mechano-transduction. Moreover, I will present a quantified analysis of the numbers of focal adhesion points under addition of the drug.

In sum, this work contributes by a number of new experimental findings to a better understanding of the importance of the mechanics of the extracellular matrix for cellular spreading and differentiation. It thereby provides the basis for further modeling of tissue dynamics. 


\section{Chapter 2. Biological Background}

\subsection{Cellular mechano-sensing}

The most important role in the cellular mechano-sensitivity play actomyosin stress fibers (SFs) and focal adhesions (FAs). Actin is a monomer composed of 375 amino acids (43 kDa). Each monomer is called global actin or G-actin and contains adenosine triphosphate (ATP) at ATP-binding site and a hydrolytic site (opposite sides of the molecule). Actin monomer binds to two other G-actin and polymerize to form actin filaments, which are called F-actin (the process is called nucleation). Hydrolysis of one monomer causes dephosphorylation of the ATP-group to ADP, which leads to a conformational change where another monomer can bind. Here one end contains ATP-binding site and another hydrolytic site. Actin filaments are able to grow by addition of other monomers to both ends, but one end called "plus end" containing ATP elongates faster than the "minus end". Actin nucleation is an essential process for actin polymerization. Myosin motors are using the actin filaments to transport vesicles or cell organelles by walking from minus end to plus end across the cell. Myosin motors are usually divided into tail and head domains. The head domain is typically bound to actin filament. Moreover, myosin II motor has a double head. Whereas the tail interacts with cargo molecules and other myosin subunits and regulates motor activity $(10,11)$. Myosin II molecules gather into bipolar filaments through the tails interaction. These myosin filaments in non-muscle cells are known as mini-filaments. The name is given due to the small size in non-muscle cells (30-40 myosin heads) in comparison to the myosin filaments in muscle cells (about 300 myosin heads). A composition of actin filaments, cross-linked by proteins like $\alpha$-actinin (12), and bipolar myosin filaments, coupled to the bundles, form stress fibers. Nowadays there are several types of stress fibers distinguished: dorsal and ventral SFs, transverse arcs and perinuclear caps (figure 2.1) (12-14).

Dorsal SFs are coupled to FAs at their one end and with another end to transverse arcs. They are mostly found in the lamelapodia and have a lack of myosin motors.

Ventral SFs are contractile SFs, bound at both ends with FAs and run along cell periphery. 
Transverse arcs are curved filaments, consisting of actin bundles. These SFs are usually not connected to FAs.

Perinuclear actin caps consist of SFs above the nucleus. The caps are regulating the shape of the nucleus.
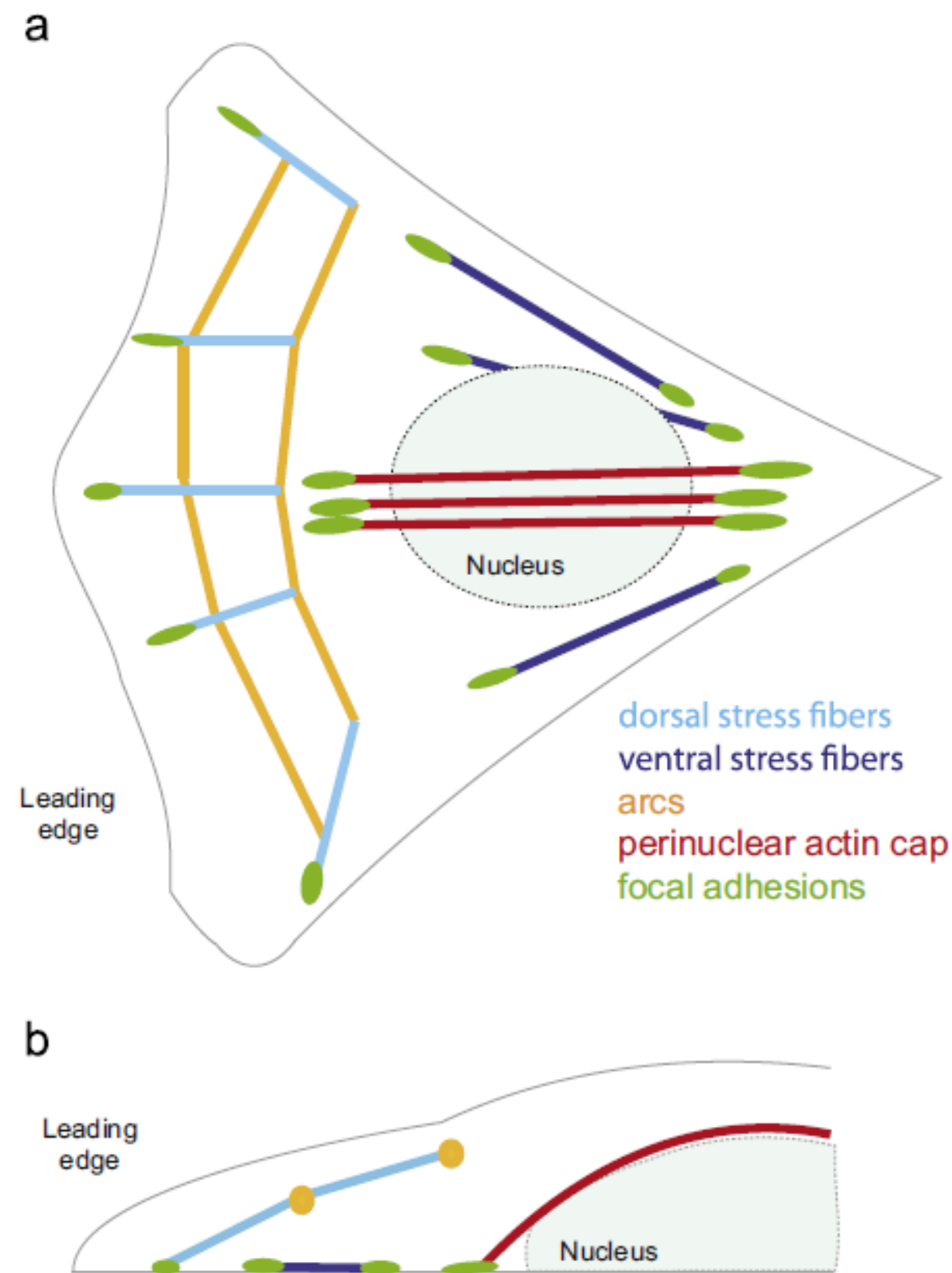

Figure 2.1. Types of stress fiber in migrating cells. Schematic representation of SFs in motile cells, (a) top and (b) side views. Four categories of SFs are observed: dorsal SFs, transverse arcs, ventral SFs and the perinuclear actin cap. (13)

During cell attachment to the extracellular matrix it forms focal contacts, which mature then to focal adhesions (FAs), see figure 2.2. This complex is shown to react to physical stimuli by altering cellular biochemical pathways $(15,16)$. Acto-myosin filaments are also known to play an important role in the 
regulation of cellular shape and its motility (17). During cell adhesion and proliferation cells exert forces by pulling and pushing the substrate (18). By these forces cells probe the substrate stiffness and depending on it actin starts to polarize.

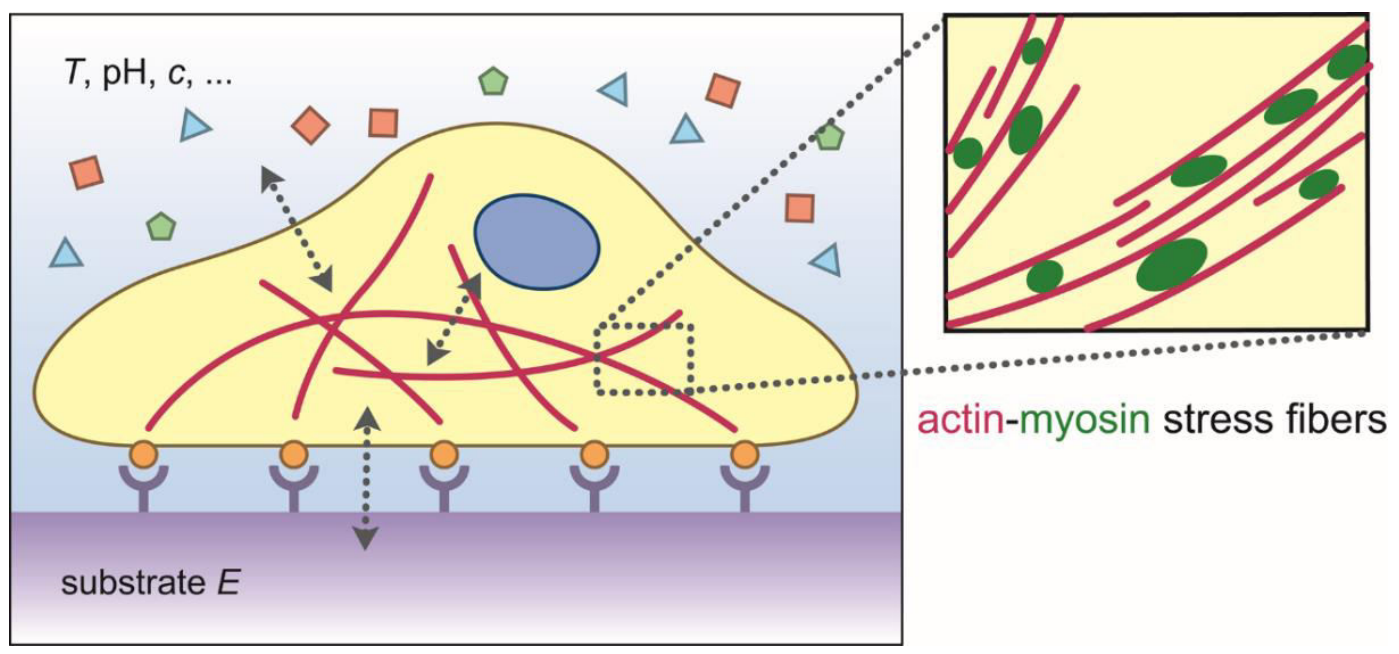

Figure 2.2. Schematic drawing of the cell adhesion to the ECM. The cell is attached via FAs (orange dots), which are interconnected with SFs, made of actin filaments (red) and myosin motors (green). (19)

Composition of a focal adhesion

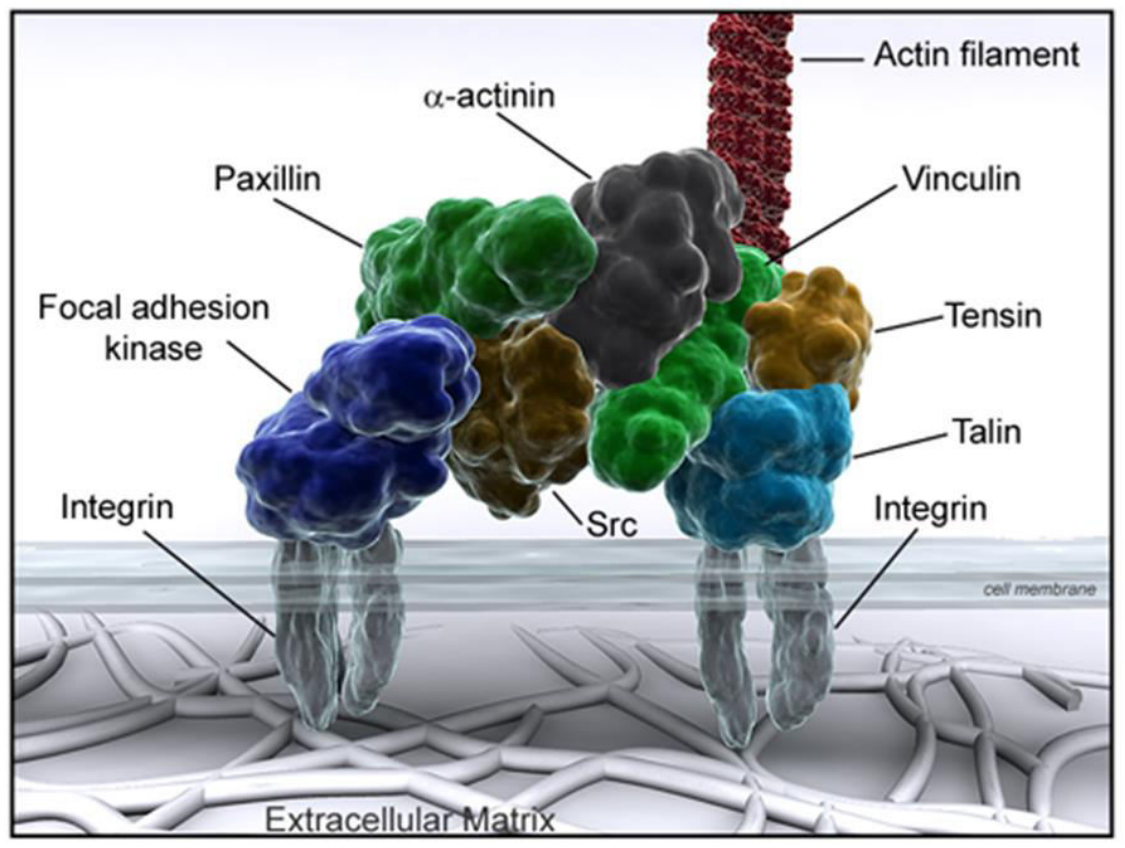

Figure 2.3. Schematic image of a focal adhesion complex. FAs are composed of many different proteins which link the cell to the ECM via integrins and such proteins as vinculin, paxillin, talin etc. They play the role of force transductors. (20) 
The sketch on figure 2.3 shows the main components of FAs. Though FAs may consist of up to 200 proteins, it was shown that integrin, talin, vinculin, paxillin and the focal adhesion kinase are the important players in cellular mechano-sensing $(20,21)$. Integrin is the essential protein especially at the first stages of adhesion to ECM, spreading and signal transmission from the substrate to the cell. It binds to proteins like collagen, fibronectin or laminin present in the ECM. One of the first proteins recruited by integrin is talin, it links integrins to actin filaments and binds to other proteins as paxillin and vinculin (22). Interestingly, researchers found that FAs can be changed in size depending on the forces applied to the cell (23). The size of the FAs varies from $1 \mu \mathrm{m}^{2}$ and greater (24).

\subsection{Cell spreading}

Cell spreading as well as cell motility are dynamic processes which require cell deformation, the formation of adhesion points and further actin polymerization. In the first stages of spreading, adhesion points play an essential role in sensing and responding to the microenvironment. To start forming connection points with the ECM, the cell needs to find surface receptors for attachment. It was shown previously that the type and speed of spreading directly depends on the amount of receptors available on the surface: a higher amount of ligands initiates faster and more isotropic spreading $(25,26)$.

Nowadays researchers are able to distinguish several phases of spreading, as presented in figure 2.4. The early stage of cell spreading is commonly characterized as a passive step, where deformation and disruption of the cell cortex occurs. This process highly depends on stiffness and tension of the cortex. The cell forms adhesion points with the ECM via integrins. It was shown that at this stage the cell already exerts forces on the substrate, but they are significantly lower than forces present at later stages $(26,27)$. These contractile forces are caused by non-muscle myosin lla motors (28). Next phase of spreading is characterized as the actin polymerization step (27), which is caused by protrusive forces in the cell periphery. The cell extends its protrusions to further attach to the substrate and form new adhesion points. This movement increases cytoskeletal tension inside the cell. 


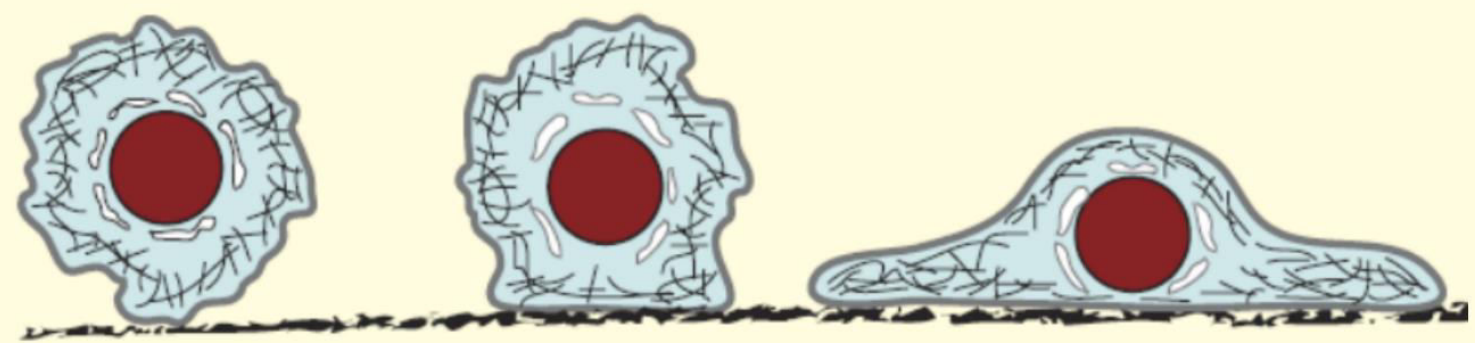

Figure 2.4. Scheme of cell attachment and spreading (29).

The last step is the most active phase, which involves simultaneous actin polymerization and myosin contraction. The cell exerts contractile forces at higher magnitudes than before, which again depends on matrix elasticity, ligand concentration in the ECM and size of the focal contacts $(26,27,30)$. In this phase acto-myosin SFs are formed and maturation of the focal contacts towards focal adhesions are observed (31).

\subsection{Inhibition of myosin motor activity}

Myosin II motors play an essential role in cellular mechano-transduction and spreading. Class two consists of skeletal, cardiac, smooth muscle myosins and non-muscle myosin. They are presented in the respective muscle tissues. In contrast, non-muscle myosin II presents in all mammalian cells and have three different isoforms: Ila, IIb and IIc (32). All the isoforms are distributed in the entire organism, but each cell type contain special amount of isoforms: when some cells have only one isoform, another can have three different (33). Additionally, all the three isoforms display similar biophysical properties, but have significant differences in their structure and dynamics (32).

As we know that non-muscle myosin II is directly involved in cellular mechano-sensing, it was the reason why inhibiting its function was a part of the investigations presented in this report. The most well-known myosin-inhibiting drug is blebbistatin, which is a noncompetitive inhibitor, blocking myosin function by preventing a critical step in the myosin-actin cycle without nonspecific binding in acto-myosin complexes (34). Namely, myosin motor moves along actin filament by using ATP energy, which is known as a power stroke (figure 2.5). The binding of ATP to acto-myosin complexes results in a 
detachment of myosin from actin filament. In the next step ATP hydrolyzes to $\mathrm{ADP}$ and phosphate $(\mathrm{Pi})$. After releasing $\mathrm{Pi}$ the myosin-ADP complex binds again to the actin filament, triggering the movement of the myosin motor along the filament. After the last step of ADP release, the new acto-myosin complex is formed (35).

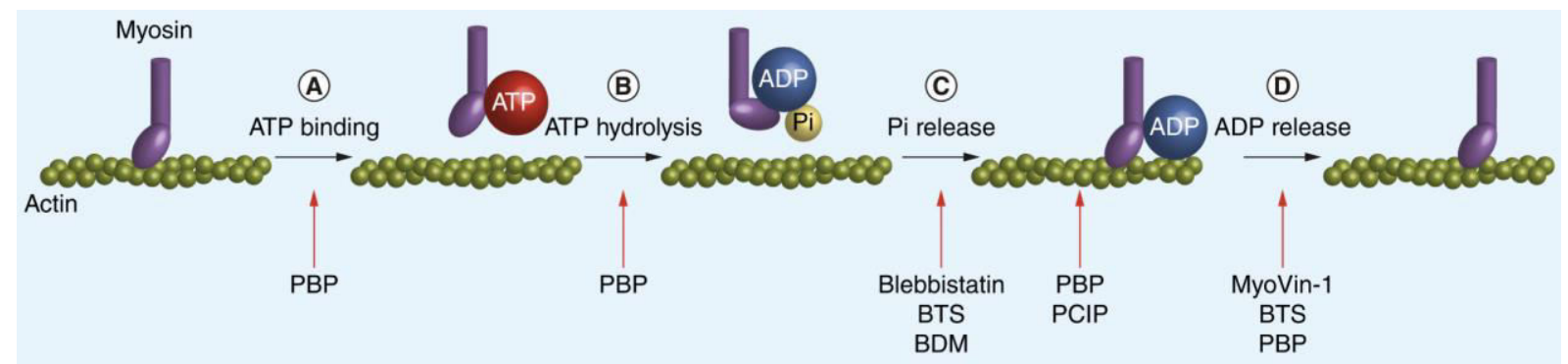

Figure 2.5. Mechanism of myosin inhibition. (36)

When blebbistatin is present, it reacts with the detached form of myosinADP-Pi. In detail, it blocks the release of the phosphate and further binding of myosin-ADP to actin.

It is still an ongoing discussion of how blebbistatin alters cell spreading driven by actin polymerization. Some investigations showed that in presence of the drug spreading is inhibited (37-41). On the contrary, several studies presented that myosin II facilitates spreading, i.e. adding blebbistatin, promoted spreading in fibroblasts and T cells $(28,42)$. Interestingly, it was also observed that inhibition of myosin motors by blebbistatin altered the formation and maturation of focal adhesions $(41,43)$

\subsection{Human mesenchymal stem cells}

Human mesenchymal stem cells (hMSCs) are multipotent stem cells, present in bone marrow, that can be differentiated to several cell types like osteoblasts, chondrocytes, adipocytes, myoblasts and neurons $(44,45)$. hMSCs can guide tissue regeneration by replacing damaged parts of the respective areas. Thus, stem cell differentiation might be a strategy for healing and replacing damaged tissues. It was previously demonstrated that hMSCs could be differentiated towards muscle cells by the addition of special chemicals, as 
dexamethasone and hydrocortisone $(1,46,47)$, or growth factors, as transforming growth factor $\beta 1$ (TGF- $\beta 1)(48,49)$, directly to the culture media.

Remarkably, it was shown a decade ago that not only chemicals in the surrounding solution can drive stem cell differentiation, but also the mechanics of the microenvironment. Engler and his co-workers mimicked the ECM by replacing it with elastic hydrogels with different elasticities (1). They produced polyacrylamide gels covering the whole physiological range of elasticities, from soft as neurons to stiff as bones. Gels were coated with collagen type I to provide the necessary binding surface receptors, and plated hMSCs on those gels.

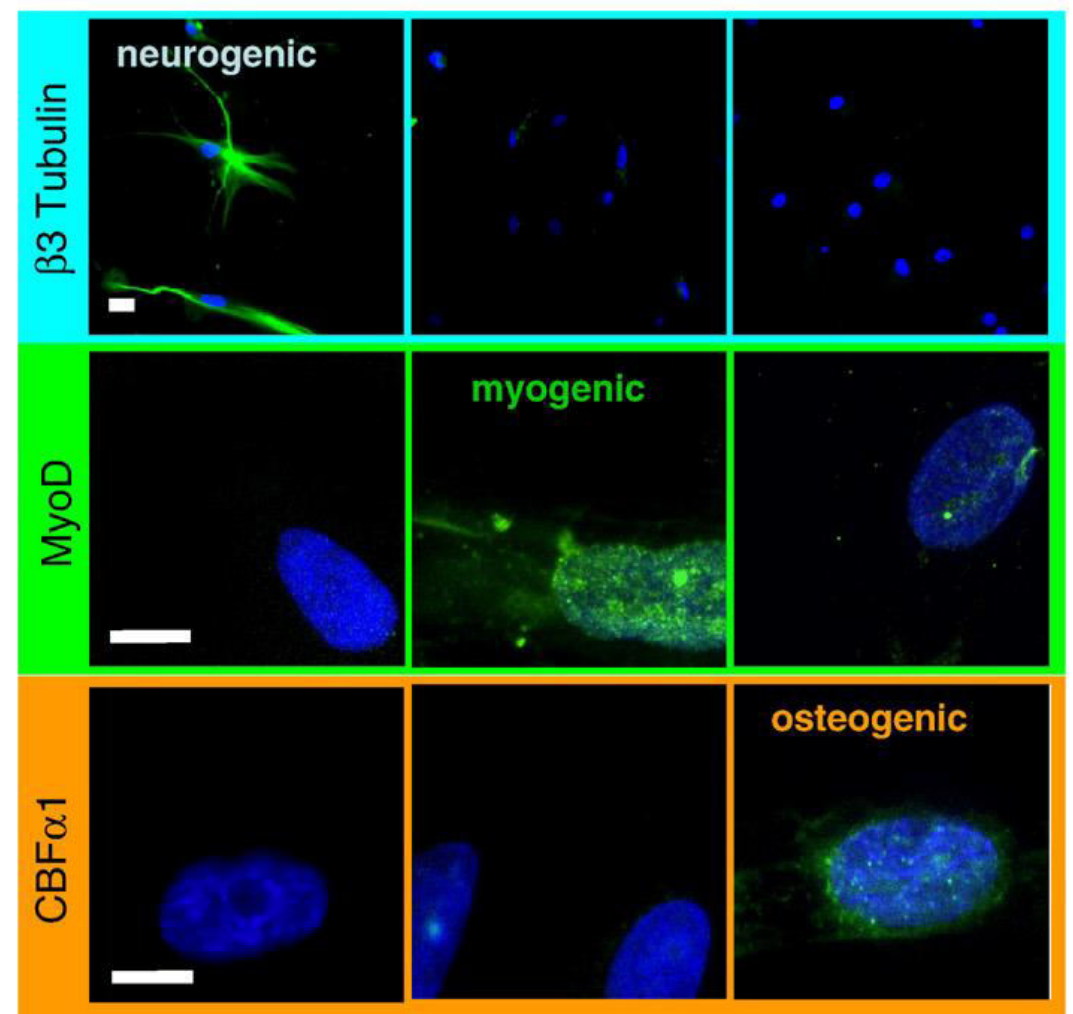

Figure 2.6. Mesenchymal stem cell differentiation on elastic substrates. The neuronal marker $\beta 3$ tubulin is expressed in hMSCs only on the soft, neurogenic, matrices. The muscle transcription factor MyoD1 is upregulated in hMSCs only on myogenic matrices. The osteoblast transcription factor CBF $\alpha 1$ is likewise expressed only on stiff, osteogenic gels.

Scale bar is $5 \mu \mathrm{m}$. (1)

Cells were kept for 1-4 weeks under the same media conditions but on different elasticities. After a week of culture they reported expression of celltype specific markers (figure 2.6). hMSCs cultured on soft gels ( 1 kPa) expressed the neurogenic marker $\beta 3$ tubulin, cells on substrates with an 
intermediate stiffness $(\sim 10 \mathrm{kPa})$ expressed myogenic markers and on stiff substrates ( $30 \mathrm{kPa})$ - osteogenic marker.

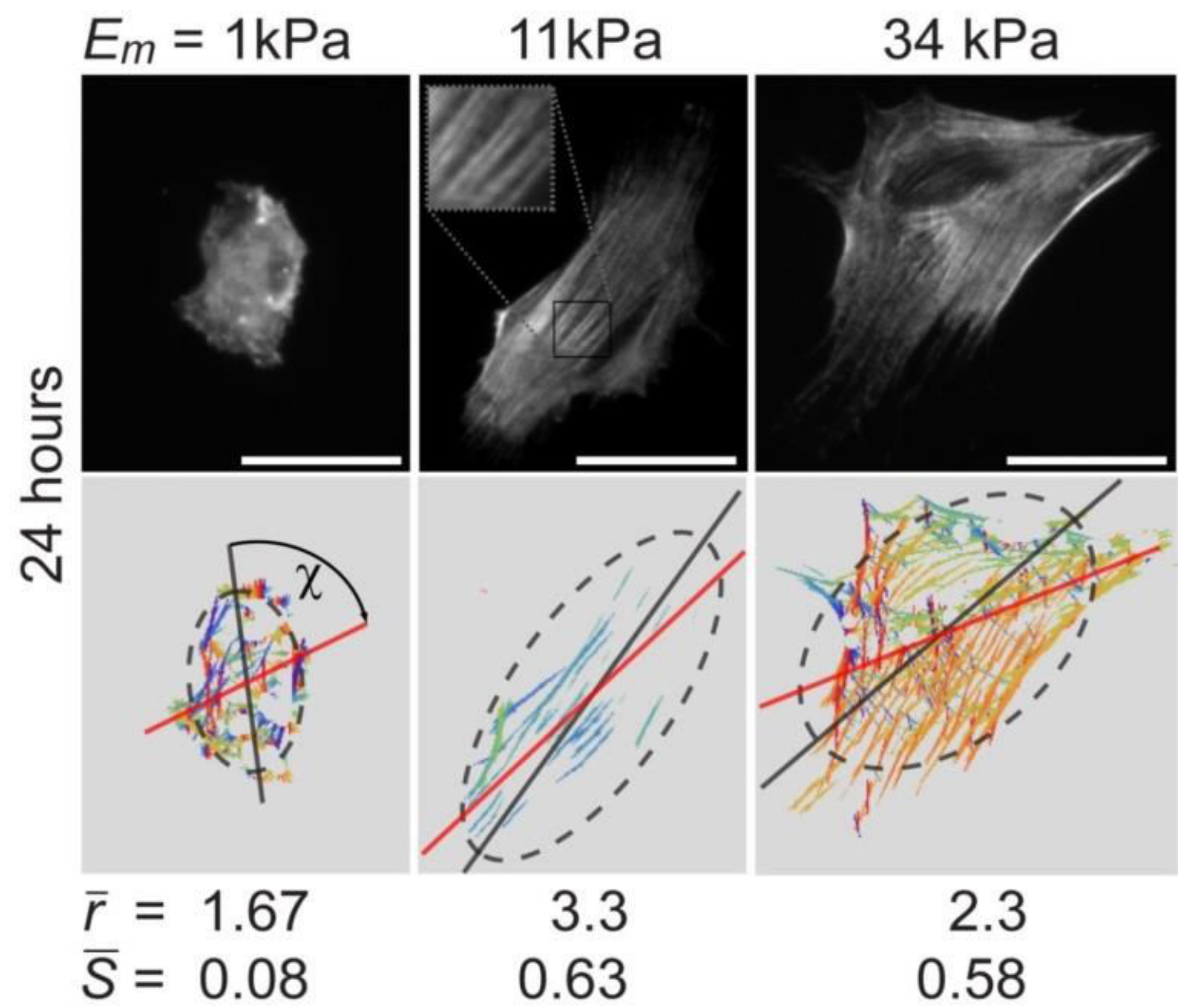

Figure 2.7. hMSCs plated for 24 hours on 2D substrates of different elasticities. The top line of images are hMSCs stained for non-muscle myosin Ila. The bottom line represents the orientations of SFs. The dashed ellipses are calculated from the moments up to the second order and represent the cell shape in terms of area and long and short axes, and the red line indicates the mean orientation of the SFs as determined by the anisotropic filter algorithm.

All scale bars represent $50 \mu \mathrm{m}(8)$.

Interestingly, morphological differences in the cells seeded on different substrates could be already seen after 24 hours of culturing (1). Apart from a changed protein expression level the substrate stiffness influences also cellular morphology. It was observed that the cell elongation (aspect ratio $r$ ) and the alignment of stress fibers (order parameter $S^{1}$ ) non-monotonically depends on matrix rigidity. hMSCs adopt the morphology of muscle cells when seeded on

\footnotetext{
${ }^{1}$ The order parameter $S$ quantifies the alignment of stress fibers. $S$ is a sum over all $\cos 2 \chi$, where $\chi$ is the angle between each stress fiber and the long axis of the cell.
} 
intermediate $(\sim 10 \mathrm{kPa})$ rigidity: aspect ratio and order parameter is the highest (figure 2.7). On the other hand, hMSCs which were seeded on soft and stiff substrates are more round and their stress fibers are aligned in a more isotopic way (8).

\subsection{Theoretical model of cell-substrate interactions}

The dynamic process of cellular attachment and further spreading on the ECM involves a shape and volume deformation of the cell. This process causes elastic stress in the cell itself and in the matrix underneath $(27,50-52)$. The process of adhesion and spreading was modeled and is sketched in figure 2.8 (8). Both, cell and matrix were taken as springs with spring constants $k_{c}$ and $k_{m}$, respectively.

\section{D Spring Model}

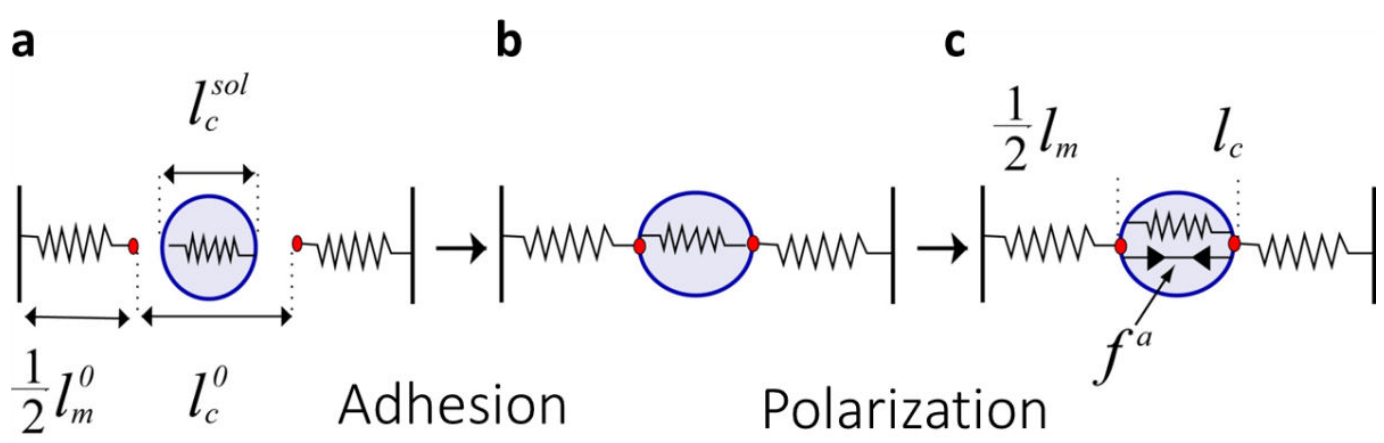

Figure 2.8. 1D spring model of cell adhesion and polarization on ECM. (a) Cell placed in the ECM with the length of the spring $I_{c}$ and $I_{m}$. (b-c) Cell polarizes in response to the elastic stress in the cell. $f^{a}$ is an active force as a feedback to the active acto-myosin force exerted by the cell. (8)

Figure 2.8 represents the elastic spring model of the cell and the matrix. Initially, cell is placed in suspension (figure 2.8a), then the cell anchors to the matrix and starts to spread isotropically (figure $2.8 \mathrm{~b}$ ) along the surface and elastic stress develops in the cell as a response to the stress in the matrix. Spreading process and the force exerted by the cell directly depends on the matrix elasticity $(5,53,54)$.

Firstly, several experiments showed that the cell spread area increases monotonically with increasing of matrix rigidity underneath $(54,55)$. Next, the spreading process was described theoretically and proven experimentally on 
the example of hMSCs. It was proposed that spreading obeys the model equation:

$$
\frac{A-A_{\min }}{A_{\max }-A_{\min }} \approx \frac{E_{m}}{E_{m}+\tilde{E}_{C}}
$$

where $E_{c}$ and $E_{m}$ are the Young's modulus of the cell and matrix, respectively, $A_{\max }$ and $A_{\min }$ are the maximum and minimum spread area of the cell population (9). Human mesenchymal stem cells were taken as an example to prove the model. Figure 2.9 shows the cell area depending on the matrix elasticity. It can be seen that the area increases monotonically with substrate stiffness and that the model fits well to the experimental data.

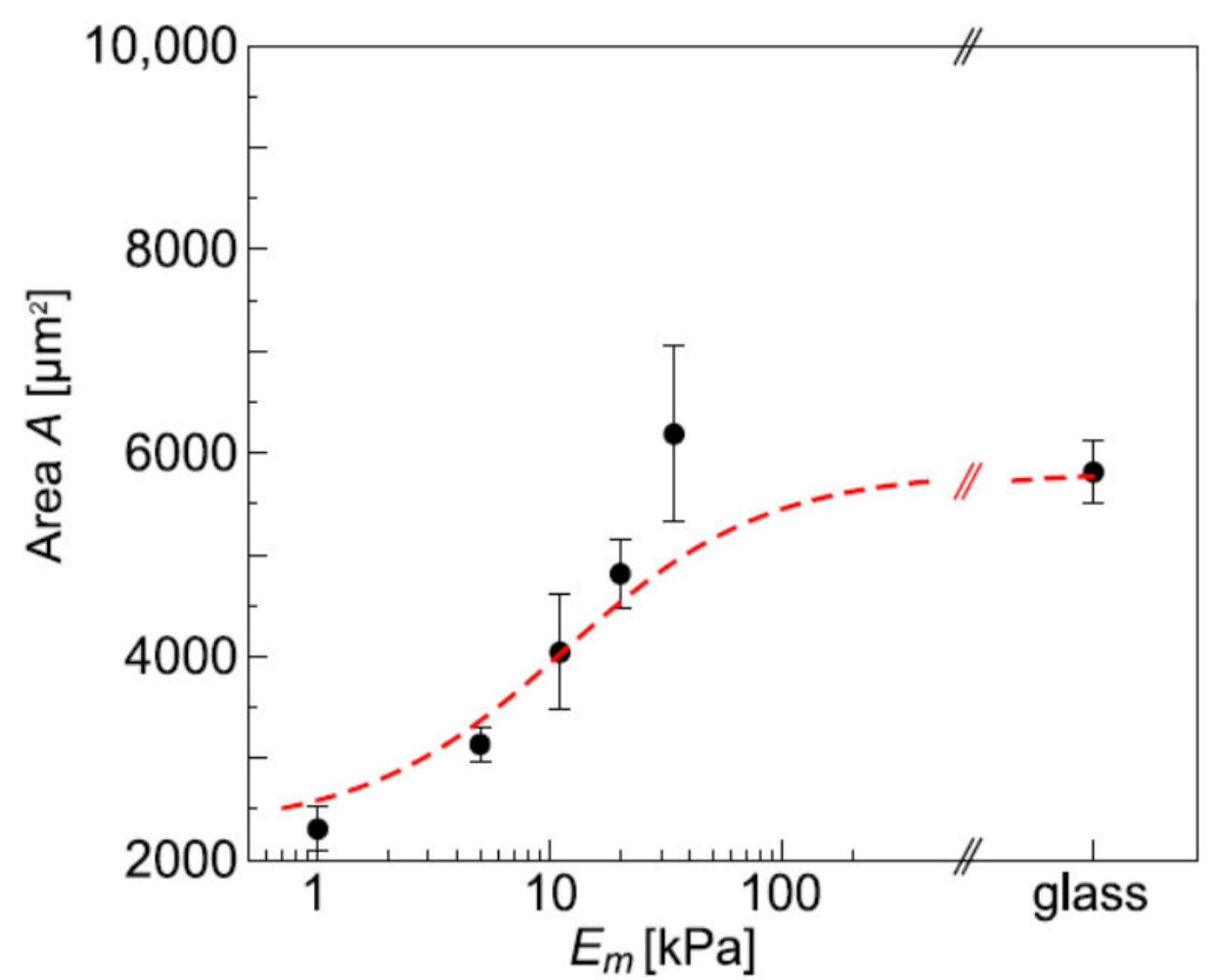

Figure 2.9. Modulation of the cell spreading area of hMSCs with matrix rigidity. Red dashed line shows the quantitative fit of the model 2.1 to the experimental data. (9) 


\section{Chapter 3 Experimental methods}

\subsection{Cell culture}

hMSCs (Lonza), C2C12 myoblasts (ACC 565, DSMZ), NIH 3 T3 fibroblasts (ACC 173, DSMZ), sarcoma osteoblasts SAOS-2 (ACC 243, DSMZ) and human primary osteoblasts ( $\mathrm{HOBs}$, PromoCell) were cultured at $37{ }^{\circ} \mathrm{C}$ and $5 \% \mathrm{CO}_{2}$ at a density of 100.000-200.000 cells per 75T Corning culture flask. Cells were split using $0.05 \%$ trypsin-EDTA (life technologies Lot\#25300-054) every 2-3 days to avoid confluence. Different media conditions were used for all cell lines: hMSCs, NIH 3T3 fibroblasts and C2C12 were kept in Dulbecco's Modified Eagle Medium DMEM (life technologies Lot\#31885-03), Osteoblasts - in McCoy's 5A Medium (Gibco Lot\#16600082); all media were supplemented with Fetal Bovine Serum (Sigma-Aldrich F2442-500ML) and antibiotics, namely $1 \%$ of Penicillin/ Streptomycin (P/S, life technologies Lot\# 15140-122). Detailed protocols for thawing, freezing and splitting can be found in the appendix A1. All the cells were chemically fixed by incubating in $10 \%$ of formaldehyde (Sigma-Aldrich Lot\#252549) in PBS on the rocker for 5 minutes.

\subsection{Chemical induction of hMSCs into muscle}

○ Dexamethasone and hydrocortisone. In this work I used $0.1 \mu \mathrm{M}$ dexamethasone (Sigma Aldrich H0888) and $50 \mu \mathrm{M}$ hydrocortisone (Sigma-Aldrich D4902), as in reference (1). Since hydrocortisone is only soluble in ethanol and cells are viable within media containing $\leq 5 \%$ of Ethanol, hydrocortisone was prediluted. Dexamethasone and hydrocortisone were added to the DMEM culture media and supplemented with $10 \% \mathrm{FBS}$ and $1 \% \mathrm{P} / \mathrm{S}$. The full protocol can be found in the Appendix A2. HMSCs were cultured in muscle induction media from 1 to 14 days.

$\circ$ Transforming growth factor $\boldsymbol{\beta} 1$ (TGF- $\boldsymbol{\beta} 1$ ). As another supplement to trigger stem cell differentiation I have used $5 \mathrm{ng} / \mathrm{mL}$ of TGF- $\beta 1$ in DMEM $+10 \% \mathrm{FBS}$ and $1 \% \mathrm{P} / \mathrm{S}$, as described in (56). 


\subsection{Blebbistatin treatment}

In this work the effects of blebbistatin (Merck, Germany), a myosin II inhibitor, were studied at concentrations of $12.5 \mu \mathrm{M}$ and $25 \mu \mathrm{M}$. During blebbistatin treatment, the drug, dissolved in dimethyl sulfoxide (DMSO), was added directly to the cell culture media while seeding cells on the substrates and was kept during the whole culture time (if not specified).

\subsection{Gel preparation}

In this thesis polyacrylamide hydrogels (PAA) were used as flat and isotropic substrates with tunable elasticities. Cover glasses were pretreated as described before (57-59). Round cover glasses were treated with $0.05 \%$ of glutaraldehyde solution (Sigma Aldrich G7651-10ML) in order to make the surface hydrophilic to allow the polymerizing PAA gel attach to the glass. We tuned the Young's modulus $E_{m}$ of PAA gels by changing the concentration of bis-acrylamide and let the gel polymerize for 60 minutes. Polymerized gels had thickness $~ 70-100 \mu \mathrm{m}$. All the gels were coated with collagen I with a concentration of $0.2 \mathrm{mg} / \mathrm{ml}$ obtained from BD Biosciences.

\section{Cover glass preparation.}

Since PAA hydrogels should be placed on round cover glasses and be as homogeneous as possible, I had to use two different types of cover glasses with different properties:

- Bottom: round cover glasses were supposed to have a strong bond between the cover glass itself and the gel.

- Top: square cover glasses were used to put pressure on non-polymerized PAA solution to equally distribute the gel solution onto the bottom round glass to have a homogeneous flat gel surface. It was prepared to be hydrophobic to not rip off the gel while pulling the top glass off the gel.

Bottom cover glass treatment: The main purpose of the chemical treatment of the bottom cover glasses was to provide PAA gel attachment to the surface. I used round glasses with a diameter of $25 \mathrm{~mm}$ (VWR ECN6311584) as hydrophilic cover glasses. Untreated cover glasses were thoroughly 
cleaned by placing them in an air absorptive plasma cleaner (HarrickTM PDC002) for 15 minutes. During this process the glasses were exposed to a low pressure ( $0.1 \mathrm{mbar}$ ) and plasma of high energetic particles flowing around the glass broke most organic bonds and removed dust from the cover slips. Thereafter, the holder with glasses was placed in a glass tube filled with $99.8 \%$ ethanol and put in an ultrasonic bath (Elma S-100) for 5 minutes in order to remove the remaining dust from the cover glasses. The round cover glasses were then washed with 3-aminopropyltriethoxysilane (APTES, Sigma-Aldrich 440140-100ML) for 15 minutes. After thorough cleaning, cover glasses were treated then with the cross-linker glutaraldehyde (Sigma-Aldrich G7651-10ML), which provides amino-groups on the glass surface by reacting with water. Then I incubated cover glasses in $0.5 \%$ glutaraldehyde solution in deionized water for 30 minutes to let aldehyde groups make a bond with the amino-groups. Due to symmetric aldehyde groups, one side binds to the amino-groups of APTES, another part of it would then further react with the acrylamide monomers, which makes the polyacrylamide network to remain on the glass surface.

Top cover glass treatment: Since polyacrylamide gels are hydrogels and the polymerization process happens between two cover glasses to make them flat, the top cover glass should be hydrophobic. In the end of the polymerization the hydrophobic, due to the water film on the gel, cover glass could be easily removed without damaging the gel. Silanization was done by dimethyldichlorosilane (DMCS, Sigma-Aldrich 85126-1L) in heptane, which reacts with the silanol groups of the glass surface by removal of hydrochloric acid. These square cover glasses were placed in petri dishes, washed fully with DMCS and incubated for 10-20 minutes. Cover glasses were rinsed with MilliQ water afterwards.

\section{Polyacrylamide gel preparation.}

Acrylamide (Bio-Rad \#161-0140) and Bis-acrylamide (Bio-Rad \#161-0140) solutions are stored at $+4{ }^{\circ} \mathrm{C}$ and were used not longer than 6 months after opening. Polyacrylamide gels were synthesized by mixing fresh acrylamide $40 \%$ $(\mathrm{w} / \mathrm{w})$ and $\mathrm{N}, \mathrm{N}$-methylene-bisacrylamide $2 \%(\mathrm{w} / \mathrm{w})$ solutions in PBS. Concentrations of acrylamide and bis-acrylamide were varied from 3 to $24 \%$ and from 0.1 to $0.3 \%$, respectively (see section in appendix A.3.3). Polyacrylamide solutions were freshly mixed every 4-6 moths. The polymerization reaction starts with the addition of $1 / 1000 \mathrm{~N}, \mathrm{~N}, \mathrm{~N}, \mathrm{~N}-$ 
tetramethylethylenediamine (TEMED) and 1/100 ammonium persulfate solution (APS), as was described in (60). After proper stirring, $35 \mu \mathrm{l}$ of the nonpolymerized PAA solution were placed on the glutaraldehyde coated cover glass. Then the square hydrophobic cover glass was placed on top to make the solution equally distribute on the bottom glass. Polymerization process took 60 minutes. Gels were kept in humid conditions not to let the water evaporate from the PAA solution. After the gel was polymerized the top cover glass was easily removed from the gel. Since acrylamide and bis-acrylamide are highly toxic for cells, PAA gels were thoroughly washed with buffer to remove all the non-polymerized residues.

All the gel solutions were polymerized and measured on the rheometer to determine their Young's moduli (see section 3.5.2).

Collagen coating. To mimic the ECM and provide ligands which the cells need to enable attachment, the gels were coated with Collagen I $(3.83 \mathrm{mg} / \mathrm{ml}$ collagen type I rat tail, BD Biosciences 354236). The widely used photoactivatable cross-linker Sulfo-SANPAH (Thermo Scientific 22589) at a concentration of $0.4 \mathrm{mM}$ solubilized in $50 \mathrm{mM}$ HEPES buffer at a $\mathrm{pH}$ of 8 was used to provide binding of collagen to the PAA gels. A drop of $\sim 400 \mu$ l was enough to cover the surface of the gel (glass), then placed under the UV-lamp at a wavelength of $365 \mathrm{~nm}$ for 10 minutes to activate the Sulfo-SANPAH. The next step was to wash out free Sulfo-SANPAH by rinsing the sample tree times with HEPES. Now the surface was ready to bind collagen. A HEPES solution with $5 \%(\mathrm{v} / \mathrm{v})$ collagen and the same volume of acetic acid $(0.02 \mathrm{mM}$ in HEPES, Riedel de Haen 27221) was added. Incubation of collagen took place over night in the cold room at $+10^{\circ} \mathrm{C}$.

After incubation, gels were thoroughly washed with Dulbecco's Phosphate Buffered Saline (PBS) to remove unbound collagen fibers and then sterilized under UV for an hour.

\subsection{Probing visco-elasticity}

\subsubsection{Atomic Force Microscopy}

Atomic force microscopy is a powerful tool for biophysical studies. On one hand it is capable of imaging biological samples down to scales of single 
molecules. Also the researchers use AFMs to measure mechanical properties of soft matter samples.

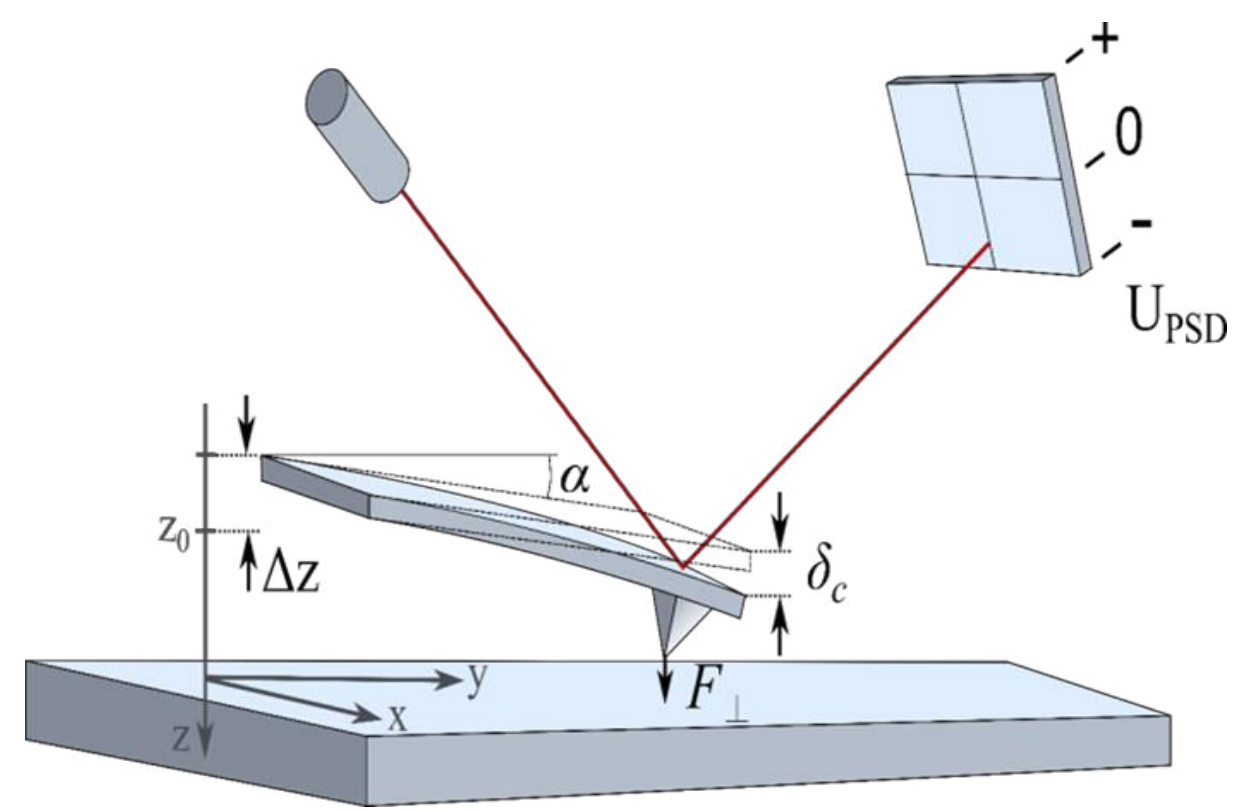

Figure 3.1. A sketch of a typical atomic force microscope (AFM) setup. (61)

The working principle of an AFM (figure 3.1) is the following: a cantilever with typical lengths of $100 \mu \mathrm{m}$ hosts at its one end a fine tip of well-defined geometry with radii of down to a few nanometer When approaching a surface the tip interacts with it according to a Lennard-Jones-potential and, according to Hooke's law (62) the cantilever starts to bend. By focusing a laser beam onto the cantilever and detecting its reflection by means of a quadrant photodetector, one can measure the deflection with high precision (61). The distance between sample and tip can be set by a piezo-crystal device with nanometer accuracy and is regulated by the machine depending on the mode of measuring. For recording the height profile of a sample a feedback loop is active, where the piezo positions the sample in a way that a constant deflection of the cantilever is maintained. By laterally scanning over the sample a threedimensional landscape of the sample can be reproduced. In ,contact mode', the tip ,touches' the sample and the interaction is dominated by the Pauli repulsion part of the Lennard-Jones-potential (61). In non-contact ,tapping mode' mainly Van-der-Waals forces play a role.

In order to measure mechanical responses of a sample the ,force curve mode' is used (63): here, the tip approaches, touches and indents the sample until a certain deflection point of the cantilever is reached. Then the cantilever retracts again. Over the whole travelling range the deflection of the cantilever 
is recorded. There by a so-called force distance curve is obtained, probing the stiffness of the sample.

In order to measure parameters of interest in physically meaningful units instrument has to be calibrated. According to a finite bending stiffness of the cantilever its deflection angle corresponds to a force exerted between sample and tip. In a liquid, the cantilever is excited by the bombardment of solvent molecules and starts to oscillate. When comparing the oscillation spectrum of the cantilever with a modeled externally -driven damped harmonic oscillator, one obtains parameters like resonance frequency and bending stiffness of the cantilever. To find the spring constant of the cantilever, it was calibrated using the thermal fluctuations method (64).

In a second step, the tip is pressed onto a flat surface. The measured deflection of the laser beam dependent on the position of the sample is used to determine the sensitivity of the quadrant photodiode. A realistic model for the cantilever tip indenting an elastic half space is the Hertz model ${ }^{2}$. By that the Young's modulus of the gel substrate can be derived (11-13), where the force $F$ of the tip indentation is established by:

$$
F=\frac{E \tan \alpha}{\sqrt{2}\left(1-v^{2}\right)} \delta^{2}
$$

where $E$ is the Young's modulus, $\delta$ the indentation depth and $\alpha$ is the opening angle of a four-sided pyramid tip. Poisson's ratio $v$ is a characteristic value defined by the ratio between a body's fractional length variation (e.g. by applying stresses, stretching etc.) and the resulting change of thickness (assumed to have a value of 0.45 for measured gels) (10).

The sample, in our case a polymerized gel, was placed into an AFM (MFP3DBio, Asylum Research) which was combined with an IX71 Olympus microscope equipped with an X-Cite laser emitter (AHF, 130 Series) and a 40x air objective. For my experiments a TR-800PB (Olympus) $100 \mu \mathrm{m}$ long cantilever with a four-sided pyramidal tip ( $\sim 3 \mu \mathrm{m}$ height, opening angle 35 degrees) was used.

\footnotetext{
${ }^{2}$ There are more sophisticated and complex mechanical models known in the AFM field to describe certain experimental conditions. Dimitrialis et al. suggested a more specific and complicated model approach for thin soft layers on a hard substrate(65).
} 
For the AFM experiments it was important to use the identical cantilever for all substrates to compare the results quantitatively. The errors were taken from the variance of 10 taken force measurements from each spot on the gel. The AFM measurement process has intrinsical imprecisions like underestimated surface interactions, an uncertainty of the spring constant of the cantilever or incomplete knowledge of the tip geometry. The magnitude of these errors was small compare to the statistical variation of the sample data values.

\subsubsection{Rheology}

Rheology describes the behavior of soft matter and fluids upon deformation under certain boundary conditions (figure 3.2). Besides the case of a pure compression, shear deformations give major contributions in soft composite materials.

In elastic samples stress $\sigma$ and strain $\gamma$ depend linearly on each other $\sigma=$ $\mathrm{E} \cdot \varepsilon$ where $E$ is the elastic Young's modulus. Purely viscous samples start to flow upon a shear stress and one finds $\sigma(t)=\eta \cdot d \cdot \varepsilon(t) / d t$. In the general case of a viscoelastic material the stress-strain relation takes an intermediate form, according to the stress relaxation processes present in the sample. Following the Boltzmann superposition principle it takes a linear form in frequency space $\sigma(\omega)=G(\omega) \cdot \varepsilon(\omega)$, where $G$ is the shear modulus.

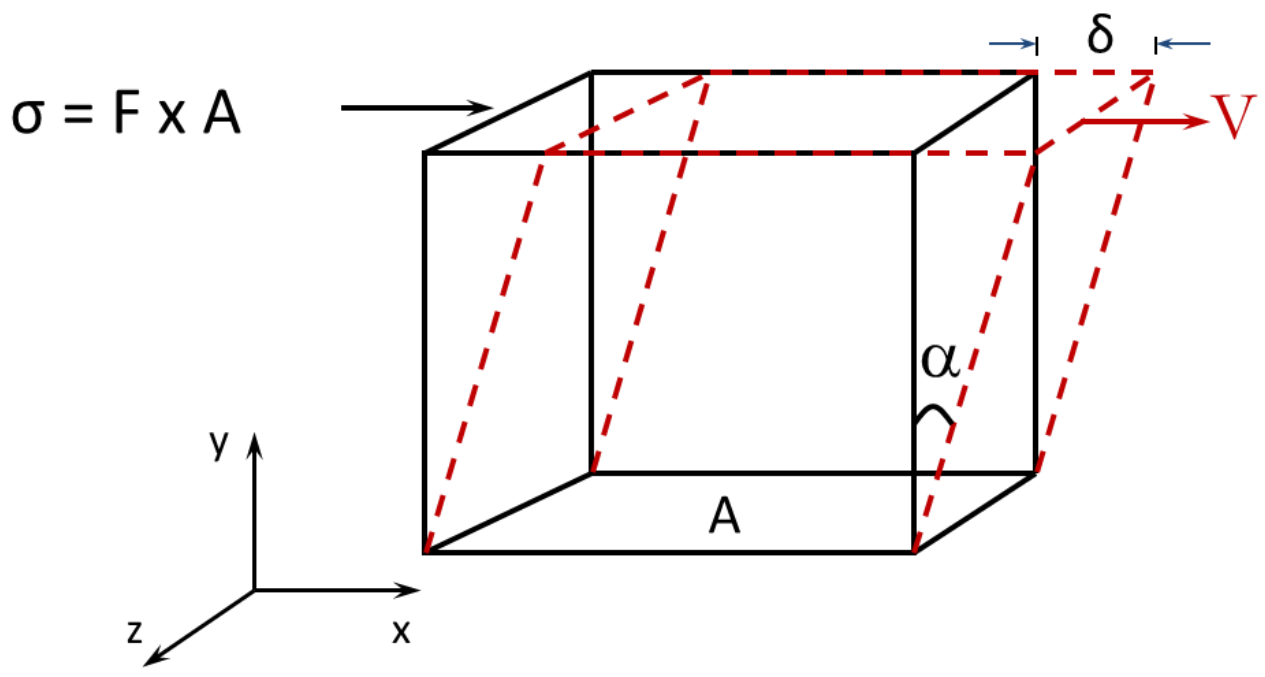

Figure 3.2. Schematic drawing of a shear deformation: A tangential force $F$ on the top surface with area A causes a stress $\sigma$ and a shear deformation $\delta$ of the volume element. The strain $\varepsilon$ can be described by the shear angle $\alpha$. 
The rheometer is commonly used to measure material responses upon shear deformations.

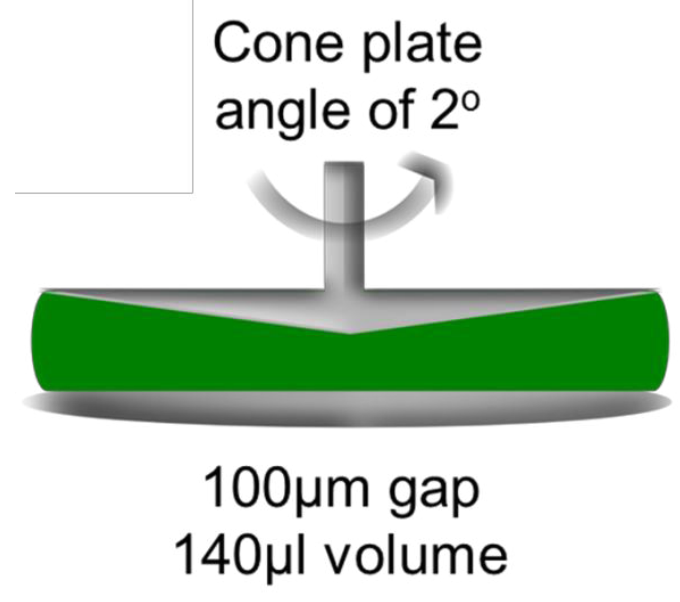

Figure 3.3. Schematic drawing of the rheometer experiment

Here, the sample is placed between a cone and a plate, as shown in figure 3.3, which are then rotated with respect to each other, typically in a sinusoidal way. In this case the stress takes the following form:

$$
\sigma=G^{\prime}(\omega) \gamma_{0} \sin (\omega t)+G^{\prime \prime}(\omega) \gamma_{0} \cos (\omega t)
$$

where $\omega$ is he oscillation frequency, $G^{\prime}$ and $G^{\prime \prime}$ are the real and imaginary part of the shear modulus, describing the elastic and viscous response of the sample.
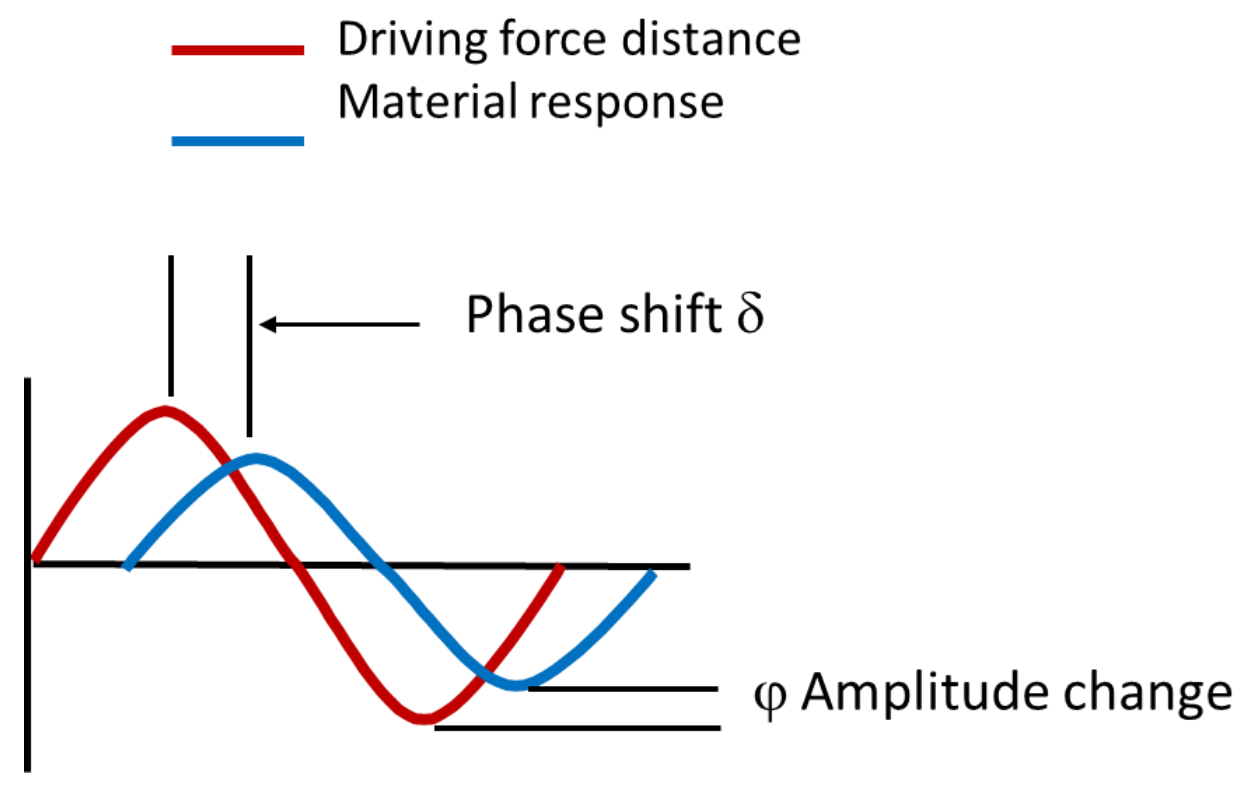

Figure 3.4. Oscillatory measurement. The response of the system to a deformation is measured. Phase shift $\varphi$ and change in amplitude $\delta$ are measured with respect to a sinusoidal driving force at a certain frequency. 
For the presented work, rheology experiments were carried out with an Anton Paar Physica MCR 501 rheometer. Non-polymerized solution in the volume of $140 \mu \mathrm{l}$ was placed between an immovable steel plate and a rotating top plate having an opening angle of $2^{\circ}$ and a diameter of $25 \mathrm{~mm}$ (Figure 3.3).

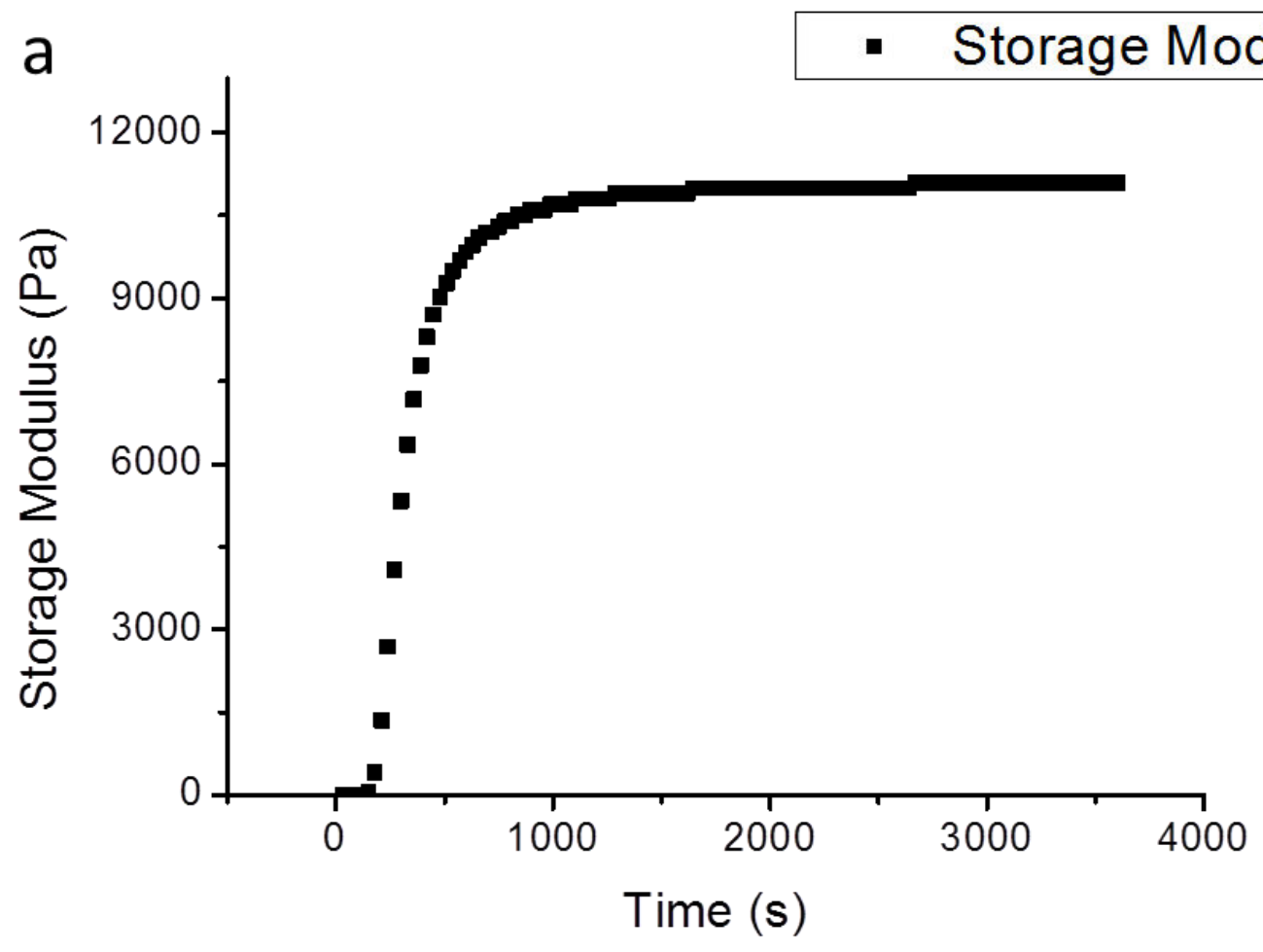

b

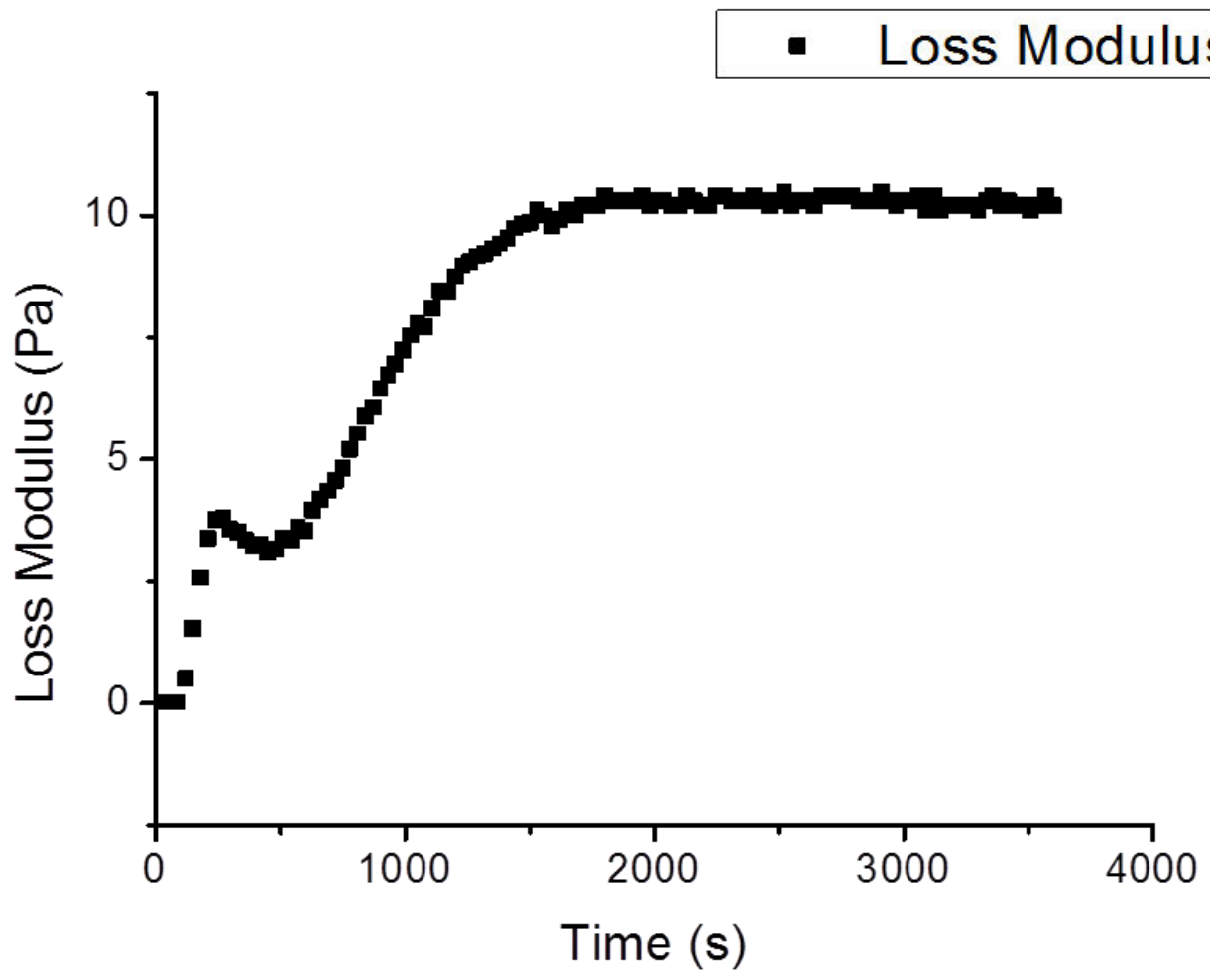

Figure 3.5. (a) Storage and (b) loss modulus of 32kPa PAA gel measured during the gelation process. 
Each measurement was taken every 30 seconds during 60 minutes of gel polymerization. In figure 3.5 you can see the changes in loss and storage modulus over time for the example of a $32 \mathrm{kPa}$ PAA gel. Polymerized PAA gels are mostly elastic substrates, you can see that loss modulus $G^{\prime \prime}$ (viscous component) is three orders of magnitude lower than the storage modulus. Hence it was neglected. Simultaneously, the storage modulus, which represents the elastic component, increases after several minutes and reaches a plateau after 60 minutes.

The absolute shear modulus $G$ was calculated as

$$
G=\sqrt{G^{\prime 2}+G^{\prime \prime 2}}
$$

where $G^{\prime}$ and $G^{\prime \prime}$ are shear storage and loss modulus, respectively. The relation of shear modulus $G$ and Poisson's ratio ( $v=0.45$ ) to Young's modulus $E_{m}$ is

$$
E=2 \cdot G(1+v)
$$

\subsubsection{Comparison PAA gel elasticity using rheometer and AFM}

The PAA solutions containing acrylamide, bis-acrylamide and PBS were prepared freshly every 4 - 6 months. Every premixed solution was measured with the rheometer to confirm the required gel stiffness. The gel elasticities were adjusted by varying concentrations of the crosslinker. The total amount of stock solution of PAA was always $10 \mathrm{ml}$ and stored in the fridge. Table 3.1 presents the concentration in percentage of acrylamide and bis-acrylamide in $10 \mathrm{ml}$ of PAA solution. Table 3.1 also presents the Young's modulus of the gels measured by the rheometer. Here I want to point out that every gel was measured 3-4 times. Due to low standard deviation, it can be concluded that these measurements give reproducible results.

In parallel, the same solution was used to polymerize gels on glutaraldehyde-coated cover glasses for further cell seeding. The storage modulus reaches a plateau after one hour, which can be also seen in figure 3.5a. PAA gel polymerization and rheometer experiments were performed in parallel out of the same premixed PAA components. It was done to measure 
exactly the same gels, where the cells would be seeded onto. Then, the Young's moduli of exactly the same gels were measured with AFM. The comparison of the results of the two approaches showed comparable trend of Young's modulus values of the gel.

Table 3.1. Comparison of Young's modulus of PA gel given by AFM and rheology

\begin{tabular}{c|c|c|c}
$\begin{array}{c}\text { Amount of acrylamide } \\
40 \% \text { in } 10 \mathrm{ml}, \%\end{array}$ & $\begin{array}{c}\text { Amount of bis-acrylamide } \\
2 \% \text { in } 10 \mathrm{ml}, \%\end{array}$ & Rheometry, kPa & AFM, kPa \\
\hline 3 & 0.2 & $1.1 \pm 0.02$ & $2.5 \pm 0.23$ \\
\hline 3.5 & 0.2 & $2.4 \pm 0.02$ & $3.6 \pm 0.63$ \\
\hline 3.8 & 0.2 & $3.7 \pm 0.01$ & $4.3 \pm 0.001$ \\
\hline 6.8 & 0.1 & $7.7 \pm 0.06$ & $6.6 \pm 0.16$ \\
\hline 6.8 & 0.2 & $13.7 \pm 0.06$ & $11.2 \pm 0.14$ \\
\hline 8.6 & 0.3 & $25.8 \pm 0.10$ & $21.8 \pm 0.05$ \\
\hline 13.2 & 0.3 & $65.8 \pm 0.38$ & $34.8 \pm 0.49$ \\
\hline 23.6 & 0.3 & $126.9 \pm 0.38$ & $71.5 \pm 1.24$
\end{tabular}

\subsection{Immunostaining}

In order to visualize distinct intracellular structures under the microscope, specific antibodies $(A B)$ were used to target these structures, which then again could be used as binding sites for fluorescent dyes (often mediated by a second $A B)$. The experimental procedures were performed according to the following protocol: after fixation, cells were permeabilized with $0.5 \%$ Triton-X100 (Carl Roth $\mathrm{BmbH}$ 6683.1) for 10 minutes. Samples stained with primary and secondary antibody, e.g. in this work anti-myogenin, anti-myosin Ila and antipaxillin as primary $A B$. Firstly, for blocking samples were incubated on a rocker in a PBS solution containing $3 \%$ BSA (Sigma-Aldrich A9418-100G) for 30 minutes. This blocking incubation is an important step to minimize non-specific binding in the cell. After blocking process, primary $A B s$ were introduced to the cells by adding them to a PBS solution containing $3 \%$ BSA in order to ensure specific bindings. Primary $A B$ incubation usually lasted from 2 to $24 \mathrm{~h}$, depending on the type of the antibody and its concentration. In this work I used the following conditions:

- Myogenin (abcam ab1835) [2.5 $\mathrm{gg} / \mathrm{ml}], 2$ hours incubation

- Myosin Ila (Sigma-Aldrich M8064) [1 $\mathrm{\mu g} / \mathrm{ml}], 3$ hours incubation

- Paxillin (abcam ab32084) [0.4 $\mathrm{gg} / \mathrm{ml}]$ overnight incubation ( 16 hours). 
The secondary $A B$ was applied for up to 2 hours of incubation.

Actin was stained with fluorescently labeled phalloidin Atto 550 (Atto Tec AD 550-81) for 1-2 hours. The nucleus was stained with Hoechst 33342 (invitrogen $\mathrm{H} 3570$ ) in a concentration of $10 \mathrm{ng} / \mathrm{ml}$ for 30 minutes. In between each step cells were incubated on the rocker for 5 minutes with Triton $X$ and washed with PBS afterwards.

\subsection{Fluorescence microscopy}

Imaging of the immunostained cells was done with the inverted fluorescence microscope Axio Observer.Z1 (Zeiss) equipped with an HXP120 illumination lamp (Zeiss) and a Zyla sCMOS 4.2 camera (Zeiss) was used. The images were captured with 32x (Zeiss, LD A-Plan 32x/0.40 Ph1) and 40x (Zeiss, LD Plan-NeoFluor 40x/0.40 Ph2 Korr, 421361-9970) air objectives, depending on the cell size.

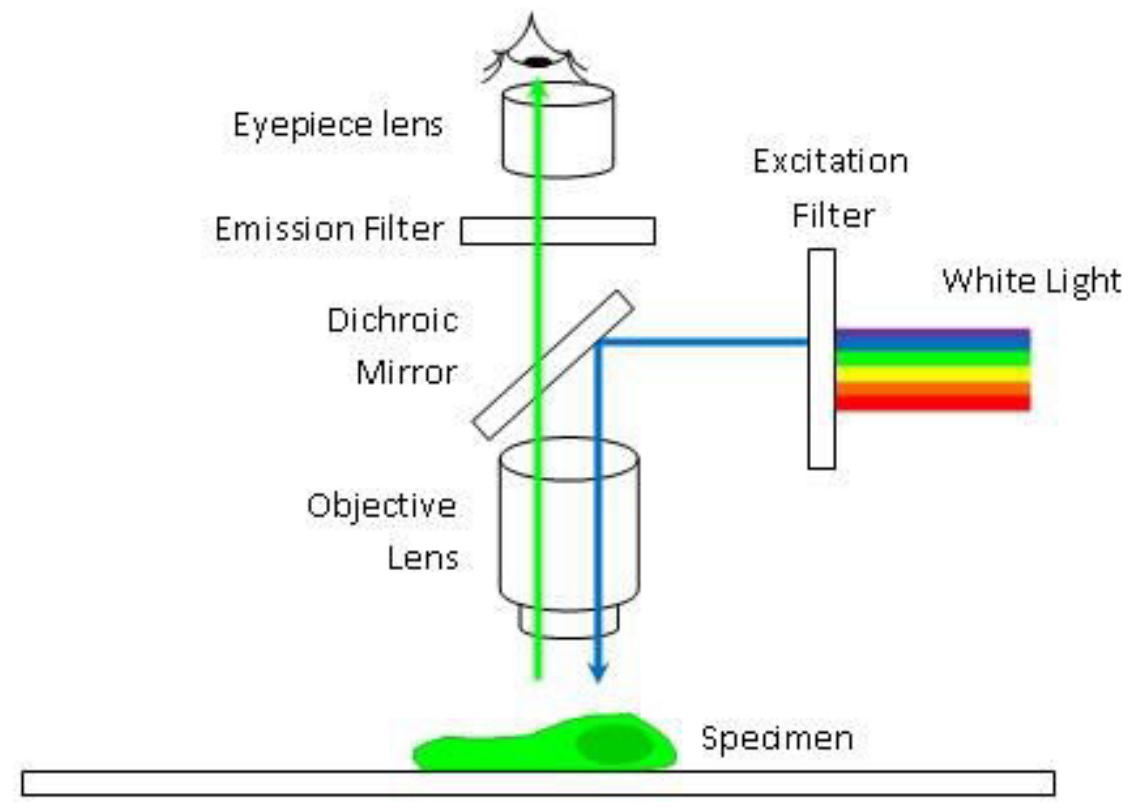

Figure 3.6. Schematic light path within a fluorescence microscope (68).

Shortly about the principle of the fluorescence microscopy: light of the desired excitation wavelength lightens the specimen, exciting the fluorescent molecules, which are specifically attached to the required structure in the cell. In general, fluorescence is a phenomenon where the dye is excited by a photon (within the excitation wavelength range) and then emits a photon by returning to its ground state at a longer wavelength (lower energy) due to the Stokes 
shift (10). For example, when light at $488 \mathrm{~nm}$ (in the blue region of the visible spectrum) goes to a green fluorescent protein, electrons in the outer orbital of the atoms within the protein complex are excited to a higher energy state. When they return to their normal energy state, they emit photons of light at $509 \mathrm{~nm}$, which is in the green region of the visible spectrum.

The emitted light is passed up through the optics of the microscope to the eyes or a light detector. Then the emitted light passes through a dichroic mirror, which at the same time prevents the excitation light to pass, as it prevents the interference from reflected excitation light entering the optics. Further sensitivity can be achieved using emission filters, which only allow light of the desired emission wavelength to pass through. Fluorescence microscopes have a number of adjustable filters, so that a range of excitation and emission wavelengths can be selected (see figure 3.6).

\subsection{Image analysis}

Fluorescence image analysis was used to obtain quantitative measures of morphological parameters of the cell and the expression of specific markers. ImageJ was used as an open source program for image processing (69). Fluorescence images were processed by applying threshold (using "default" method) in order to obtain the actin area of the cell.

\subsubsection{Area and aspect ratio analysis}

In order to obtain cell area and aspect ratio ImageJ was used. The images were opened with ImageJ, as shown on figure 3.7a. The appropriate threshold was chosen for each cell set depending on the behavior brightness of the staining. In the same experiment, all images were analyzed with the same threshold. With the 'wand tracing tool' the area was selected and analyzed using the ImageJ operators (figure 3.7b). The main parameters I drew from the images were the area in pixels, the aspect ratio, which is the ratio of the major to minor axis of an ellipse with identical area calculated from the second moments of the the thresholded region. The aspect ratio shows the elongation of the cell: the cell is round when the aspect ratio is 1 and more elongated with higher aspect ratio. In principle the error of the measured value is caused by the imprecision of the measurement process and of the statistical intrinsic data 
spreading of the sample. Statistical data spreading within the sets of cells turned out to contribute the most to the error compared to measurement precision errors (introduced for instance by pixilation during camera recording or the arbitrariness of the thresholding value). That is why only the statistical spreading error was taken into account for further data analysis.

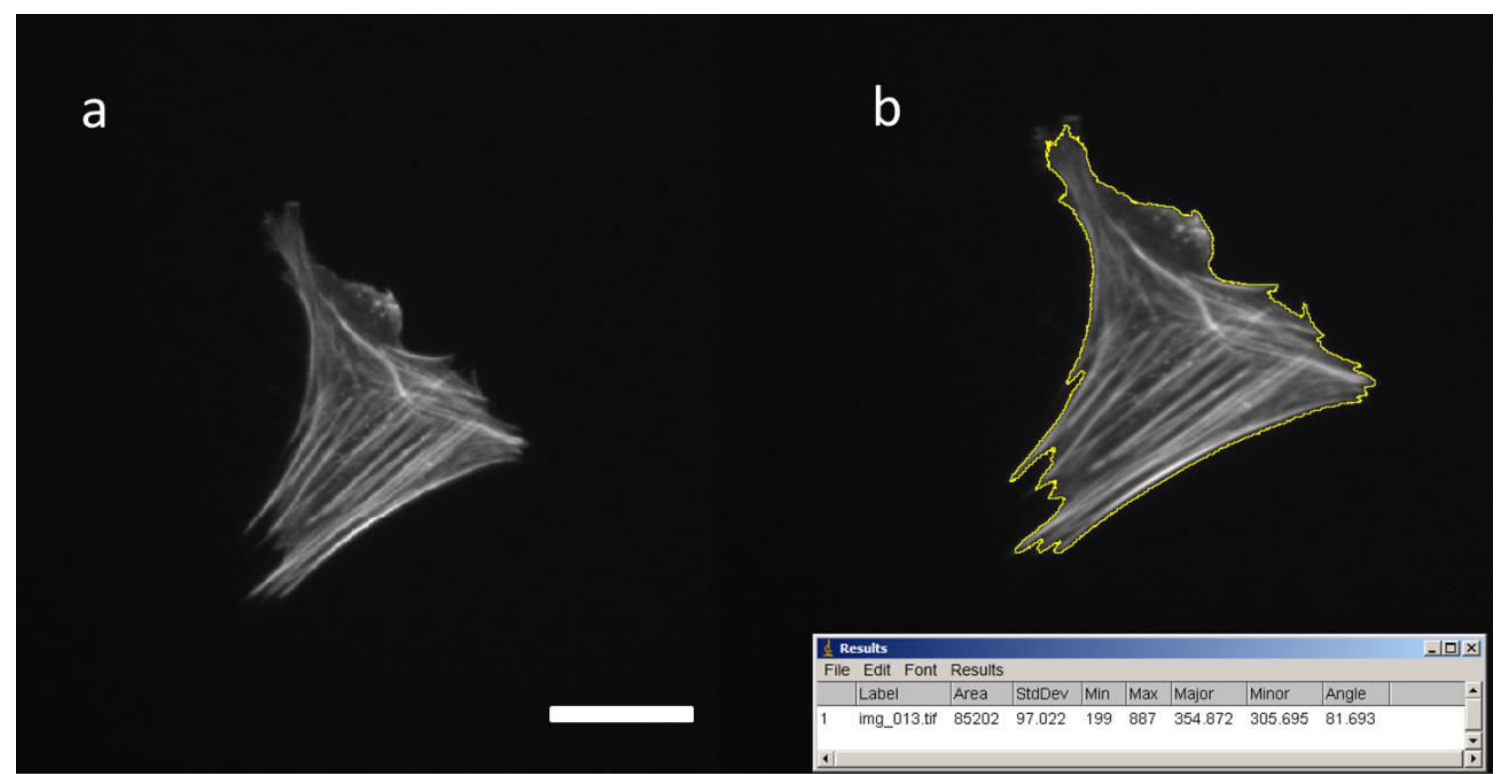

Figure 3.7. Image analysis with ImageJ. Image analysis of a representative cell in ImageJ. (a) A raw image. (b) Outlined cell image (after thresholding), the chosen area in yellow. In the box in the low right corner represents the analysis of the selected area. Scale bar $25 \mu \mathrm{m}$

\subsubsection{Focal adhesion analysis}

In order to analyze the formation of focal adhesions on 2D substrates, immunofluorescent staining of several scaffolding proteins (e.g. vinculin, paxillin, talin, zyxin) are widely used. In this PhD work I chose to analyze the localization, amount and the average size of one of these scaffolding proteins paxillin. For that I have used a primary AB against paxillin (abcam ab32084) produced in rabbit. I applied it in concentrations of $0.4 \mu \mathrm{g} / \mathrm{ml}$ and incubated it overnight. Paxillin staining of the cells exhibited high background noise (figure 3.8a), that is why images had to be preprocessed so that the image quality was sufficient to use a particle tracker (see figure $3.8 b$ ).

Image processing steps:

1. ImageJ, first I cropped all images so that on each image only one cell and minimum amount of dirt was left, that the algorithm does not track it as the particles. 
2. I opened images in a stack

3. Process $\rightarrow$ Subtract background (2 px)

4. Process $\rightarrow$ Math $\rightarrow$ Gamma (1.4)

5. Process $\rightarrow$ Filter $\rightarrow$ median (2)

6. Threshold, the same for all images

7. Analyze $\rightarrow$ Analyze particles $\rightarrow 5-80 \mathrm{px}$

a

Figure 3.8. Analysis of paxillin staining with ImageJ. (a) A raw image of hMSC stained for paxillin. (b) Processed image with ImageJ. Scale bar is $25 \mu \mathrm{m}$.

\subsubsection{Protein expression analysis using immunofluorescence}

To analyze the expression of requested proteins, these proteins were specifically immunostained. The fluorescence images of special proteins I analyzed by recording the fluorescent intensity distribution of labeled markers. In other words, with increasing intensity, more protein was expressed. E.g. in our case the expression of myogenin in muscle induced cells and myosin lla in blebbistatin treated samples. In this case indirect two-stepped incubation was performed. Firstly, specific primary $A B$ was used against the targeting protein in the cell. Then a fluorophore-coupled secondary antibody was applied to specifically bind to the primary $A B$. Specificity for this secondary $A B$ means that the secondary $A B$ is against the species in which the primary was produced. For proper analysis, all images were recorded at the same exposure time and illumination intensity. 
The analysis of the intensity distribution was done in several steps in ImageJ. Firstly, the image recorded in the actin channel was thresholded. Then the area of the cell was selected by a "wand tool" and saved to the tool called ROI (Region of Interest) Manager, as demonstrated in Figure 3.9a. The saved region was then applied to the image of the expressed protein (see figure 3.9b). By that I selected the area of interest to further analyze the mean of the intensity distribution in this area $I_{C A}$. For each set of images the intensity of the background $I_{\text {background }}$ was taken into account. For this purpose the area around the cell was selected (Figure 3.9c).

The total intensity was calculated as:

$$
I_{\text {total }}=\left(I_{C A}-I_{\text {background }}\right) * A_{\text {cell }}
$$

Statistical variation of the data from cell to cell turned out to give the far most major error compared to measurement precision errors which were neglected for further analysis then.

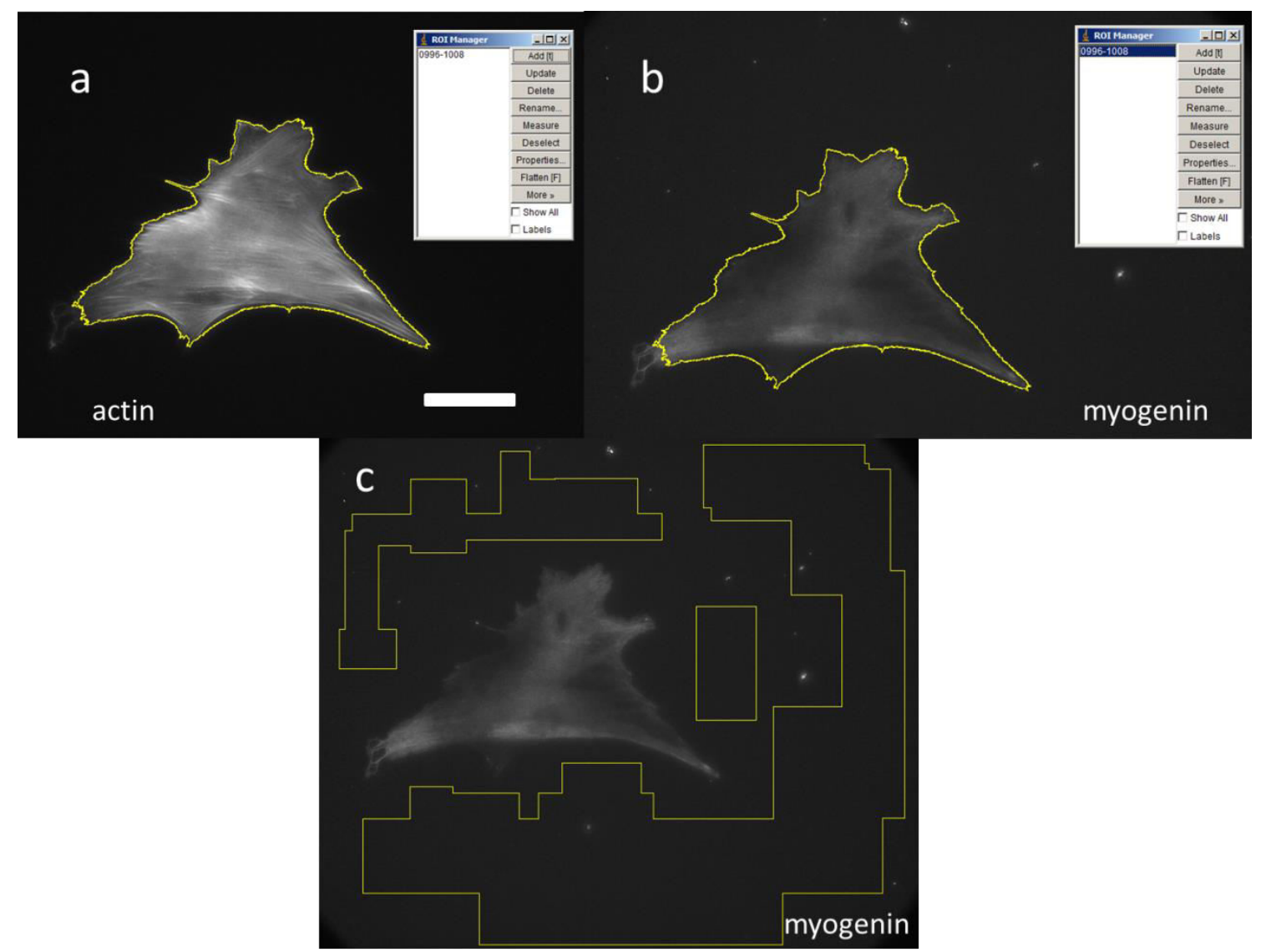

Figure 3.9. Protein expression analysis. (a) Threshold and selected actin area, added to the ROI manager. (b) Selected area from the ROI manager transferred to the myogenin expression image. (c) Selected background area around the cell. Scale bar is $25 \mu \mathrm{m}$. 


\subsection{Filament sensor}

To analyze the alignment of actin SFs within the cell, I used a program called filament sensor. It is a filament tracking Java program based on a finger print analysis algorithm (70). It tracks the filaments and provides the information about position, length, width of each filament and the angle towards the x-axis (71). With this information I was able to quantify the alignment of the SFs encoded in the order parameter $S=\cos 2 \vartheta$, where $\vartheta$ is the angle between each stress fiber and the long (main) axis of the cell (8).

\subsection{Extraction of the effective cell elasticity from the Zemel's} model

According to the Zemel's model we fit our data points with the following equation:

$$
A\left(E_{m}\right)=\frac{E_{m}}{E_{m}+\widetilde{E}_{C}}\left(A_{\max }-A_{\text {min }}\right)+A_{\text {min }}
$$

In a second step we checked if an additional exponent in the model equation would make it fit the data better. The resulting equation

$$
A=\frac{1}{1+\left(\frac{\widetilde{E}_{C}}{E_{m}}\right)^{n}} \cdot B+C
$$

with $B=\left(A_{\max }-A_{\min }\right)$ and $C=A_{\min }$, looks similar to the formula known as the Hill equation where $n$ describes the cooperativity. However, in our context the cooperativity would have an abstract meaning, at first, not comparable to what is typically known from e.g. enzyme cooperativity. Nevertheless, we found that $n$ was always close to 1 (data not shown) when applying numerical iteration fitting with OriginLab 8. That is why we kept on fitting all data for further analysis with the original model $(n \equiv 1)$.

By fitting the obtained data points we were able to extract the elasticity of the cells $E_{C}$. The parameters $A_{\min }, A_{\max }$ and $E_{C}$ were kept not fixed, i.e. freely floating, while fitting. The error of $E_{C}$ was calculated by the fitting program based on the standard Gaussian error propagation, given in general by 


$$
\begin{aligned}
& f=f\left(x_{1}, x_{2}, \ldots, x_{n}\right) \\
& \Rightarrow \sigma_{f}=\sqrt{\left(\frac{\partial f}{\partial x_{1}} \sigma_{x_{1}}\right)^{2}+\left(\frac{\partial f}{\partial x_{2}} \sigma_{x_{2}}\right)^{2}+\ldots+\left(\frac{\partial f}{\partial x_{n}} \sigma_{x_{n}}\right)^{2}}
\end{aligned}
$$

In this thesis the so called $\mathrm{R}^{2}$ value was used to grade the quality of a model fit. $\mathrm{R}^{2}$ is defined as $R^{2}=1-\operatorname{Var}(r) / \operatorname{Var}(y)$, where $r$ are the residues, i.e. the difference between data point value and expected value by the fit, $y$ the data point values. According to this definition $\mathrm{R}^{2}$ gives a measure of the percent of variance which can be explained by the model. It is a number between 0 and 1. In the first case the variance of the residues equals the total variance, i.e. the chosen model is not able to fit the data better then the zero baseline of the coordinate system (72). The latter case can only be reached if the expected values of the fit coincide with the data point values, standing for a model which fits the data without any deviation (the fit goes exactly through every data point). In this work I used the $R^{2}$ value to specify if the model explains the experimental data well.

\subsection{Optical trap}

\section{Cell elasticity measurements with optical tweezers}

In order to measure the stiffness of different cell types, a custom-built dual optical trap was used where a laser is split into two beams which are focused by an objective and therefore form two optical traps in the sample plane. Both traps can be steered independently, one of them by an acustooptical deflector (AOD) (73). The position of an object within the trap can be measured for both traps independently by a quadrant photodetection (QPD) system (73). A detailed description of the setup can be found in $(74,75)$.

For the experiments two $4 \mu \mathrm{m}$ diameter carboxylated polystyrene beads (PPs4.0COOH, Kisker Biotech, Steinfurt, Germany) coated with fibronectin (\#F0895, Sigma-Aldrich) were attached to a cell from different sides. To prevent surface attachment of the cells the sample chamber was treated with dimethyldichlorosilane (DDS, \#85126, Sigma) and 1\% pluronic F108 (\#3402.13, BASF, Ludwigshafen, Germany).

The figure 3.10 demonstrates the schematic drawing of the setup. Basically, a suspended cell attached to two beads (red and blue), exerts forces $F_{1}$ and $F_{2}$. The displacement $u_{1}$ and $u_{2}$ of these beads are detected by QPD. In 
active fluctuation measurements, the position of one trap is sinusoidally modulated by the AOD while the second trap measures the transmitted fluctuations (73). In these experiments displacements of $500 \mathrm{~nm}$ at a frequency of $0.2 \mathrm{~Hz}$ were applied.

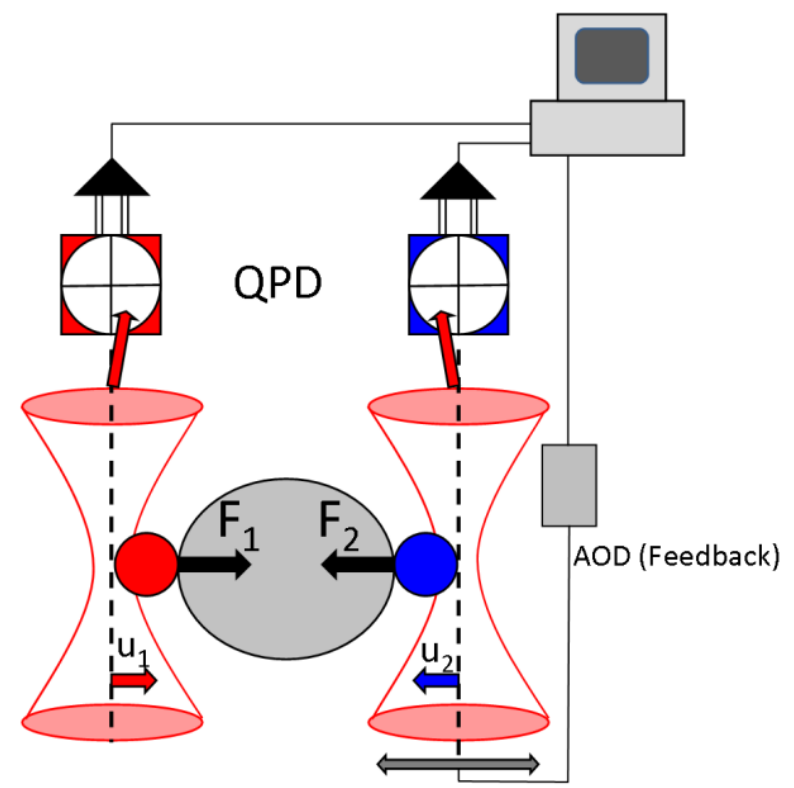

Figure 3.10. Schematic image of the optical trap setup. (75) 


\section{Chapter 4. Chemical and mechanical induction of hMSCs}

\subsection{Introduction}

How cells respond to the combination of the chemical and mechanical cues is the key for understanding tissue regeneration. Understanding how human mesenchymal stem cells (hMSCs) from the bone marrow can differentiate into different cells types is one of the interests, but the underlying mechanisms are not well known. Full knowledge of the mechanisms of differentiation will be the key to the successful medical application. Till date, several triggers, such as chemical and mechanical differentiation, of stem cell differentiation paths have been reported. In this chapter, I demonstrate both mechanical, triggered by changes in the physical microenvironment (1), and chemical, promoted by addition of small chemicals and growth factors, differentiation of hMSCs towards muscle cells. Both approaches were shown to promote stem cell differentiation towards muscle cells $(46,47,49,76)$. For the chemical differentiation, I used two different approaches, which include the addition of chemicals (dexamethasone and hydrocortisone) or growth factors (transforming growth factor $\beta 1$ ) directly to the cell culture. For mechanical induction, I cultured cells on collagen-coated polyacrylamide (PAA) hydrogels of Young's modulus of $11 \mathrm{kPa}$. This gel stiffness mimics the natural muscle microenvironment and is known to promote stem cell differentiation towards muscle cells (1).

For most of the experiments presented in this chapter, cells were placed on collagen-coated PAA gels with elasticities from 1 to $30 \mathrm{kPa}$ and glass for 24 hours after chemical or mechanical pre-culture. I further analyzed cellular susceptibility (response to the physical microenvironment) to the substrate. The time point of 24 hours was shown to be a short incubation to allow complete spreading of hMSCs and adapt morphological changes on different substrates $(1,8)$.

The morphological changes which were investigated were as follows:

- actin spreading area,

- aspect ratio or quantitative elongation of the cell, which is the ratio of long to short axes of the cell, 
- order parameter $S$, which is quantification of the alignment of stress fibers in the cell.

It is known that in comparison with other cells, muscle cells are more elongated and their SFs align along the long axes of the cell (9). Therefore, in this chapter, I will refer mostly to the aspect ratio of induced cells and compare it to physiological values of committed cells. Here we questioned the following: after the differentiation started and the morphological changes occurred, can the cell readapt to the new physical microenvironment?

\subsection{Chemical induction}

\subsubsection{Effects of dexamethasone and hydrocortisone on stem cell differentiation}

It was shown in the previous studies that human mesenchymal stem cells (hMSCs) cultured in the media supplemented with dexamethasone and hydrocortisone may differentiate towards muscle cells $(1,46,47)$. After the first weeks of culture, cells already expressed the early myogenic markers, such as MyoD1 and myogenin. On the contrary, hMSCs seeded on different substrates could differentiate towards various cell lines (e.g. neurons, muscle cells, osteoblasts) (1). In this part of the thesis, I performed cell culture experiments under both conditions: hMSCs cultured in dexamethasone and hydrocortisone and on PAA gels for 4 days. I prepared 2 sets of collagen-coated PAA gels from 1 to $30 \mathrm{kPa}$. Cells (about 2500) were seeded per gel or glass, and in one set of gels, supplements for muscle induction media (MIM) were added. After 4 days of culture, cells were chemically fixed and fluorescently labeled for actin and nucleus. About 30 cells per condition were measured. The images were analyzed, as described in 3.8 , to extract the actin spreading area and to calculate the aspect ratio.

Cells were viable in both control media (figure 4.1b) and induction media (figure 4.1c). In case of hMSCs cultured only on gels, I observed an increase in the aspect ratio of the cells on gel of intermediate muscle-like rigidity $(11 \mathrm{kPa})$, consistent with previous reports (1). In case of cells cultured in MIM, the aspect ratio on a gel of intermediate stiffness $(11 \mathrm{kPa})$ is clearly higher than the aspect 
ratio of hMSCs in control media. Cells on soft and stiff gels were comparably round (figure 4.1a), which is typical for neurons and bone cells.

a

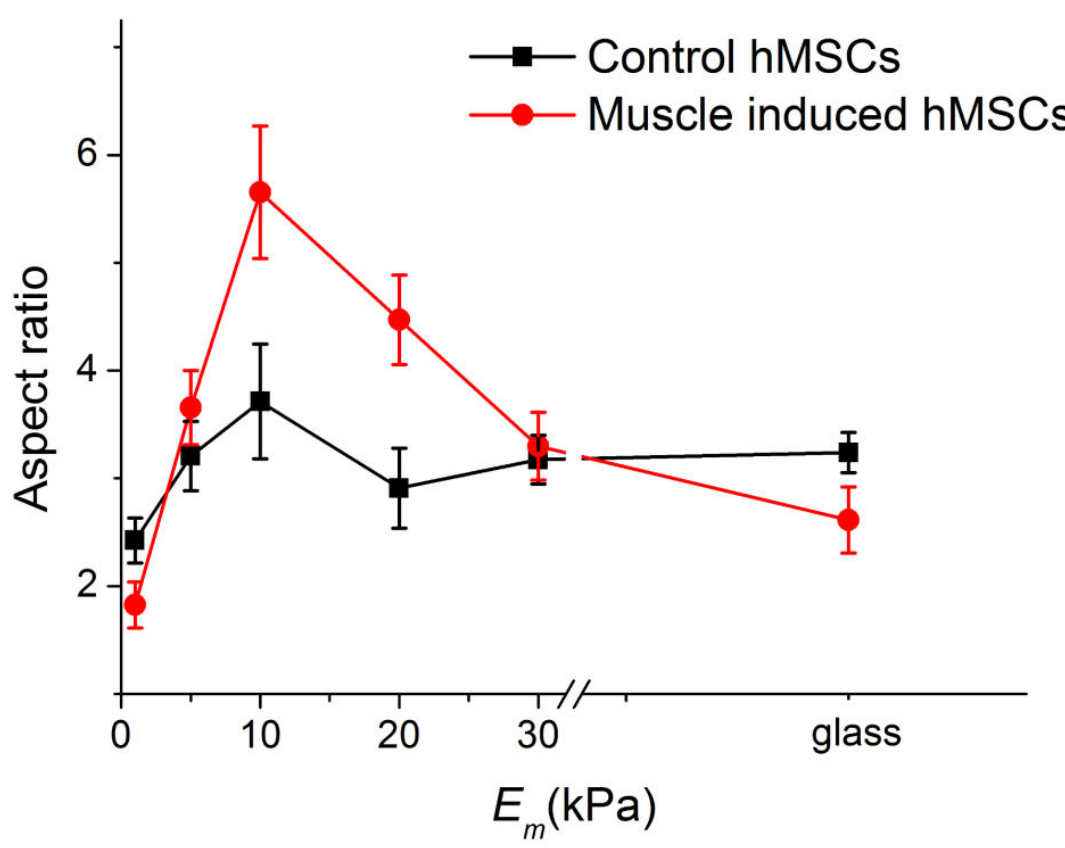

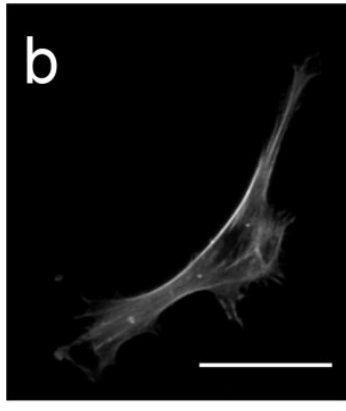

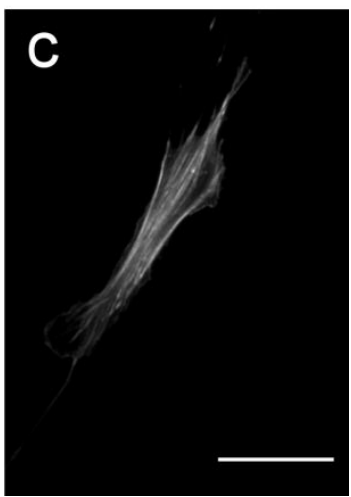

Figure 4.1. (a) Aspect ratio of control and muscle induced hMSCs on substrates with different elasticities after 4 days of culture. Error bars: standard error of the mean. Representative images of fluorescently labeled hMSCs on $10 \mathrm{kPa}$ gel in control (b) and MIM (c). Scale bar: $25 \mu \mathrm{m}$.

This measurement indicates that in short culture of hMSCs on intermediate substrates and in presence of MIM promotes more morphological changes resembling muscle cells, than culture only on gels. However, cells seeded on soft and stiff substrates and cultured in control or in presence of MIM are comparable in terms of their aspect ratio. Hence, MIM does not influence the morphology of cells on non-intermediate substrates.

Additionally, cellular behavior and susceptibility to the new mechanical environment after a longer culture in MIM was assessed. I cultured stem cells for 1 week in control DMEM and MIM to further promote stem cell differentiation towards muscle cells. The two flasks with cells were incubated under identical environmental conditions, but in different media. Culture media was exchanged every 2-3 days to provide the cells with necessary supplements. After a week of culture, cells were detached from the culture flasks and seeded on gels with different elasticities and on cover glasses at a density of 2500 cells per well, followed by incubation for 24 hours. Then, cells 
were chemically fixed and fluorescently labeled for actin and the nucleus and imaged using an inverted fluorescence microscope.

Figure 4.2a shows the monotonic increase in the actin area with matrix elasticity under both conditions. This follows the theoretical predictions that the cell spreading area is highly dependent on the substrate elasticity: it increases monotonically with the increase in matrix elasticity (9). The area of induced cells appears to be significantly larger than the area of control cells. Thus, we concluded that MIM changes the susceptibility of the cells to the ECM. I then analyzed the aspect ratio of cells on different substrates in both samples (see figure 4.2b). I found that aspect ratios in both samples were similar, i.e. MIM pre-culture did not reveal morphological changes, in contrast with the control sample. This finding is contradictory to our hypothesis: since muscle cells are morphologically more elongated than other cell types, and MIM was shown to drive stem cell differentiation towards muscles (1), the aspect ratio of the chemically induced cells was expected to be higher than naive cells.
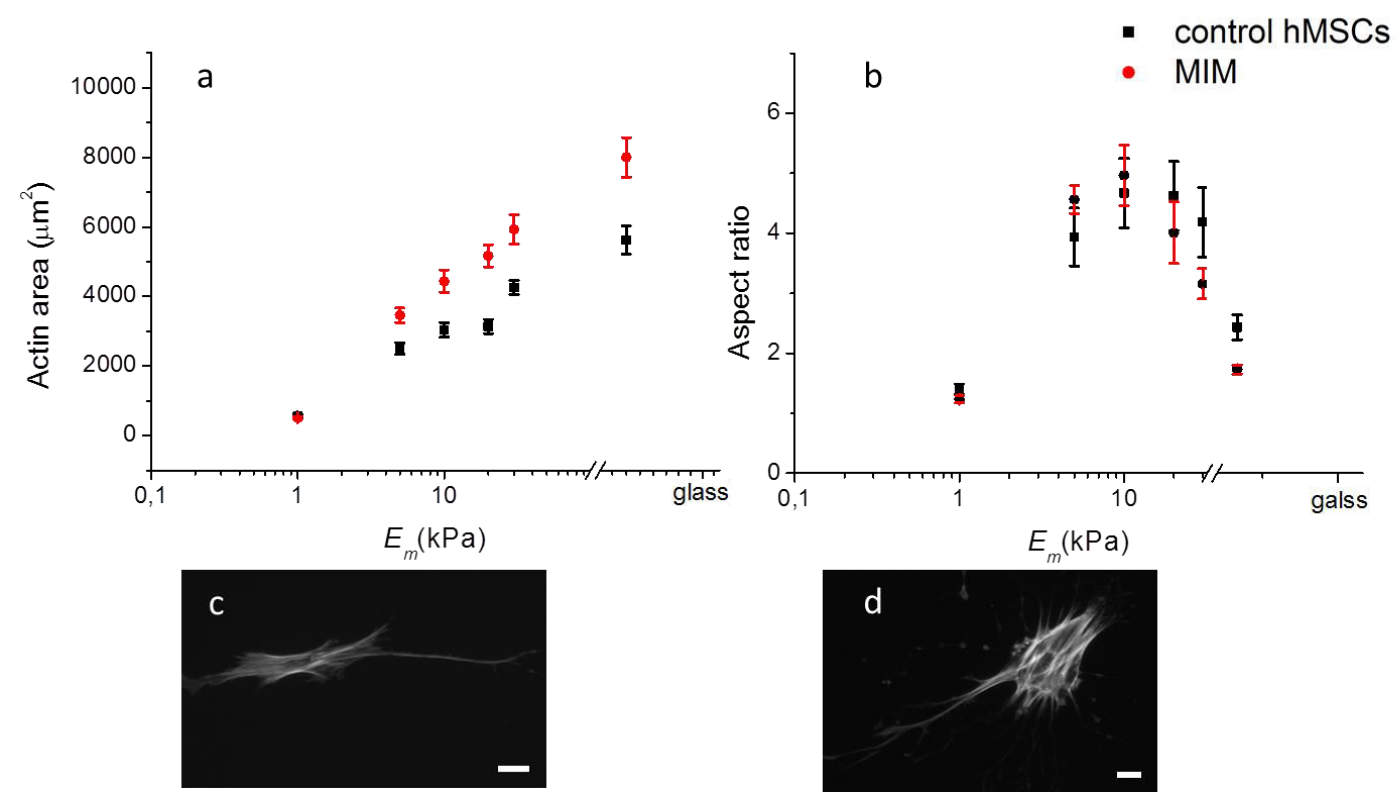

Figure 4.2. (a) Actin area in $\mu \mathrm{m}^{2}$ and (b) cell aspect depending on matrix elasticity. hMSCs cultured 1 week in control DMEM (black) and in MIM (red), and then replaced for 24 hours to PAA gels. Error bars: standard error of the mean. Representative hMSCs on $30 \mathrm{kPa}$ gel in control (c) and muscle induction media (d). Scale bar: $25 \mu \mathrm{m}$.

It should be pointed out that already after 1 week of culture, cells did not seem to be viable anymore (see examples of the cells $4.2 \mathrm{c}$ and $4.2 \mathrm{~d}$ ), which 
might have been caused by the addition of muscle induction supplements. Both dexamethasone and hydrocortisone are soluble only in ethanol, which, in high concentrations, is toxic to cells. Hence, the total amount of ethanol in the culture media was set to not exceed $5 \%$. In order to check if our cell treatment might have influenced the behavior of cells, I performed control experiment with the addition of the same amount of ethanol as in MIM. Cell areas measured in the control media samples and cell areas in samples of DMEM added with $5 \%$ ethanol showed no significant differences (tested by two sample t-test) (see the appendix A.8). Thus, ethanol in concentrations of less than $5 \%$ does not affect the cellular behavior, similar results were reported earlier $(77,78)$.

In these experiments the method of muscle induction with dexamethasone described by Engler et al. (1) does affect cellular viability and cellular ability to differentiate. Therefore, long term culture experiments could not be performed under these conditions.

\subsubsection{Effects of long- and short-culture in transforming growth factor $\beta 1$ on stem cell differentiation}

\section{Short - term culture}

For several decades, research evidenced the importance of the transforming growth factor $\beta 1$ (TGF- $\beta 1$ ) in cell culture. TGF- $\beta$ proteins are multifunctional proteins that regulate cell growth, differentiation, and migration (79-82). It was shown in previous studies that short term cell culture changes cell contractility and its response to the environment on addition of TGF- $\beta 1$ (83-87). Interestingly, Liu showed that the maximum changes in fibroblasts contractility cultured in TGF- $\beta 1$ were observed in the first 48 hours (88). Tomasek and co-workers proposed another example of the importance of TGF- $\beta 1$ in cell culture, namely that the growth factor fully differentiates fibroblasts to myofibroblast within a short time (89). On the contrary, TGF- $\beta 1$ is also known to promote hMSCs differentiation towards muscle cells. It was shown that TGF- $\beta 1$ increases alpha-actin (an early marker of MSC differentiation) expression in MSCs and promotes their specification into a smooth muscle lineage (90). These findings motivated me to analyze morphological changes in hMSCs induced by TGF- $\beta 1$ in a short-term (48 hours) culture and observe modifications of cellular susceptibility to ECM. 
With this intention, I cultured hMSCs for 48 hours in 2 different flasks: one containing only control DMEM, another DMEM supplemented with TGF$\beta 1$. After the pre-culture, cells were trypsinized and seeded on collagen type I coated PAA gels for 24 hours in two 6-wells containing control and differentiation media. Afterwards, cells were chemically fixed, F-actin and nucleus were fluorescently immunostained and about 30 cells per condition were imaged. Morphological parameters, such as actin spreading area and aspect ratio of the cell, were extracted from the fluorescent images using ImageJ.

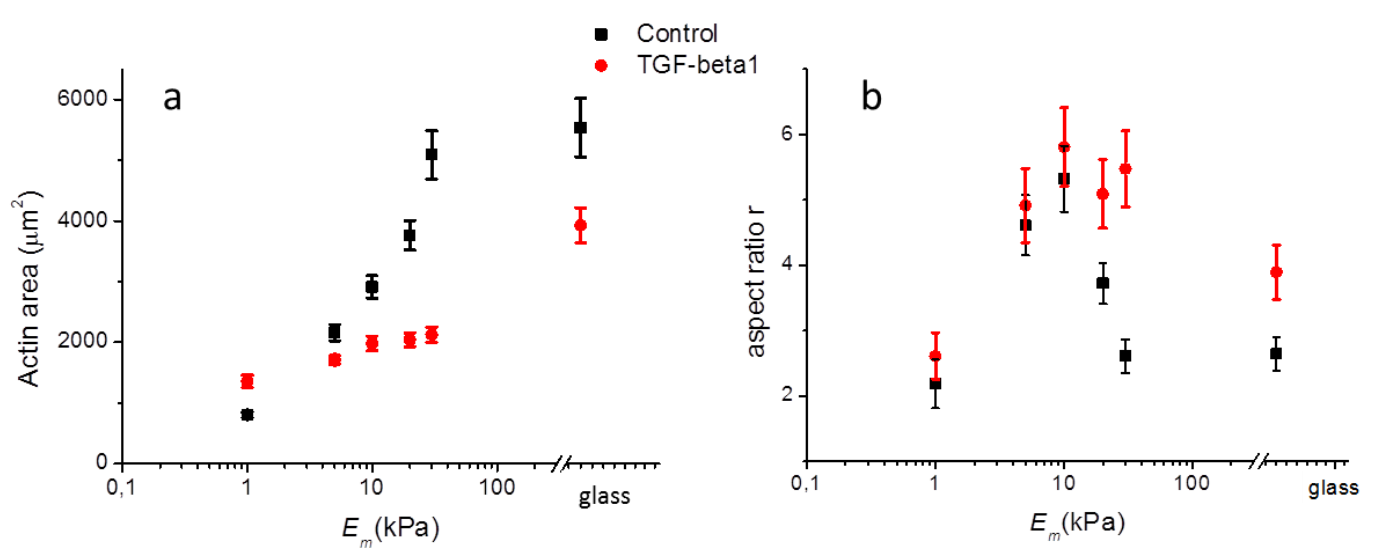

Figure 4.1. (a) Actin spread area and (b) aspect ratio of hMSCs induced with TGF- $\beta 1$ for 48 hours in flasks, then cultured on PAA gels and glass for 24 hours. Error bar: standard error of the mean.

Figure 4.3 shows actin area and aspect ratio of cells cultured in control medium (black) and in the growth factor medium (red). Indeed, the 48 hours pre-culture of stem cells in TGF- $\beta 1$ changes the cellular response to the matrix. In comparison with the monotonic increase in the spreading area of naive cells, treated cells revealed a different behavior on the gels with stiffnesses of 1-30 $\mathrm{kPa}$. On intermediate substrates in the stiffness range of $10-30 \mathrm{kPa}$, cell area stays small, whereas aspect ratio of the TGF- $\beta 1$ cells is higher than the control values. Aspect ratio values of the treated and untreated cells on soft substrates (1-5 kPa) are similar. Thus, the presented results indicate that TGF- $\beta 1$ changes the susceptibility of human mesenchymal stem cells in a short-term culture. For comparison of the morphological changes, I used naive and TGF- $\beta 1$ inhibited mouse myoblasts $\mathrm{C} 2 \mathrm{C} 12$ (see appendix A.7). These results do not show any differences between treated and untreated cells. Pre-cultured cells were tested 
for the expression of myogenin, an early myogenic marker, using Western blot. No evidence of expression was found (see image in the appendix A.6).

\section{Long-term culture}

Since TGF- $\beta 1$ not only changes contractility of different cell lines, but also promotes hMSCs differentiation towards smooth muscle cells $(49,76)$, it was interesting to investigate changes in cell morphology in response to long term induction. For this purpose, a week-long culture of hMSCs in DMEM supplemented with TGF- $\beta 1$, as well as a control sample, were tested. The culture medium was changed every 2-3 days to provide fresh supplements. After a week of culture, cells were detached and transferred onto the collagencoated gels with different elasticities of 1-30 kPa and on a glass substrate. Cells were chemically fixed after 24 hours of seeding and stained for actin and nucleus. As TGF- $\beta 1$ is supposed to promote stem cell differentiation towards smooth muscle cells, is was expected that hMSCs, after a week of pre-culture, would be elongated as muscle cells and further seeding on gels will not change their morphology. The aspect ratio of the pre-cultured cells was expected to be higher than control cells' on all substrates. As shown in figure 4.4, I observed that the aspect ratio of control cells showed a monotonic increase on soft substrates, followed by a decrease on stiff substrates, and a peak on intermediate muscle-like rigidity, as expected. Simultaneously, the aspect ratio of TGF- $\beta 1$ pre-cultured cells showed an increase on soft substrates, peaking on intermediate rigidity, whereas on stiff substrates cells were as elongated as in the intermediate range. On glass, the aspect ratios of both sample cells were comparable. Hence, independent of pre-culture, seeding on soft substrates and glass, the cellular microenvironment dictates its fate. At the same time, cells seeded on 10-30 kPa gels kept their morphological memory. This shows that the chemical induction prevents pre-cultured cells from adapting to different substrates within the first 24 hours, as demonstrated for the control case.

Here, I show that TGF- $\beta 1$ changes cellular susceptibility to the substrate in short- and long-term culture: cells spread in a different way on identical substrates. It is also interesting that stem cells change their morphology towards muscle cells and become more elongated. 


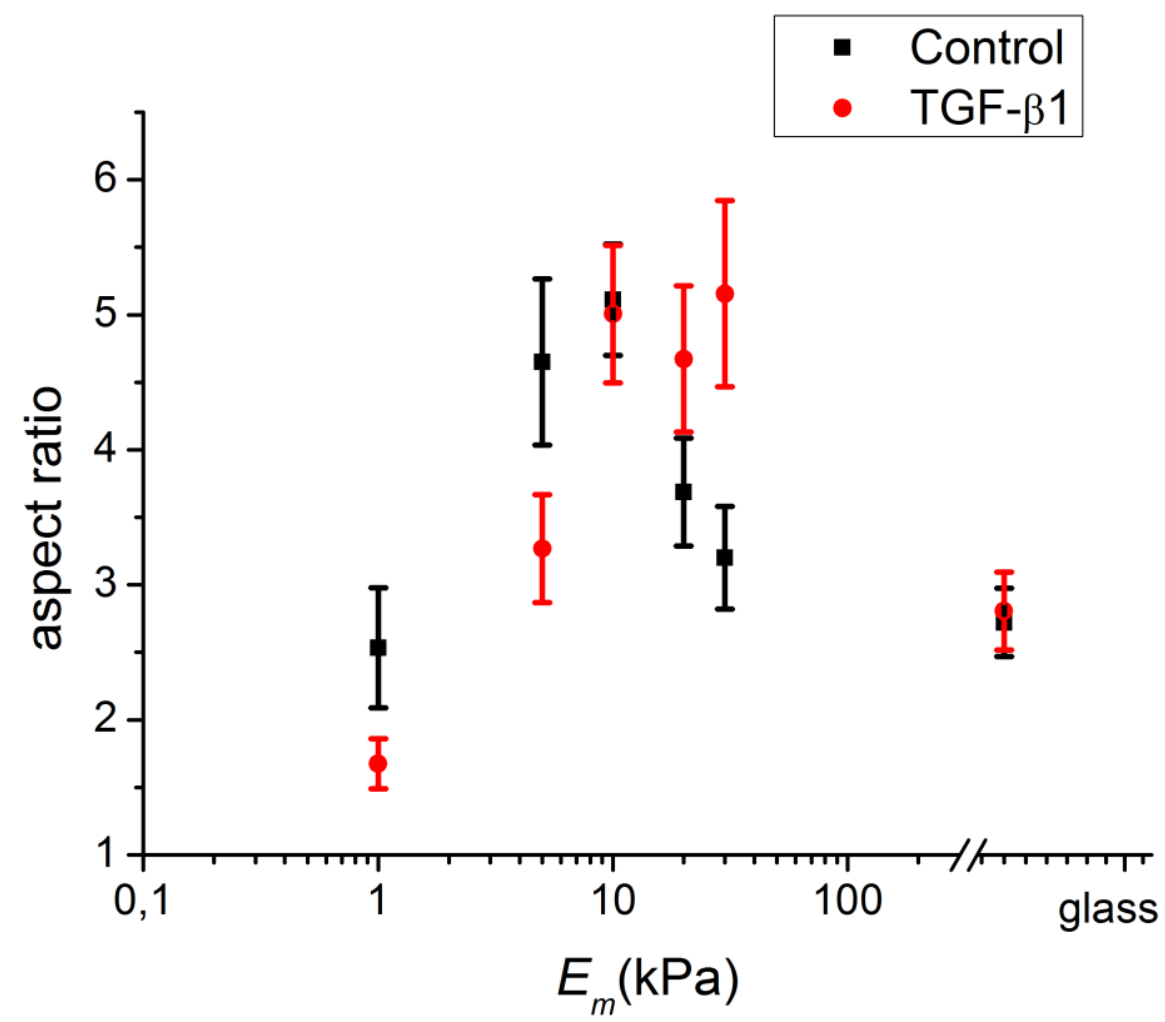

Figure 4.4. Aspect ratio of control cells and hMSCs chemically induced by TGF- $\beta 1$ and then cultured on PAA gels with different elasticities for 24 hours. Error bars: standard error of the mean.

\subsection{Mechanical induction of hMSCs on gels with muscle-like rigidity}

A decade ago, Engler and his co-workers showed that just culturing cells on muscle-like rigidity is enough to drive stem cell differentiation (1). The proof of the differentiation is the expression of early myogenic markers, such as MyoD1 and myogenin. The expression of myogenic markers in mechanically induced $\mathrm{hMSC}$ corresponded to $50 \%$ of the protein expression in mouse myoblasts $\mathrm{C} 2 \mathrm{C} 12$. Hence, as mechanical induction promotes differentiation, after a week of pre-culture on gels with muscle-like rigidity, hMSCs should lose their ability to readapt to other microenvironments. In order to evaluate this assumption, I cultured hMSCs on $11 \mathrm{kPa}$ gels for 1 and 2 weeks in order to mechanically induce differentiation. Six PAA gels coated with collagen with a large diameter of $50 \mathrm{~mm}$ were prepared to provide enough space to allow the cells to freely migrate and divide. Cells were cultured onto the substrates at a density of 7000-8000 cells per gel to avoid confluence, media was changed every 2-3 days. After a week of culture, half of the cells were detached and 
transferred to other collagen-coated substrates with elasticities from 1 to 30 $\mathrm{kPa}$ and glass for 24 hours. The remaining cells were cultured for another week, and the procedure was repeated. As a control, I cultured hMSCs in parallel for 1 and 2 weeks on a collagen-coated glass substrate and simultaneously with the pre-cultured samples, transferred the cells onto gels with different elasticities, and cultured them for another 24 hours.

After 24 hours of culture on different substrates, cells were chemically fixed, immunostained for F-actin and nucleus and imaged (30 cells per condition). Image analysis was done, as described in chapter 3.8, to extract actin spreading area and to calculate aspect ratio. The actin area in control sample grew with the increase in the matrix elasticity, following the predictions (9). I applied the fitting equation 2.1, which describes the spreading behavior of cells depending on the substrate. When applying this prediction to the experimental data, one can extract a fitting parameter $E_{c}{ }^{3}$, which is the effective Young's modulus of the cell. For the described control experiment, this parameter is $E_{\mathrm{c}}=8.4 \pm 1.6 \mathrm{kPa}$ (see figure $4.5 \mathrm{a}$ ).

When comparing the cells pre-cultured on $11 \mathrm{kPa}$ gels with the control cells, pre-cultured cells changed their susceptibility to the same underlying matrix. Both, control cell area (black) and pre-cultured cell area (red), shown in the figure 4.5a, grew monotonically with the matrix elasticity from 1 to $10 \mathrm{kPa}$. Then, in the range of 10 to $30 \mathrm{kPa}$, cell area of pre-cultured cells did not significantly differ anymore (verified by T-test, $\rho=0.5-0.8$ ). The fit in the case of pre-cultured cells yielded an elasticity value of $E_{c}=6.7 \pm 6.2 \mathrm{kPa}$, which differed significantly from that of the control sample. The aspect ratio analysis of both samples showed that pre-cultured hMSCs are more elongated on intermediate substrates than the control cells, whereas aspect ratio of cells on soft ( 1 and 5 $\mathrm{kPa}$ ) and stiff (30 kPa and glass) substrates showed similar values (figure 4.4b).

\footnotetext{
${ }^{3}$ For plotting the graphs, fitting the model equation and extracting fitting parameters OriginLab program was used. The error of the cellular elasticity was calculated by a regression algorithm based on the Gaussian error propagation
} 

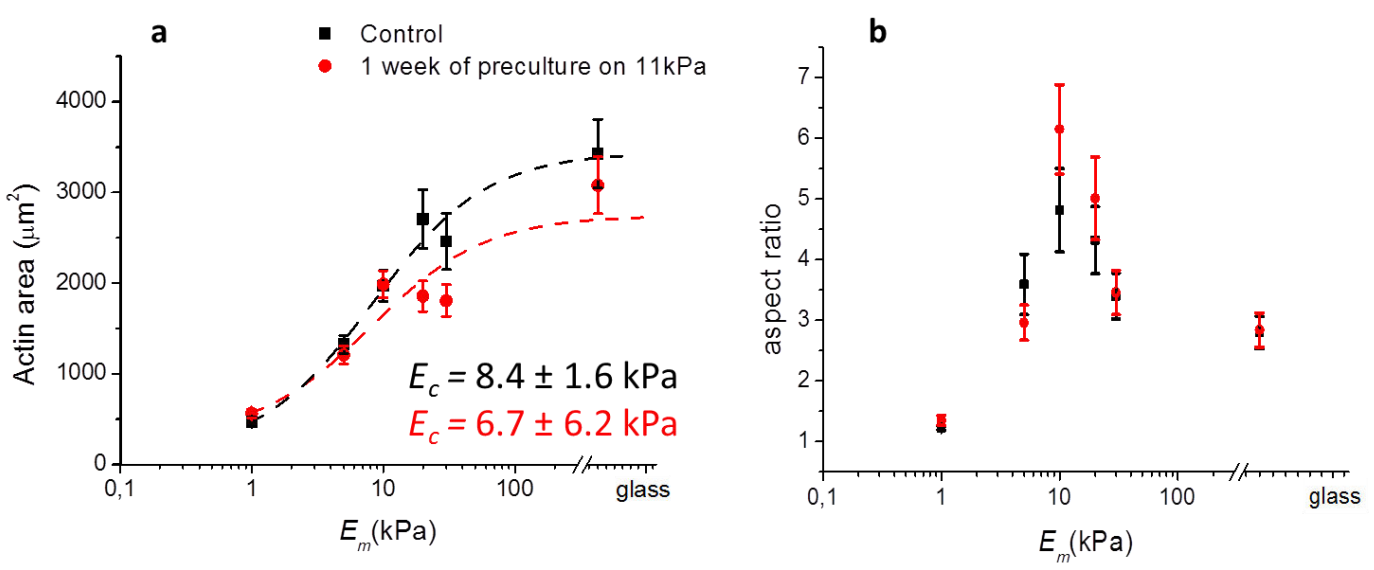

Figure 4.5. (a) Actin spread area and (b) aspect ratio of hMSCs pre-cultured for one week on $11 \mathrm{kPa}$ gels (red) and glass (black), then replaced for 24 hours on gels of 1-30 kPa and glass. 1 week pre-culture on glass was taken as control. Error bars: standard error of the mean.

In addition to changing the spreading area and aspect ratio, matrix rigidity also influences the alignment of SFs in the cell. It is known that cells cultured on $11 \mathrm{kPa}$ substrates have their SFs aligned along the long axes of the cell (8). This inspired a question: will the alignment of SFs readapt to substrates with different rigidities after hMSCs differentiate towards muscle cells by culturing them a week on muscle-like rigidity substrates?

The images presented in figure 4.6a show the quantification of the alignment of the stress fibers using a finger print detection algorithm, which was established by Eltzner and co-workers (71). The analysis of the order parameter $S$ gives a measure of the alignment of stress fibers with the long axis of the cell (see section 3.9). A comparative analysis of control and mechanically induced sample showed that the alignments of SFs do not differ for most substrate rigidities, except for the $11 \mathrm{kPa}$ gel (see figure 4.6a), wherein precultured cells align their fibers more isotropically. In other words, cells precultured on muscle-like rigidity are able to adapt their stress fiber alignment within 24 hours of seeding on different gels. Images of representative cells with tracked fibers are shown in figure 4.6b. Basically, filaments of cells on $11 \mathrm{kPa}$ are mostly aligned along the long axis of the cell (high $S$ values). Cells on soft 1 $\mathrm{kPa}$ gel are small, round, and barely exhibit filaments, though they show an anisotropic alignment, similar to cells on stiff substrates (30 $\mathrm{kPa})$ or glass. 
a

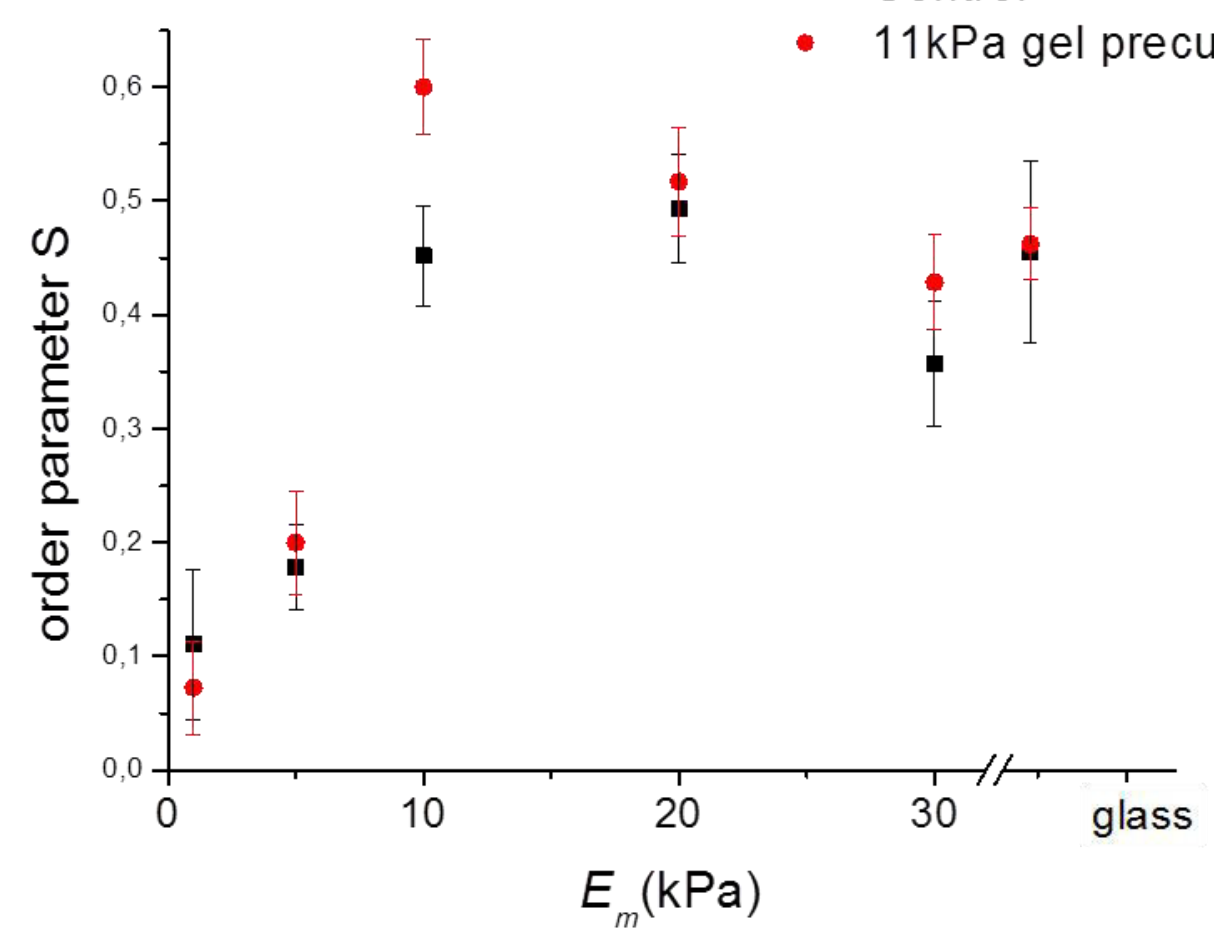

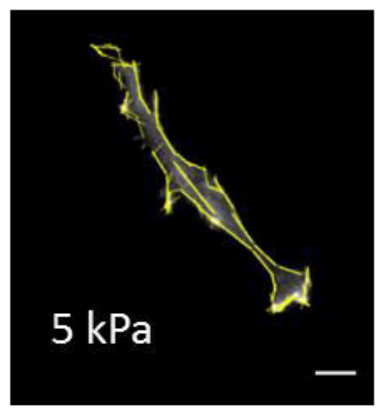

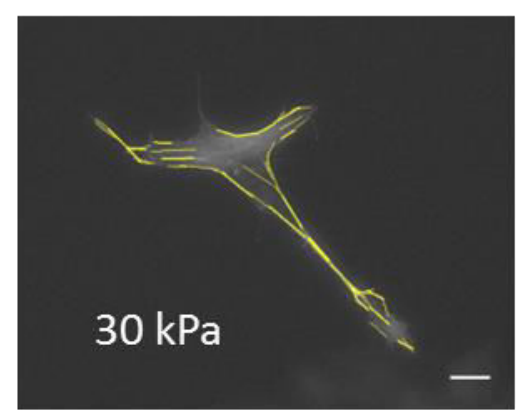

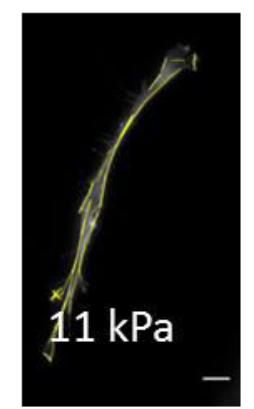

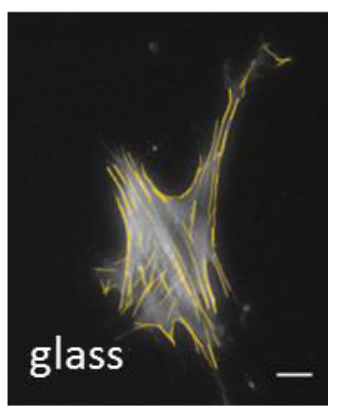

Figure 4.6. (a) Order parameter $S$ of hMSCs pre-cultured for one week on $11 \mathrm{kPa}$ gels (red) and glass (black), then transferred for 24 hours onto gels with elastic moduli of 1-30 kPa and onto glass. 1 week pre-culture on glass was taken as control. Error bars standard error of the mean. (b) Fluorescent images of representative hMSCs on different substrates with tracked filaments (yellow). Scale bars: $25 \mu \mathrm{m}$

In summary, mechanically induced hMSCs revealed morphological changes in the response to the underlying matrix. However, they were able to 
readapt the shape and alignment of SFs to the new conditions within 24 hours, similar to the cells that did not undergo the mechanical differentiation procedure.

To further test if this effect also occurs after longer times of preculturing, cells were treated under the same experimental conditions as described above, but cultured for 2 weeks. As described in section 4.2.1, regarding the case of a long chemical culture in dexamethasone and hydrocortisone, cells did not remain viable, hence these data have to be taken as preliminary. Nevertheless, analysis of the aspect ratio of cells pre-cultured 2 weeks on the $11 \mathrm{kPa}$ gel and then 24 hours on gels with different elasticities showed the same tendency of readapting to the new mechanical environment (figure 4.7).

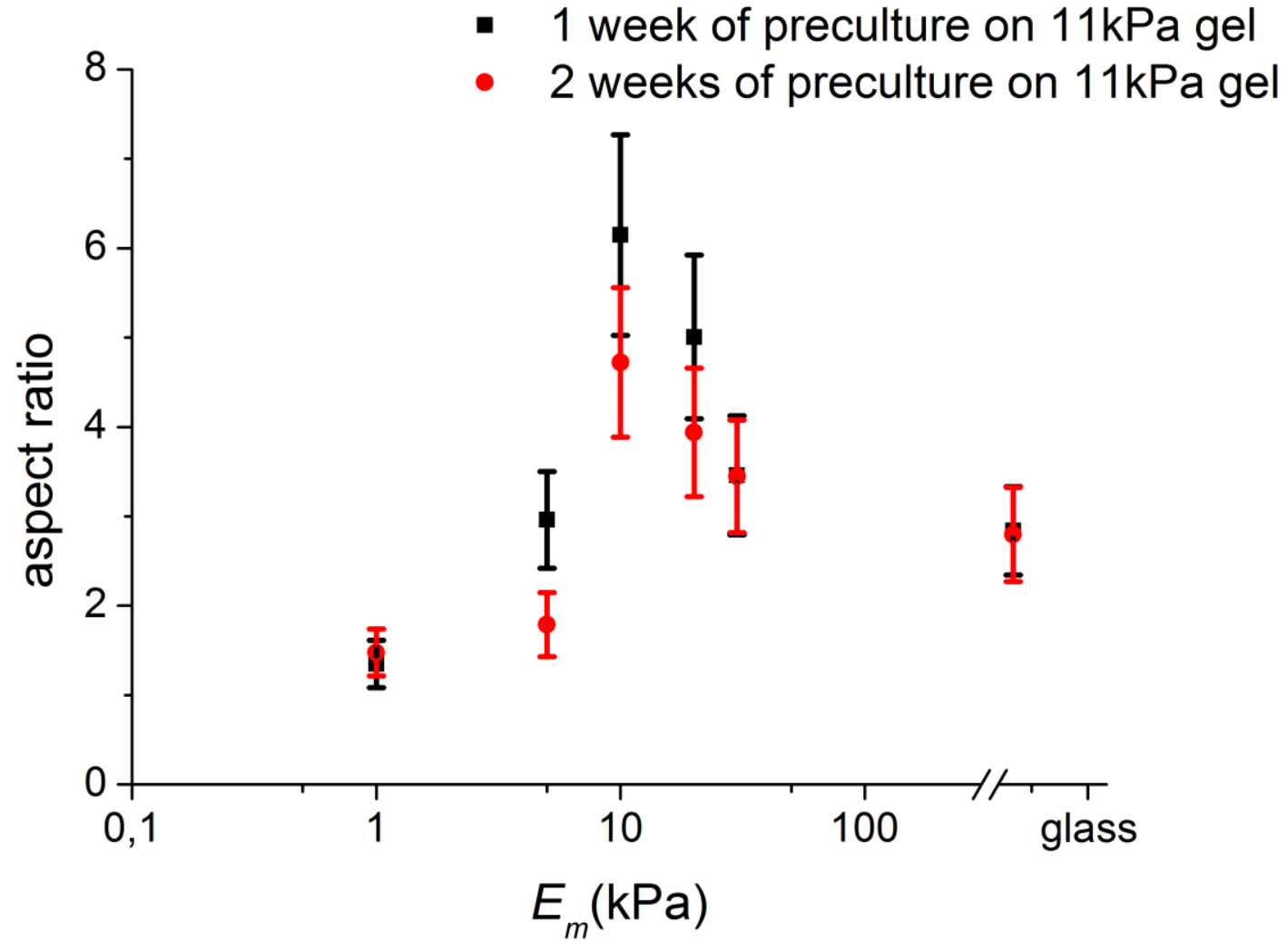

Figure 4.7. Aspect ratio of hMSCs pre-cultured one and two weeks on $11 \mathrm{kPa}$ PAA gel before replacing them for 24 hours to the gels with 1 to $30 \mathrm{kPa}$ rigidity and glass. Error bars: standard error of the mean.

When comparing the aspect ratios of the 1 and 2 weeks pre-culture, cells of the 1 week sample showed a higher aspect ratio than cells of 2 weeks samples. A potential explanation is the low viability of cells in the 2 weeks 
samples. Nevertheless, these results prove that mechanically induced cells do not lose their ability to shape according to the underlying substrate.

\subsection{Myogenin expression in muscle-induced hMSCs and committed myoblasts}

In case a stem cell undergoes differentiation process towards specific commitment, it should express special markers corresponding to the cell line. In our experiments, the cells promoted morphological changes towards muscle cells. Therefore, it was essential to analyze the expression of the early myogenic marker, such as myogenin. I used fluorescent immunostaining of myogenin in the cells after a long-term pre-culture. Here, the intensity of the florescent response was supposed to give the amount of the specific stained protein.

A fraction of the hMSCs pre-cultured 1 week under different conditions, described above (11 kPa gel and TGF- $\beta 1$ ), were seeded on glass for one hour and then chemically fixed. One hour in culture is enough for cells to attach to the substrate, but it is not enough time to adapt morphologically and physiologically to it. These cells were stained for the early myogenic marker myogenin, actin, and nucleus. Here, I analyzed the total intensity of the marker, while taking the cell area into account (as described in 3.8.3). For this experiment, it is essential to have a "non-primary control", i.e. to stain the sample only with secondary antibodies, because it may reveal unspecific binding of the fluorescent dye in the cell. By that, the intensity of the nonspecific binding of the secondary antibody was excluded in all the samples.

The results of this experiment are shown in figure 4.8. It reveals that the expression of myogenin in both, mechanically and chemically pre-cultured cells is not significantly $(\rho=0.065)$ different from each other, but differs from that in the control hMSCs. These results of the expression were compared with the expression of myogenin in committed cells, mouse myoblasts C2C12. This expression showed $21 \%$ (mechanically induced) and 22\% (chemically induced) from expression of myogenin in mouse myoblasts $\mathrm{C} 2 \mathrm{C} 12$ (Figure 4.8). The high intensity in naive hMSCs raised doubts. The high intensity of myogenin expression can be described as a non-specific binding or not bound at all molecules of primary $A B$ in the cell, which caused the binding of secondary $A B$ to these free molecules and as the result high intensity. 


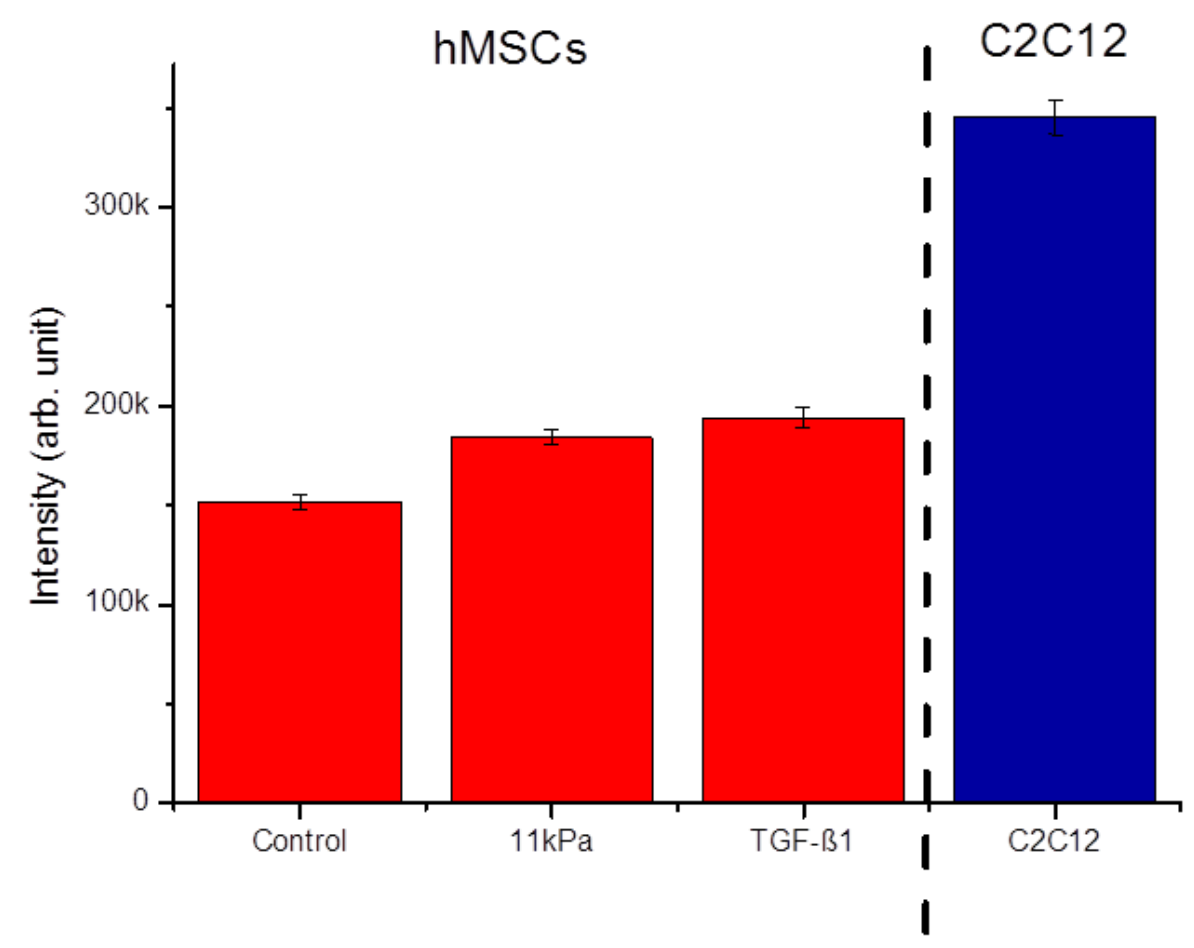

Figure 4.8. Myogenin expression intensity of control, pre-cultured on $11 \mathrm{kPa}$ and in TGF- $\beta 1$ hMSCs, and then seeded for 1 hour on glass substrate. In blue: myogenin expression intensity in mouse myoblasts $\mathrm{C} 2 \mathrm{C} 12$. Error bars: standard error of the mean.

Moreover, after a week of pre-culture, chemically and mechanically induced hMSCs were analyzed for the expression of myogenin using western blot, which did not show any protein expression. This result can be due to the low amount of the cells for western blot and not enough sensitive protein detection for that amount of protein expression. 


\subsection{Summary and discussion}

In this chapter, I presented the results of the differentiation of hMSCs towards muscle cells using mechanical and chemical induction. Firstly, stem cell differentiation by the addition of dexamethasone and hydrocortisone was performed, as described previously $(1,46,47)$. Long term culture did not work out well due to low cellular viability. Short term culture in dexamethasone and hydrocortisole on substrates with muscle-like elasticities revealed significant morphological changes, particularly in cells seeded on substrates with intermediate rigidities. The elongation of these cells was close to that of muscle cells.

Secondly, TGF- $\beta 1$ promoted drastic changes in cellular morphology: in a week of culture, it changed the stem cell contractility and susceptibility to the matrix. Cells that were cultured in TGF- $\beta 1$ did not exhibit the ability to fully adapt to the new matrices within 24 hours, as control cells do. Moreover, these changes started already within the first 48 hours of culture in the growth factor supplemented medium, which was shown in the figure 4.3. This result promotes the idea that TGF- $\beta 1$ is a very important supplement in the cell culture and can change cellular fate in a short period of time (48 hours). Here, I showed that this growth factor changes the contractility not only of fibroblasts $(86,88)$ or myofibroblasts $(83,85,89)$, as was described previously, but also hMSCs.

Furthermore, the transforming growth factor $\beta 1$ is known to promote the expression of alpha-actin (90). That means it changes not only the cellular contractility, but also drives the stem cell differentiation towards muscle cells. Here, I showed that the expression of the early myogenic marker myogenin could be seen already after a week of culture in the fluorescent immunostaining of the marker, which was $22 \%$ from the expression in $\mathrm{C} 2 \mathrm{C} 12$ myoblasts.

Additionally, fluorescently staining myogenin in the mechanically induced hMSCs expressed $21 \%$ of the myogenic marker in comparison with the same marker expression in $\mathrm{C} 2 \mathrm{C} 12$ myoblasts.

In addition to these findings, I showed that pre-culture on muscle-like rigidity affected cell spreading on different substrates, noted by changes in the fitting parameter $E_{c}$. It was expected that mechanically induced hMSCs, after introduction them to another mechanical properties of the environment, 
would not readapt to them. Whereas morphological changes of the precultured cells showed the opposite: cells are adaptable to new rigidities. Thus, mechanical pre-culture has a reversible effect. The result contributes the theory of Frank and co-workers (91) that hMSCs do not lose their "stemness" within a week of culture on a substrate. In fact, I showed that hMSCs cultured on $11 \mathrm{kPa}$ substrate for a week can be transferred to different substrates and can adapt to them within 24 hours. 


\section{Chapter 5 Mechanics of hMSCs and committed cells}

\subsection{Spreading mechanics on elastic substrates}

Since hMSCs can differentiate into different cell lines, from neurons to osteoblasts, it is interesting to analyze and compare morphological changes of the already committed cells in response to elastic substrates. For that purpose 4 additional adherent cell types were chosen:

- $\quad \mathrm{C} 2 \mathrm{C} 12$ is a mouse myoblast cell line,

- $\quad 3 T 3$ NIH fibroblasts from mouse,

- $\quad$ SAOS-2 human sarcoma osteoblasts and

- HOBs human primary osteoblasts.

These cell lines were cultured in the incubator at $37{ }^{\circ} \mathrm{C}$ and $5 \%$ of $\mathrm{CO}_{2}$, the used medium is described in the 3.1 section. For all these cell lines I simultaneously prepared gels from 1 to $30 \mathrm{kPa}$ and glass, as they were used for hMSCs and described in the previous chapter. Cells were seeded on the collagen-coated substrates for 24 hours and then chemically fixed. To analyze the cellular morphology, actin and the nucleus were fluorescently labeled, using the methods described in the 3.6 section. The samples were imaged with an inverted fluorescence microscope, 30 cells per condition and the images were analyzed using ImageJ (see 3.8 section).

Figure 5.1 shows the spreading behavior of 4 out of 5 cell lines: hMSCs, C2C12, 3T3 fibroblasts and SAOS-2 osteoblasts on different substrates from 1 to $30 \mathrm{kPa}$ and glass. All cell lines show a similar trend of monotonic increase of the cell area with increasing matrix elasticity, which is in a good agreement with the theoretical predictions (9). Apparently, cells on infinitely stiff substrate, as glass, have the maximum spreading area. Spreading behavior of hMSCs cultured on $30 \mathrm{kPa}$ corresponds the behavior on an infinitely stiff, what can be seen from the spreading comparable with the maximum area on glass. From figure $5.2 \mathrm{a}$ it can be seen that hMSCs already reach their maximum spreading on $30 \mathrm{kPa}$ in comparison with stiff glass. Whereas, for such cells as $3 T 3$ fibroblasts and SAOS-2 osteoblasts a $30 \mathrm{kPa}$ gel is not stiff enough to fully spread, since the mean area of the cells is significantly smaller then mean area on the glass substrate (figure 5.3). In case of C2C12 myoblasts, cell spread and 
shape already on soft substrates, in contrast to SAOS-2 osteoblasts which find 1-10 kPa gels too soft to spread.

Fitting Zemel's model 2.1 to the different cell lines enables me to extract the cellular elasticity $E_{c}$ (Table 5.1). From the table it can be seen that the effective Young's modulus of the cell is the lowest in case of hMSCs (8.4 1.6 $\mathrm{kPa})$ and the stiffest for SAOS-2 (56.4 $\pm 140.1 \mathrm{kPa})$. Here, the big error reflects the intrinsic scattering of the data. Nonetheless, the quality of the fit $\mathrm{R}^{2}$ shows hMSCs and C2C12 data sets are good fit by the model. $\mathrm{R}^{2}$ and errors of the fitting parameter $E_{c}$ designate the worse fitting of the Zemel's model to the spreading behavior of fibroblasts and SAOS-2 osteoblasts.
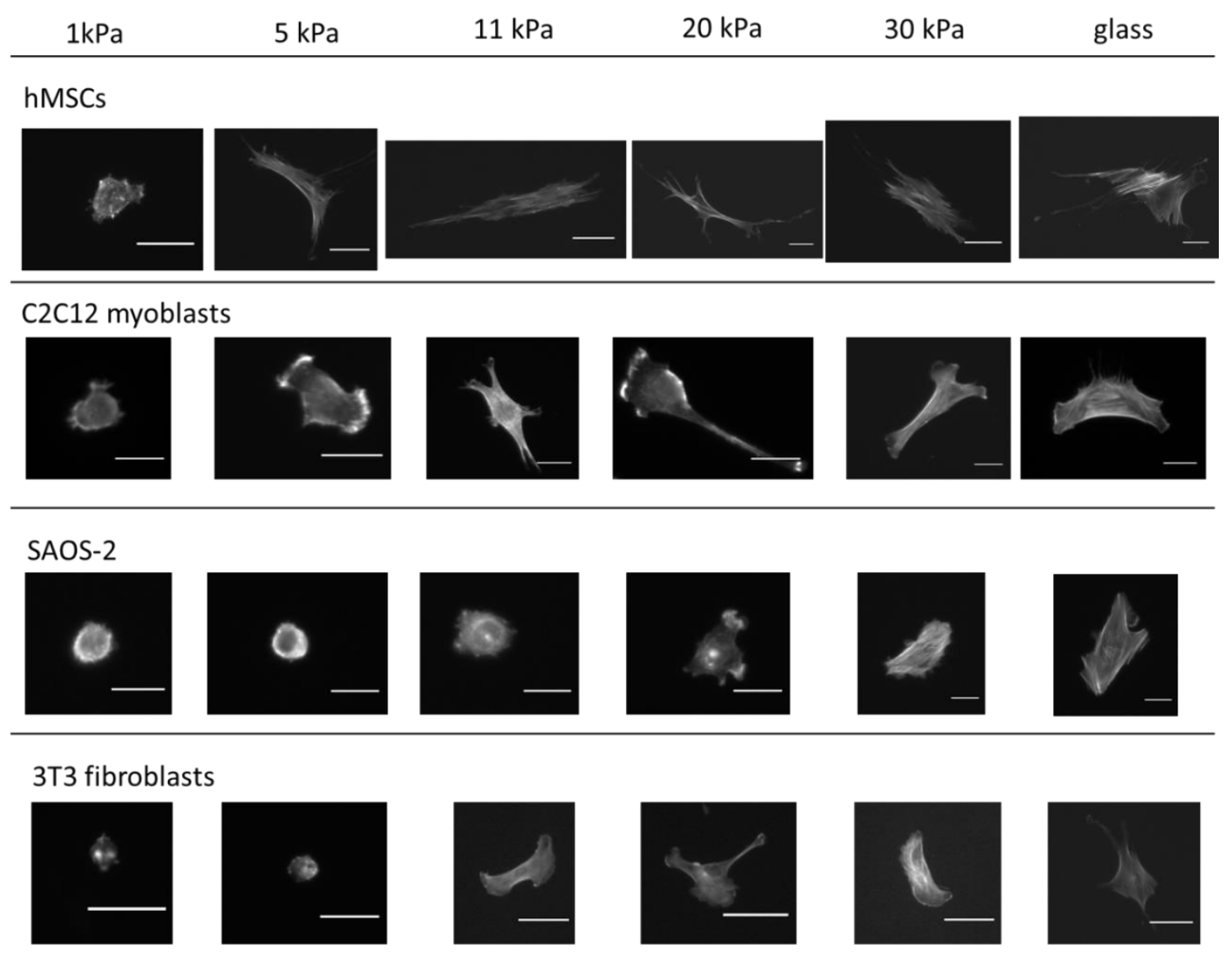

Figure 5.2. Representative images of the used cell lines seeded on elastic substrates with Young's modulus from $1 \mathrm{kPa}$ to $30 \mathrm{kPa}$ and glass after 24 hours of culture. Scale bar $25 \mu \mathrm{m}$. 

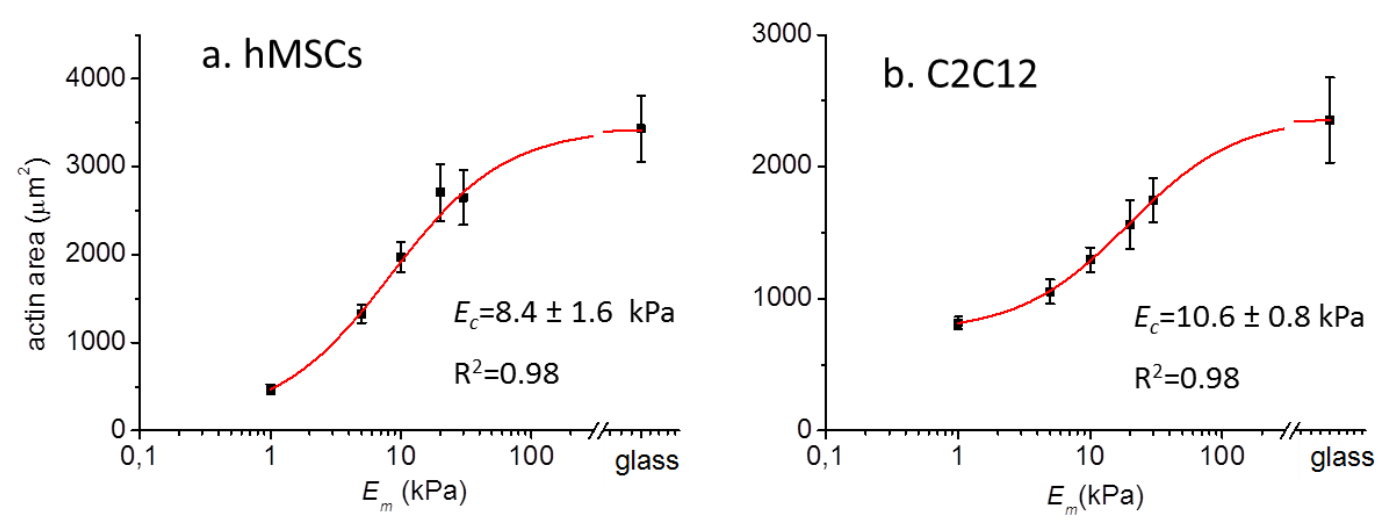

Figure 5.2. Actin spread area of (a) hMSCs and (b) C2C12 myoblasts cultured on elastic PAA gels for 24 hours. The red curve represents the fit of the model equation 2.1 to the data, where $\mathrm{R}^{2}$ represents the quality of the fit. $E_{c}$ is a fitting parameter representing the Young's modulus of the cell. Error bars: standard error of the mean.

\section{4 hours on gels}
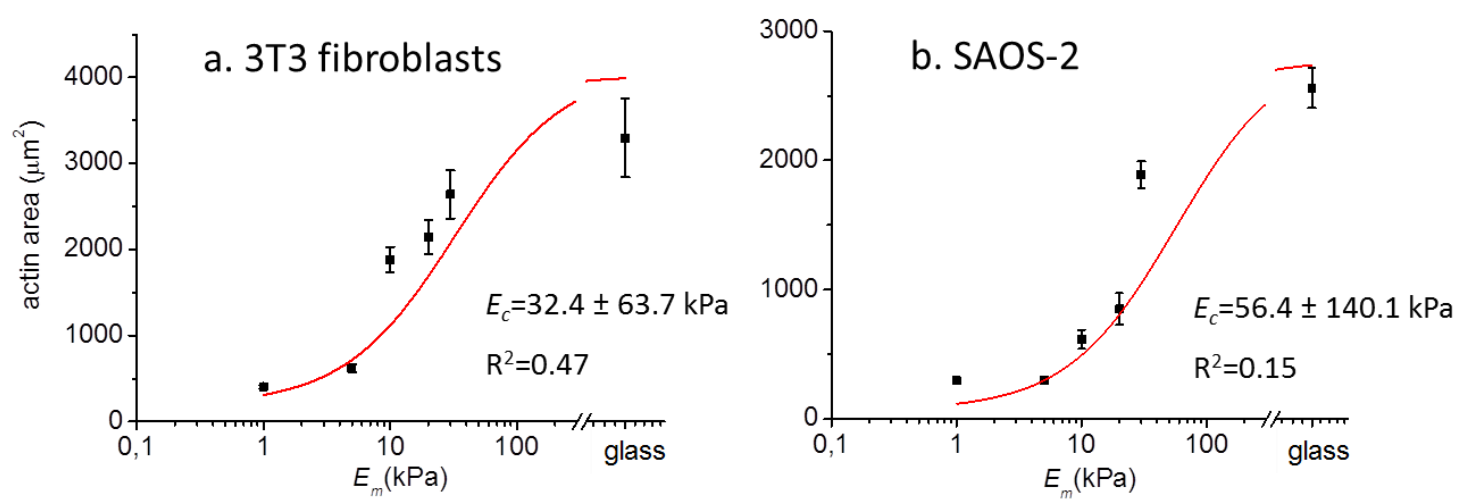

Figure 5.3. Actin spread area of (a) 3T3 fibroblasts and (b) SAOS-2 cells cultured on elastic PAA gels for 24 hours. The red curve represents the fit of the model equation 2.1 to the data, where $\mathrm{R}^{2}$ represents the quality of the fit. $E_{c}$ is a fitting parameter representing the Young's modulus of the cell. Error bars: standard error of the mean.

The described results motivated to fill the gaps in the data graphs by preparing stiffer gels. Therefore I prepared additional gels with stiffnesses of 66 $\mathrm{kPa}$ and $130 \mathrm{kPa}$. The concentrations of PAA gel solution components and the gel preparation procedure is described in 3.4. 
Table 5.1. Fitting parameters of the model to the spreading behavior of 4 presented cell lines.

\begin{tabular}{l|c|c} 
Cell line type & $E_{c}, \mathrm{kPa}$ & $\mathrm{R}^{2}$ \\
\hline hMSCs & $8.4 \pm 1.6$ & 0.98 \\
\hline C2C12 myoblasts & $10.6 \pm 0.8$ & 0.88 \\
\hline 3T3 fibroblasts & $32.4 \pm 63.7$ & 0.41 \\
\hline SAOS-2 osteoblasts & $56.4 \pm 140.1$ & 0.15 \\
\hline
\end{tabular}

\subsection{Cellular spreading dynamics}

Already during cell imaging, I noticed that C2C12 and SAOS-2 cells fixed after 24 hours of culture were in a doubling phase. For my experiment this conditions are not appropriate, we analyze single and isolated cells, which fate was not affected by the interaction with another cell or doubling within this short time gap. Hence, 24 hours is not an appropriate time point to fix all the cell lines. Thus, we decided to investigate the dynamics of cells spreading over time on collagen-coated glass substrates to find a proper fixation time. For this purpose, I plated cells on cover glasses and fixed them after different time points $(1,2,4,8,12,16,24,36$ and 48 hours). The spreading dynamics of these cell lines are shown in figure 5.4. Since individual cells differ in size, I normalized the spreading dynamics of each cell line to its area after 24 hour of seeding to compare their spreading. Figure 5.4 demonstrates that all cell lines have different spreading dynamics. For example, hMSCs and C2C12 cells reach $60 \%$ of their maximum spread area already after one hour of seeding on glass. In comparison, C2C12 cells reach the maximum area within 8-12 hours, whereas hMSCs are fully spread after 24-36 hours. SAOS-2 and HOBs spread on glass about $40 \%$ after 1 hour of seeding, but take longer to reach the maximum (about 16 hours). Conversely, fibroblasts take very long to fully spread on glass substrates: after an hour of seeding they reach about $20 \%$ of their maximal area and are fully spread only after 36 hours. Interestingly, one can see in the spreading dynamics the time point when the cell doubling happens. Especially in the case of HOBs it can be seen that the area is increasing over time and 
then at a certain time point between 24 and 36 hours it drops and then increases again.

Taking the doubling time into account of the maximum spreading area of each cell line on glass substrate, I chose the fixation time (see table 5.2). For osteoblasts and $\mathrm{C} 2 \mathrm{C} 12$ I chose the optimal fixation time to be 16 hours after seeding. For hMSCs I have shown that 24 hours was the appropriate time for the full spreading. NIH 3 t3 fibroblasts needed the longest time to fully spread out of presented cell lines, namely 36 hours.
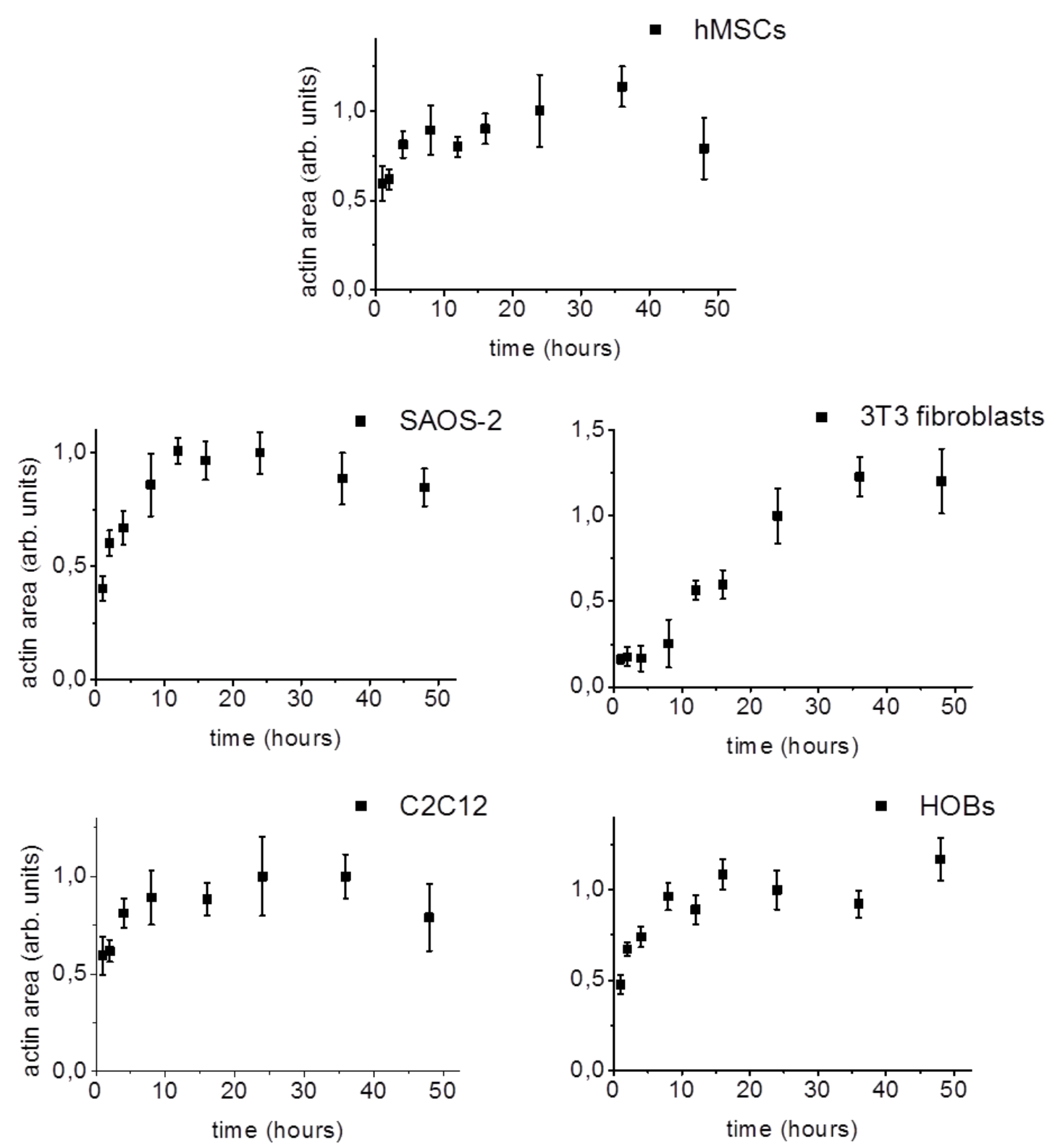

Figure 5.4. Spreading dynamics of actin polymerization of hMSCs, SAOS-2, 3T3 fibroblasts, $\mathrm{C} 2 \mathrm{C} 12$ and $\mathrm{HOBs}$ myoblasts on collagen-coated glass substrate. Error bars: standard error of the mean. 
Table 5.2. Doubling time and the optimal fixation time point of the 5 cell lines.

\begin{tabular}{l|c|c} 
Cell line & $\begin{array}{c}\text { Literature: doubling time, } \\
\text { hours (reference) }\end{array}$ & Optimal fixation time, hours \\
\hline hMSCs & $33(92)$ & 24 \\
\hline C2C12 & $20(93)$ & 16 \\
\hline NIH fibroblasts & $18-20(94)$ & 16 \\
\hline SAOS-2 & $38(95)$ & 16
\end{tabular}

\subsection{Applying the theoretical model on cellular spreading}

Being aware of the spreading dynamics of each cell line and after choosing appropriate timings, as well as making gels with defined elasticities, I moved to the next step of analysis of the spreading behavior of the 5 different cell lines (hMSCs, C2C12 myoblasts, 3T3 fibroblasts, HOBs and SAOS-2 osteoblasts). For that purpose, I prepared 5 sets of collagen-coated PAA gels having 8 different elasticities from $1 \mathrm{kPa}$ to $130 \mathrm{kPa}$ and glass. During each gel preparation, the gel solution's stiffness was measured by a rheometer to control the matrix elasticity of the substrates. After that, cells were seeded in the density of 2500-3000 cells per well and cultured for the optimal time (see table 5.2) to guarantee that they fully spread and adapt their morphology. Then cells were chemically fixed and F-actin and the nucleus were fluorescently labeled. About 60 cells were imaged per condition and fluorescence images were analyzed as described in the 3.8 section in order to extract the actin spread area. In figures 5.4-8 the cellular actin spread area on different elastic substrates and the resulting fit of the model equation 2.1 can be seen. The results show a similar tendency for all presented cell lines: spread area increases monotonically with the substrate stiffness.

Figure 5.5 demonstrates actin spread area in $\mu \mathrm{m}^{2}$ of hMSCs on different substrates within the first 24 hours. One can see that cells cannot spread if seeded on very soft substrates and that their area is small. With increasing substrate stiffness, the area is increasing as well. This spreading behavior follows the theoretical predictions (9). Fitting the model equation to the data set shows the quality of the fit of $R^{2}=0.96$. The extracted effective Young's modulus of the cells is $9 \pm 2.8 \mathrm{kPa}$. 


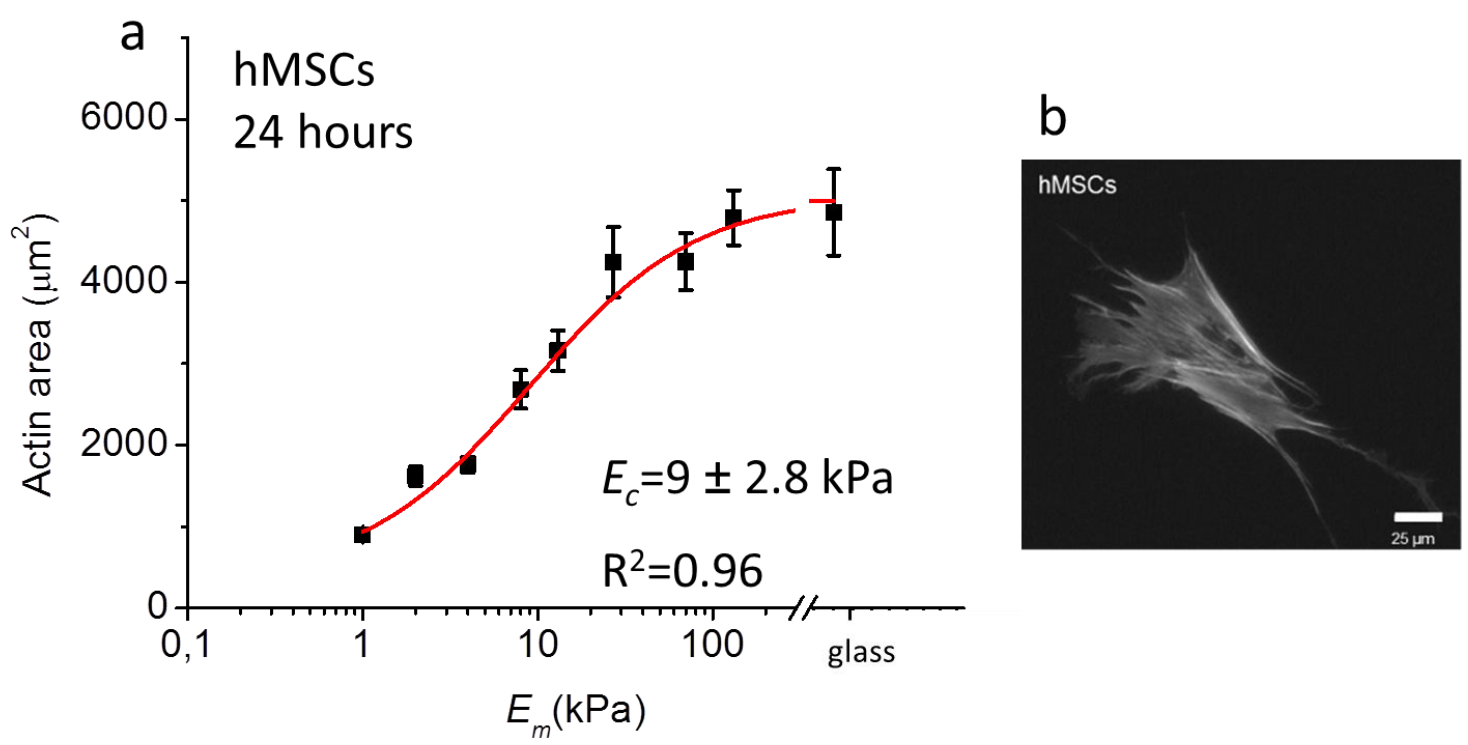

Figure 5.5. (a) Actin spread area of hMSCs on elastic substrates and glass, fixed after 24 hours of culture. Shown in red is the fit of the model equation. Error bars: standard error of the mean. (b) Representative image of hMSCs on a glass substrate, actin staining.

In case of mouse myoblasts, cells were cultured for 16 hours on equally prepared substrates as before. C2C12 cells appeared to be 5-6 times smaller than hMSCs. On soft substrates these cells were also small and the spread area was increasing with matrix elasticity (figure 5.6 ). $R^{2}=0.92$ shows that spreading behavior of $\mathrm{C} 2 \mathrm{C} 12$ also follows theoretical predictions. The Young's modulus of the cell, extracted from the fit, is $7.1 \pm 3.0 \mathrm{kPa}$.

a

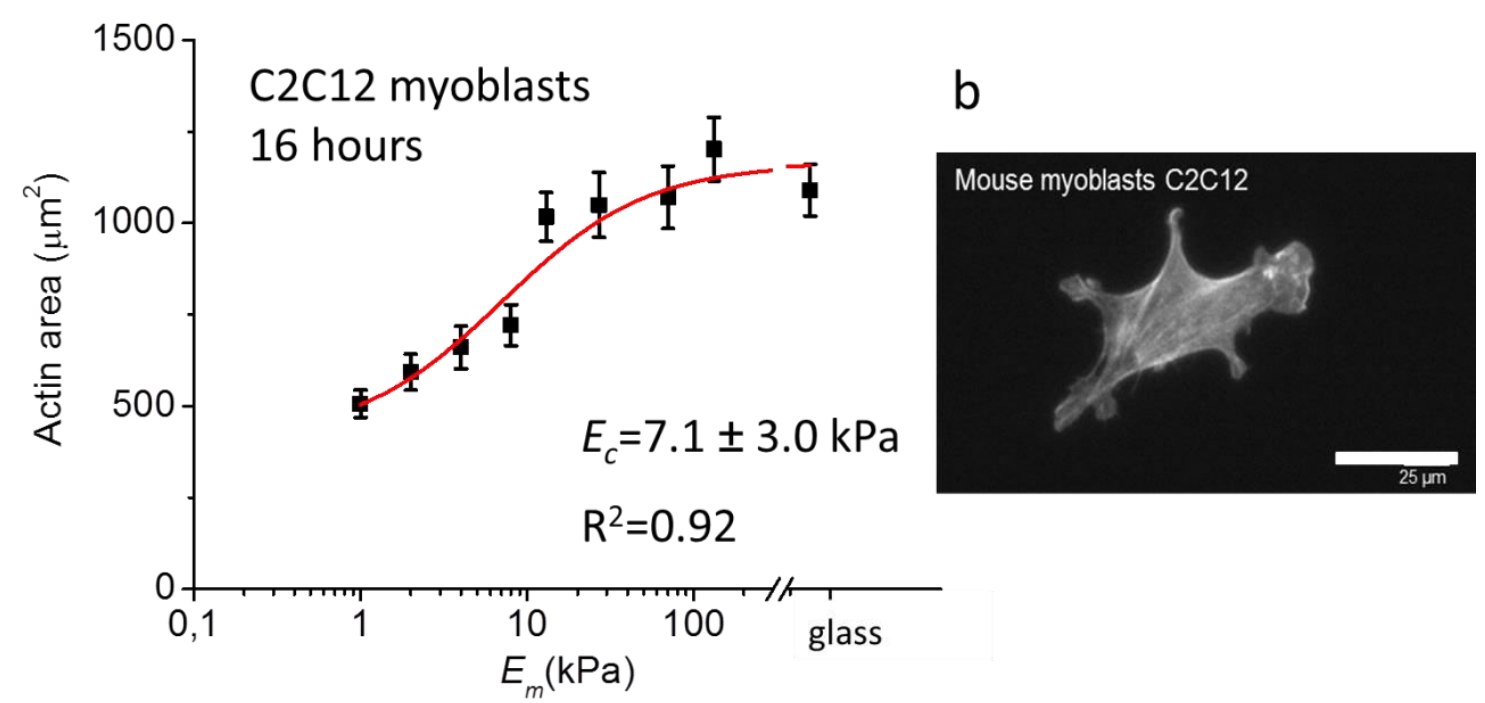

Figure 5.6. Actin spread area (a) of $\mathrm{C} 2 \mathrm{C} 12$ myoblasts on elastic substrates and glass, fixed after 16 hours of culture. Red is the fit of the model equation. Error bars: standard error of the mean. (b) Representative image of $\mathrm{C} 2 \mathrm{C} 12$ on a glass substrate, actin staining. 
Seeding fibroblasts on identical substrates as before leads to the same tendency: cells are small on soft substrates and the area is growing with the matrix elasticity (figure 5.7). Spreading behavior of this cell line is also described by the theoretical predictions and the model equation fits well to this data set $\left(R^{2}=0.95\right)$. The Young's modulus of the cell, extracted from the fit gives a value of $E_{c}=10.3 \pm 2.6 \mathrm{kPa}$. These cells turned out to be as big as C2C12 cells and 5-6 times smaller than hMSCs (figure 5.5).

a

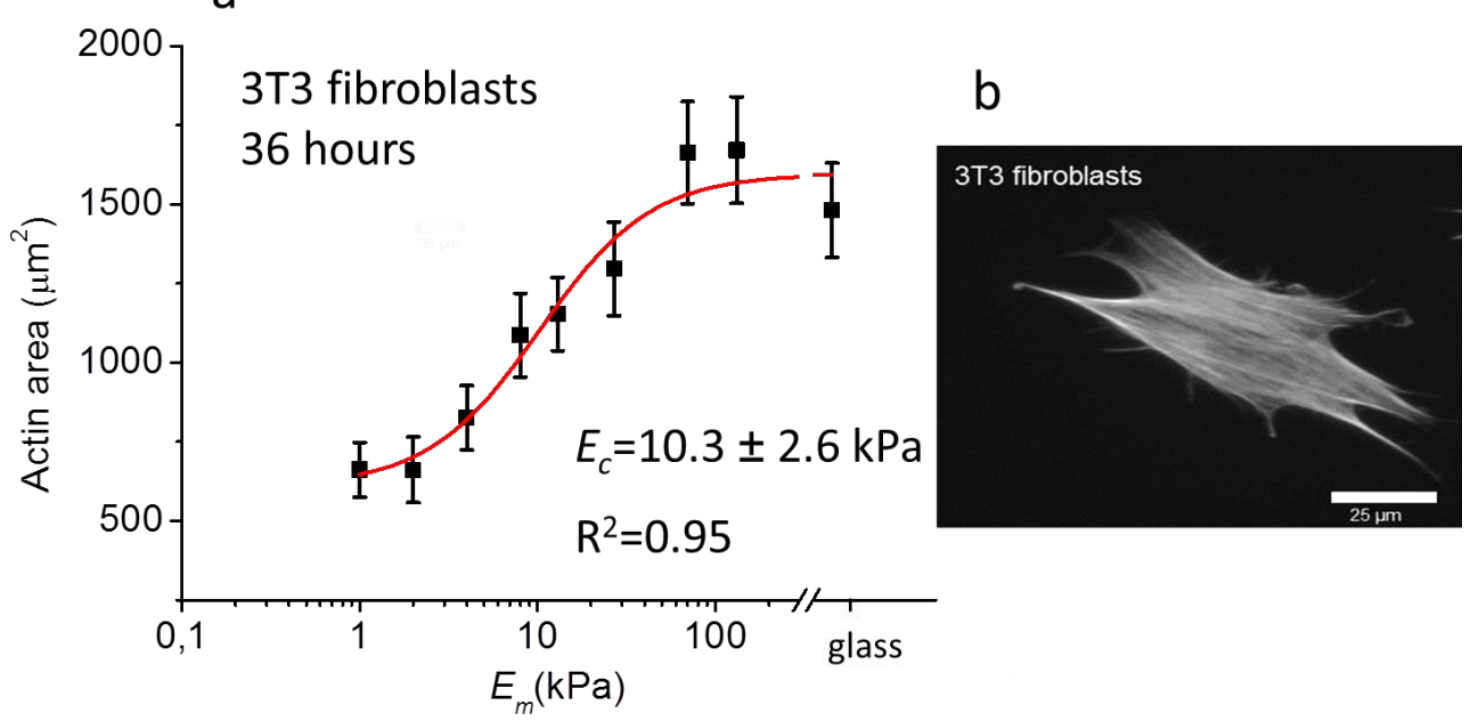

Figure 5.7. Actin spread area (a) of 3 T3 fibroblasts myoblasts on elastic substrates and glass, fixed after 16 hours of culture. Shown in red is the fit of the model equation. Error bars: standard error of the mean. (b) Representative image of fibroblasts on a glass substrate, actin staining.

Human primary osteoblasts appeared to be the biggest cell line out of the five presented cell lines. It can be seen that HOBs cell area is small on $1 \mathrm{kPa}$, but already on $2 \mathrm{kPa}$ the area is clearly increasing (figure 5.8). The cells spread fully already on $30 \mathrm{kPa}$, exhibiting a comparable value as on glass. Again, the area of these cells grows monotonically with substrate elasticity. Unlike the previous cell lines, HOBs on $1 \mathrm{kPa}$ gel are already spread. It seems that this elasticity is not soft enough to be non-spread. In consequence, the inflection point of the fit is moved to the lower values. That is the reason that the fitting parameter $E_{c}=3.4 \pm 1.3 \mathrm{kPa}$ gives a comparably low value, though the fit is $\operatorname{good}\left(R^{2}=0.95\right)$. 


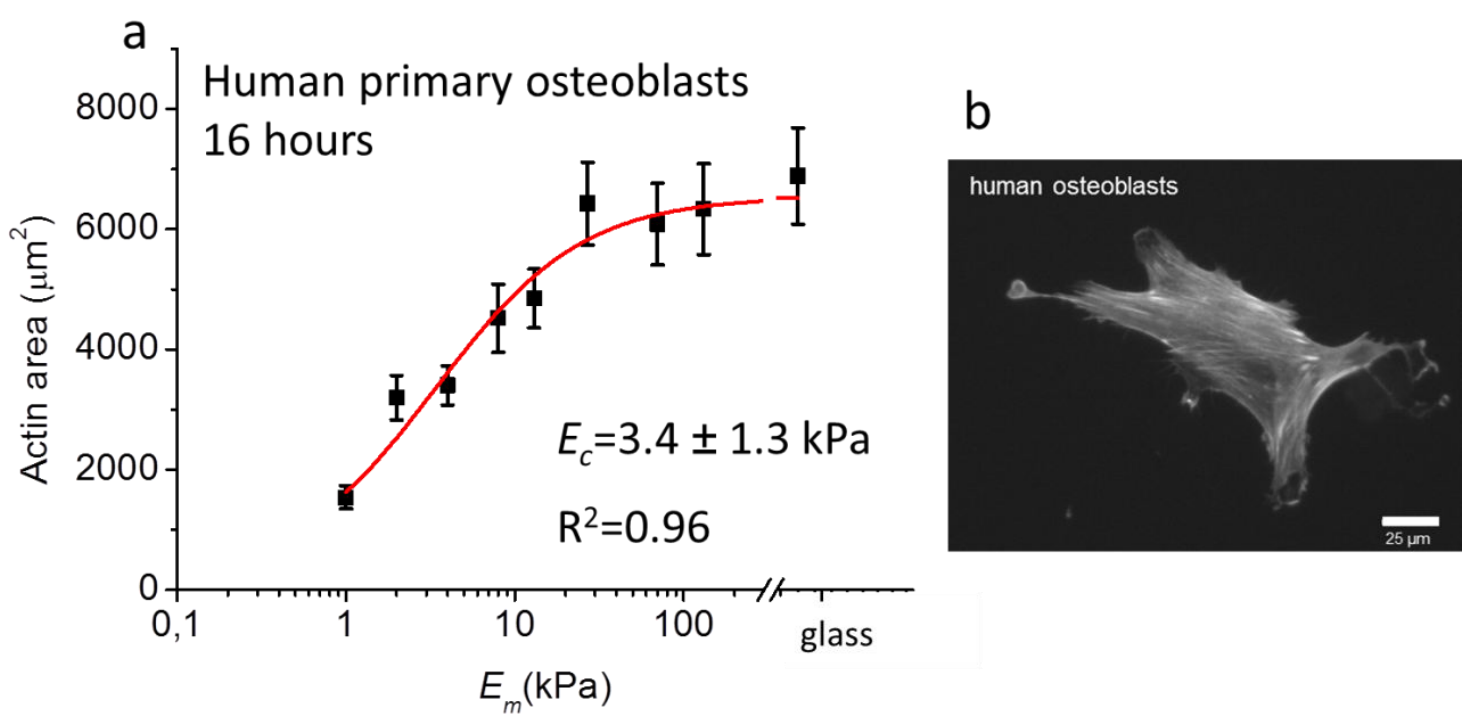

Figure 5.8. Actin spread area (a) of HOBs myoblasts on elastic substrates and glass, fixed after 16 hours of culture. Shown in red is the fit of the model equation. Error bars: SEM. (b) Representative image of HOBs on a glass substrate, actin staining.

SAOS-2 osteoblasts appeared to be the stiffest cells with Young's moduli of $E_{c}=14.8 \pm 4.2 \mathrm{kPa}$ and with $\mathrm{R}^{2}=0.95$. SAOS-2 cells were also small on soft substrates and the spread area increased with the substrate elasticity increase. Unlike HOBs (figure 5.8), SAOS-2 were small on 1-4 kPa with a monotonic increase of the area on stiffnesses higher than $4 \mathrm{kPa}$ (see figure 5.9). Cells reach their maximal spreading area only on very stiff substrates, namely $130 \mathrm{kPa}$.

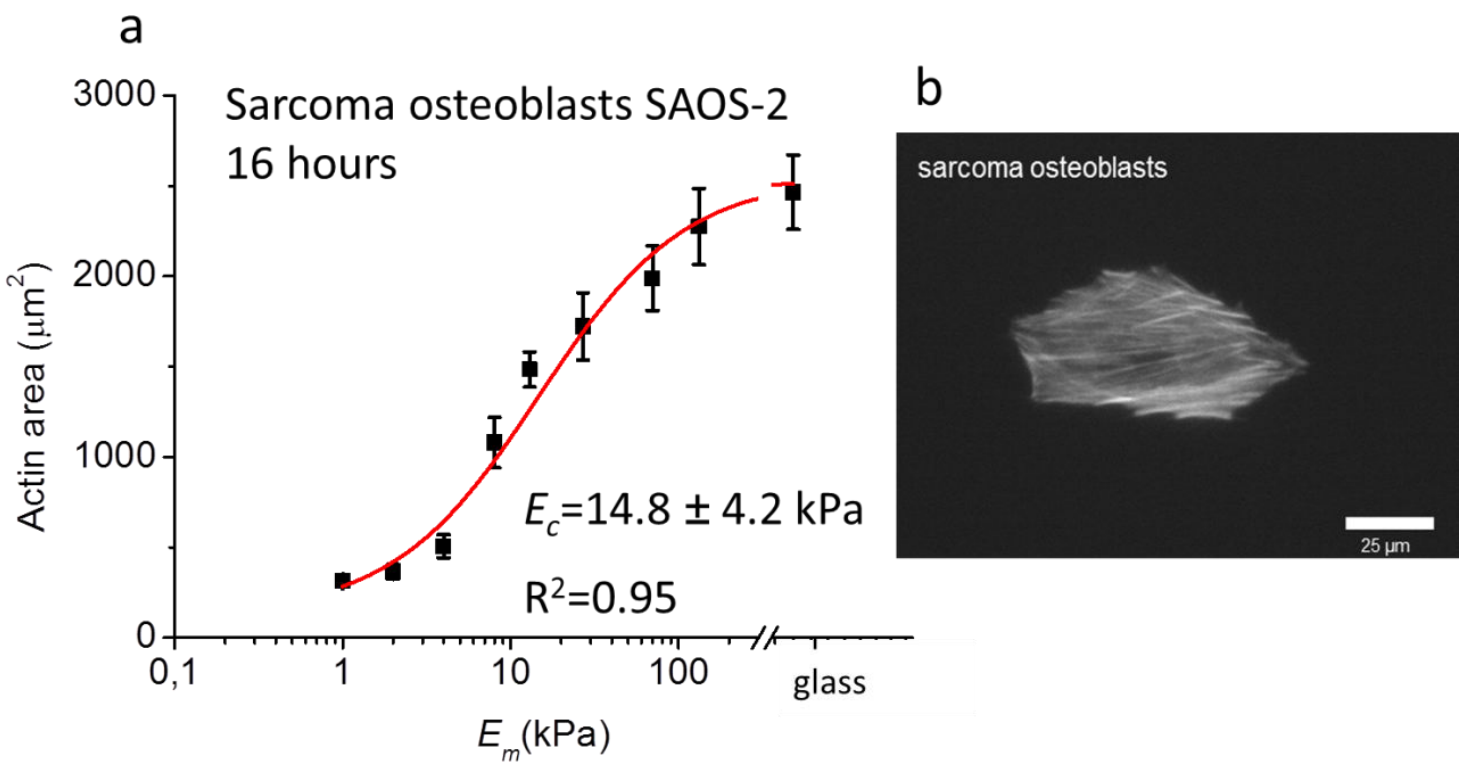

Figure 5.9. Actin spread area (a) of SAOS-2 myoblasts on elastic substrates and glass, fixed after 16 hours of culture. . Shown in red is the fit of the model equation. Error bars: standard error of the mean. (b) Representative image of SAOS-2 on glass substrate, actin staining. 
Three out of five cell lines such as hMSCs (figure 5.5b), HOBs (figure 5.8b) and SAOS-2 (figure 5.9b) exposed very well pronounced stress fibers. That is why I decided to analyze and compare their alignment. For that I used a filament sensor, which was established by Eltzner and co-workers (71) and described previously in this work in 3.9. In short, the tool was used to track the localization and alignment of fluorescently labeled actin filaments. For quantification of the alignment of SFs I have used order parameter S, where $S=\cos 2 \vartheta, \vartheta$ is the angle between each stress fiber and the long (main) axis of the cell (8). That means if SFs aligned mostly along the long axes of the cell the order parameter is close to 1 , but when the alignment is anisotropic, is $\mathbf{S}$ close to 0 .

In figure 5.10 I present order parameters of hMSCs, HOBs and SAOS-2 cells dependent on the substrate elasticity. The alignment of SFs showed the same tendency: on soft substrates, the order parameter is low then increasing with matrix elasticity and at a certain stiffness reaches a plateau and stays constant.

The result shows that the substrate elasticity $E$ directly dictates preferential alignment of the stress fibers in the cell. On soft substrates, fibers are aligned almost randomly in different directions. Cells seeded on stiffer substrates align their stress fibers more along the long axes of the cell. In the case of stem cells (figure 5.10a) the maximum of the order parameter is at approximately $11 \mathrm{kPa}$. This is exactly the stiffness that mechanically induces differentiation towards muscle cells. These results are in good agreement with data previously published by Zemel et al. (9), where they theoretically predicted and showed experimentally that the order parameter of stress fibers directly depends on the Young's elastic modulus of the substrate and peaks at $11 \mathrm{kPa}$. 

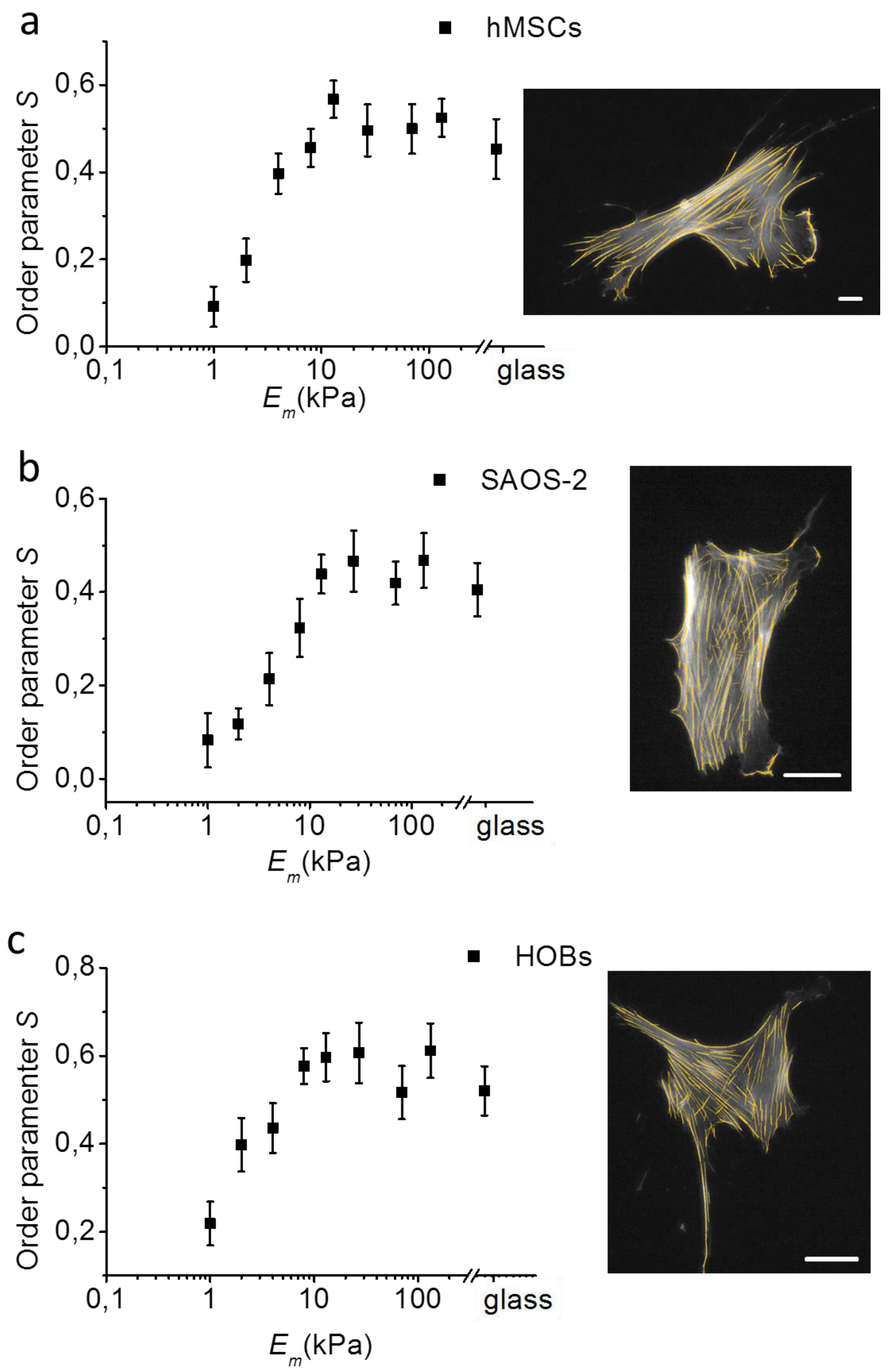

Figure 5.10. Order parameter $S$ and representative cells on glass of (a) hMSCs, (b) SAOS-2 and (c) HOBs seeded on substrates with different stiffnesses. Error bars: standard error of the mean. Insets: Exemplary fluorescence images of representative cells seeded on glass, yellow lines highlight the tracked fibers. Scale bar: $25 \mu \mathrm{m}$. 


\subsection{Myosin II inhibition}

Non-muscle myosin II plays an important role in cellular mechanosensitivity. To elucidate its fundamental mechanisms, we decided to inhibit the activity of myosin motors with an inhibitor called blebbistatin. It specifically inhibits non-muscle myosin II in a step when the myosin head is detached from

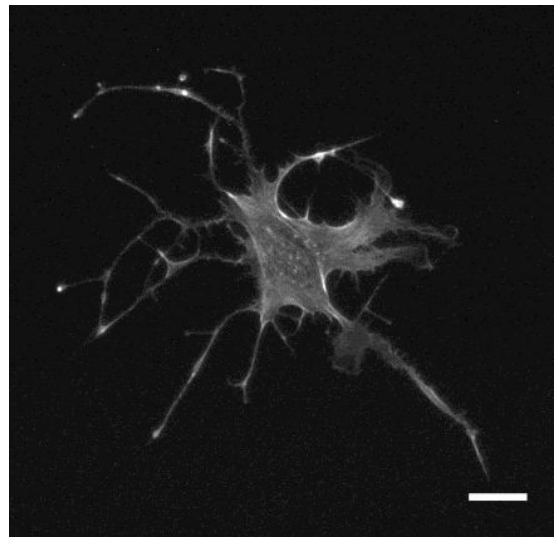

Figure 5.11. Fluorescent image of hMSC fixed on glass and treated with $50 \mu \mathrm{M}$ blebbistatin. Scale bar $25 \mu \mathrm{m}$. the actin filament (34). This inhibition is fully reversible, i.e. washing out blebbistatin and filling with culture media resulted in the normal morphology $(41,97)$. Most of the studies used high concentrations of the drug, namely 50-100 $\mu \mathrm{M}(41,54,98)$, which already broke SFs structure and caused the formation of the dendritic structures of the cell. Figure 5.11 shows an example of the dendritic actin morphology of hMSC after addition of $50 \mu \mathrm{M}$ blebbistatin.

\subsubsection{Inhibition of the myosin activity in SAOS-2 cells}

In this research I used low concentrations of blebbistatin (12.5-25 $\mu \mathrm{M})$ to better understand the cellular morphology and susceptibility to the matrix by inhibiting lower amount of myosin II motors. Notably, SAOS-2 cells have wellpronounced stress fibers and their perturbations could be well studied. These cells were cultured for 16 hours on collagen-coated PAA gels with Young's moduli from 0.5 to $130 \mathrm{kPa}$ in control medium, and the media supplemented by 12.5 and $25 \mu \mathrm{M}$ of blebbistatin. After fixing, cells were fluorescently stained for F-actin and the nucleus, and about 30 cells per condition were imaged with an inverted fluorescence microscope. At these concentrations cells still could form stress fibers, as shown in the example image $5.11 \mathrm{~b}$ (glass).

The drug was added to the culture media during cell seeding. Figure $5.12 \mathrm{~b}$ shows the morphological behavior of SAOS-2 cells on $1 \mathrm{kPa}$ gel and glass substrates. The black curve with the fitting parameter $E_{c}=14.6 \pm 4.7 \mathrm{kPa}$ reproduce the previously shown results (see figure 5.9). Whereas cells cultured in the presence of blebbistatin have changed their susceptibility to only soft 


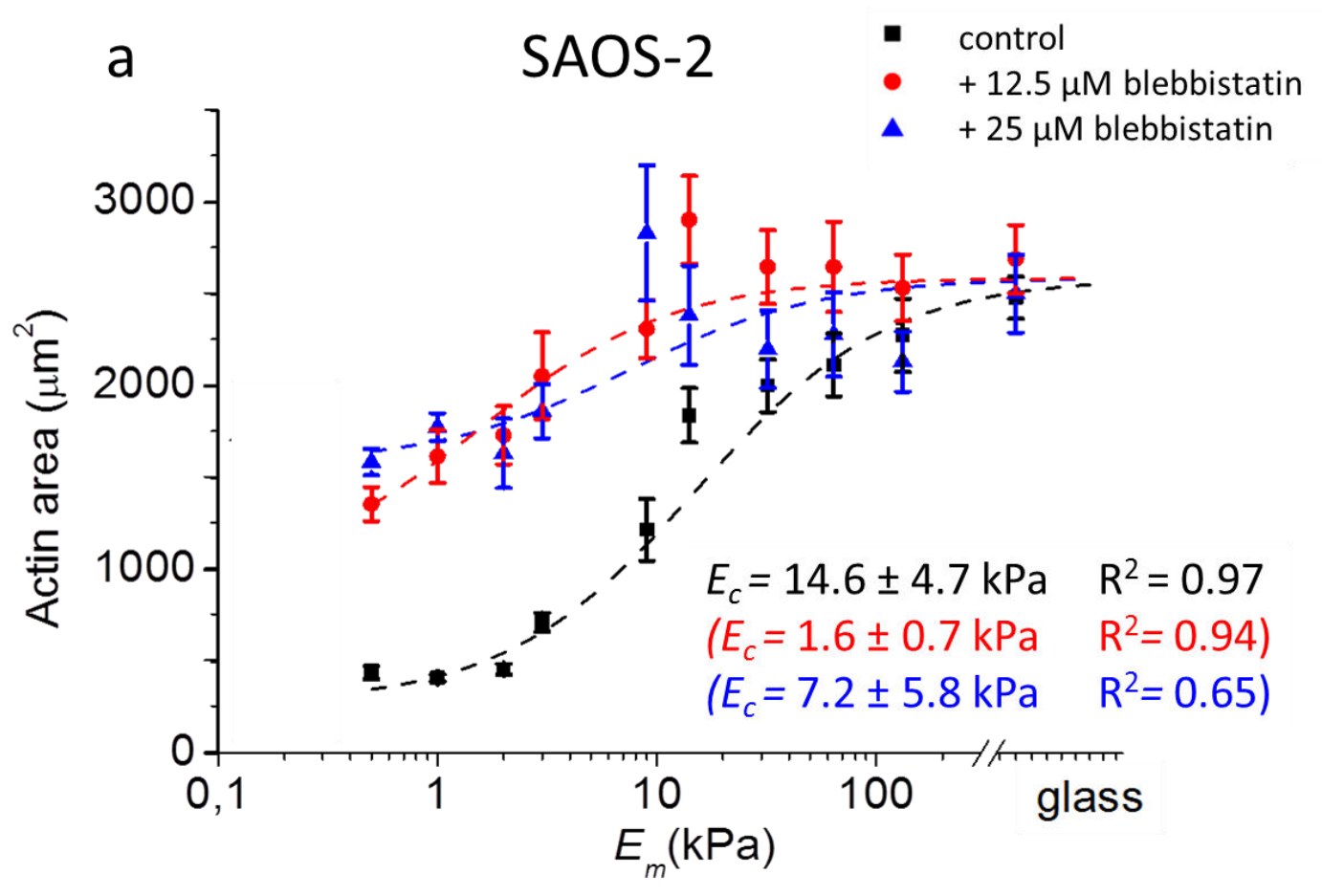

b

$1 \mathrm{kPa}$ PAA gel
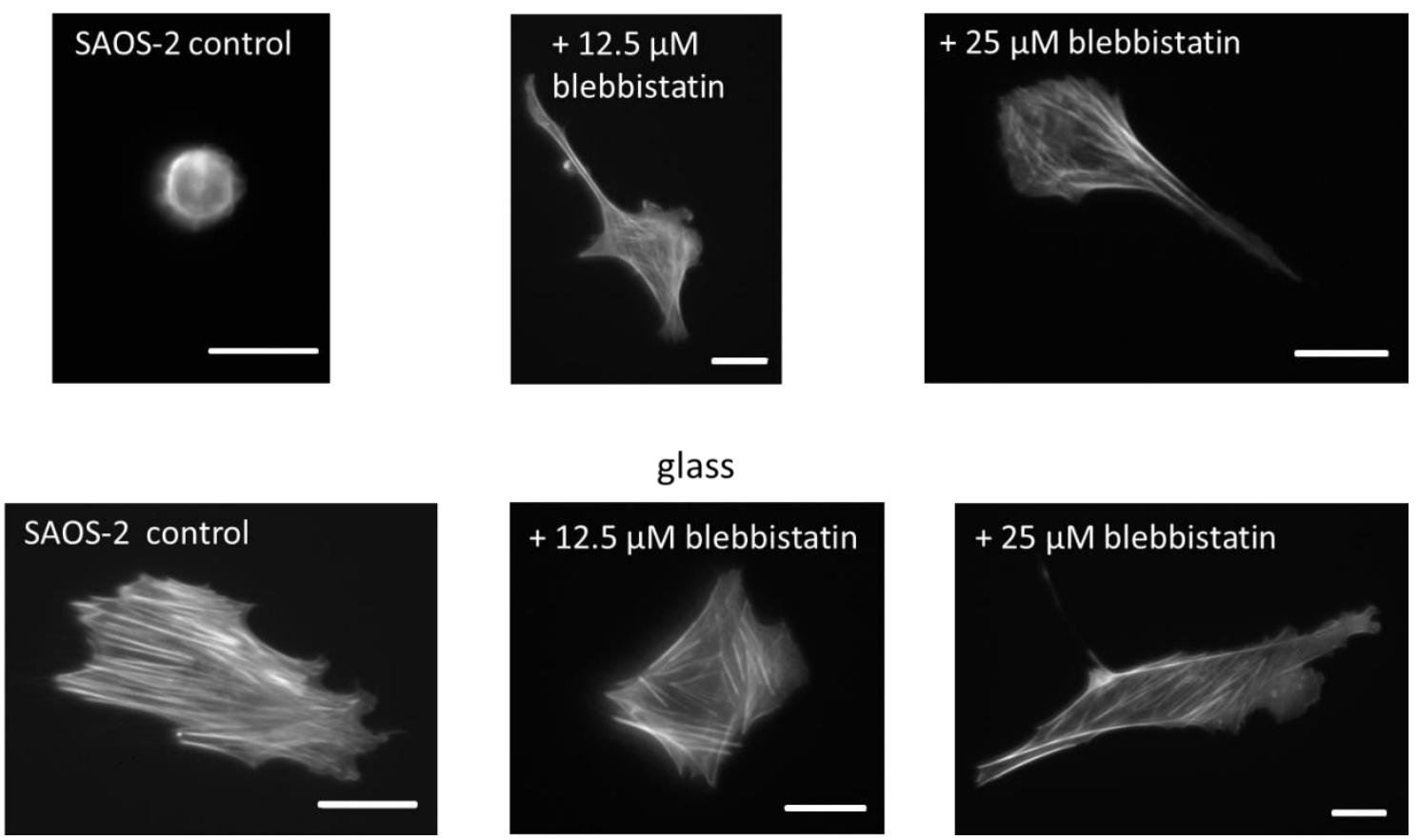

Figure 5.12. (a) Actin spread area vs. matrix elasticity of SAOS-2 cells in control medium (black) and treated with 12.5 (red) and $25 \mu \mathrm{M}$ (blue) of blebbistatin. Error bars: SEM. Black, red and blue curves represent the fit of the model equation 2.1. $E_{c}$ is the fitting parameter representing the Young's modulus of the cell and $R^{2}$ is the quality of the fit. (b)

Representative images of stained actin in SAOS-2 cultured on $1 \mathrm{kPa}$ gel and on glass and in addition of blebbistatin in concentrations of 12.5 and $25 \mu \mathrm{M}$. Scale bar $25 \mu \mathrm{m}$. 
substrates (on stiff substrates and glass the spread area is comparable): cells appeared to be drastically larger than non-treated cells, whereas the cell area on stiff substrates and glass is comparable (see figure 5.12a). Remarkably, the drug did not affect the spreading area on stiff substrates, i.e. the area stayed in a comparable range on glass and $130 \mathrm{kPa}$ gels. For the case of $25 \mu \mathrm{M}$ blebbistatin treatment it seems that fitting of the theoretical model to the experimental data is worse than control sample, since the quality of the fit is $R^{2}$ $=0.65$.

Furthermore, a control experiment was performed. Since blebbistatin is dissolved in dimethyl sulfoxide (DMSO), to make sure there is no effect solely by DMSO, it was added to the control media at the same amount as contained in the $25 \mu \mathrm{M}$ blebbistatin sample (0.5\% of DMSO in the medium). The result shows no effect upon the addition of $0.5 \%$ of DMSO on cell spreading (see appendix A.9).

\subsubsection{Inhibition of the myosin activity in hMSCs}

Since these experiments gave a clear proof of a blebbistatin-caused effect on increased cellular spreading on soft substrates at low concentrations, we wanted to test if this is a cell line specific finding. Hence, I performed a similar experiment with another cell line. Since Engler (1) also showed that treating hMSCs with blebbistatin at concentrations of $50 \mu \mathrm{M}$ and higher blocks stem cell differentiation, it was interesting to see the changes of the morphology after a mild drug treatment. I cultured hMSCs, under the same conditions as SAOS-2 cells, on collagen-coated PAA gels with stiffness ranging from 0.5 to $130 \mathrm{kPa}$ and glass for 24 hours in control DMEM and in DMEM supplemented by 12.5 and $25 \mu \mathrm{M}$ of blebbistatin. As control media was taken DMEM in addition of $0.05 \%$ of DMSO, the same amount of the solvent as in 25 $\mu \mathrm{M}$ blebbistatin. The DMSO control was done to exclude the effect of it on the cell spreading. Cells were also fluorescently stained for F-actin and the nucleus, about 30 cells were imaged by condition.

Already fluorescence images of hMSCs on the soft $1 \mathrm{kPa}$ gel and glass substrate revealed a similar trend as for the previous cell line (figure 5.13b). Control hMSCs on the soft gel were not well spread and look round, whereas the addition of blebbistatin facilitates the spreading. Moreover, cells seeded on 
glass did not show any morphological differences which is in good agreement to my previous investigation.

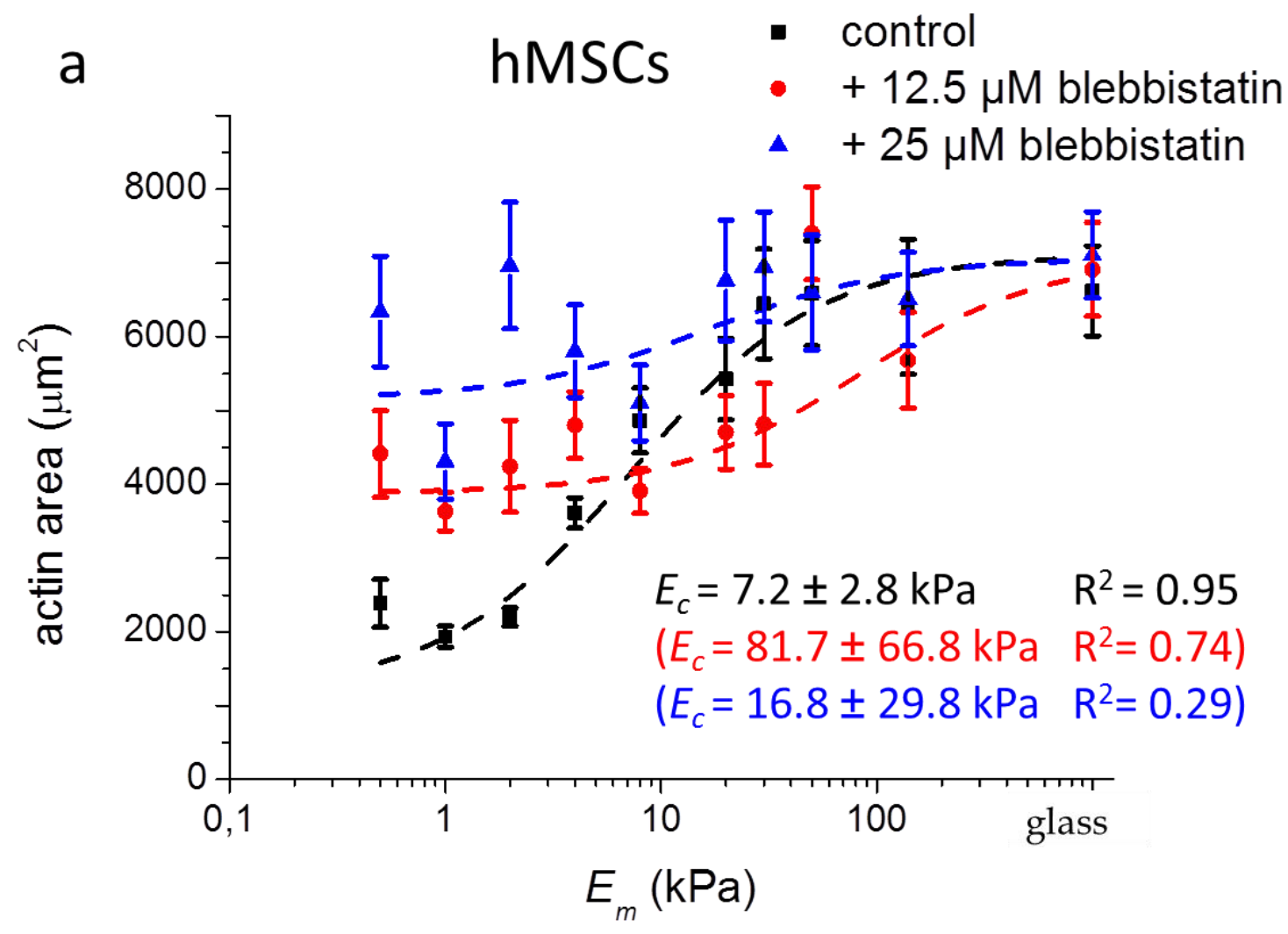

b

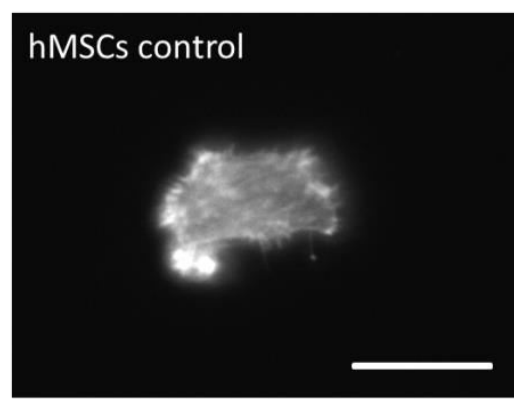

hMSCs control

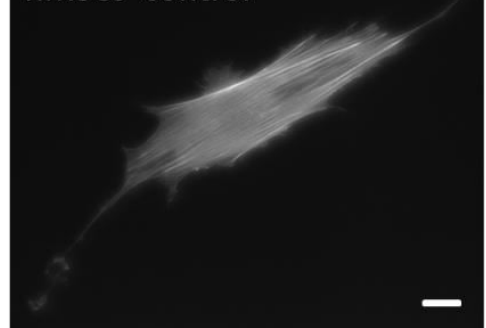

$1 \mathrm{kPa}$ PAA gel
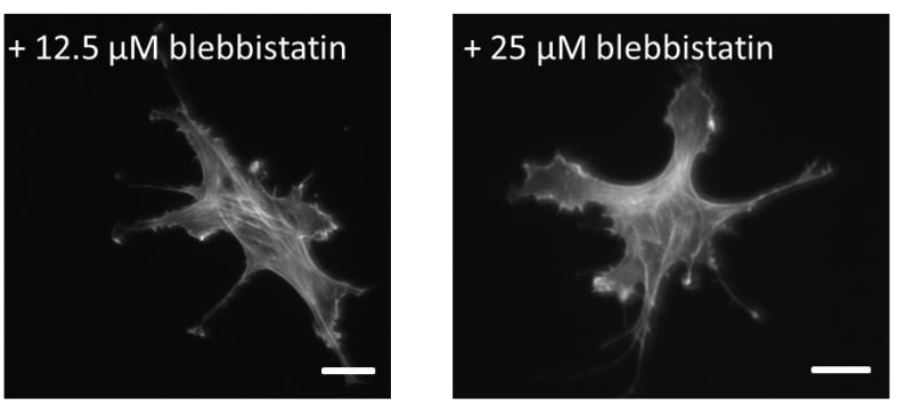

glass
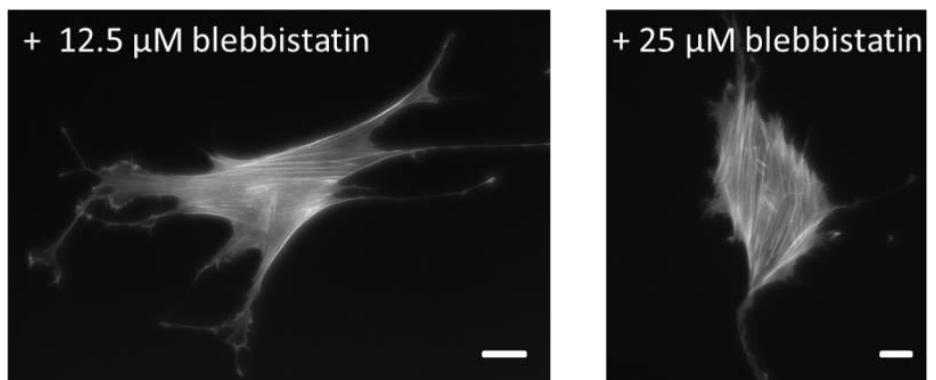

Figure 5.13. (a) Actin spread area vs. matrix elasticity of hMSCs in control medium (black) and treated with 12.5 (red) and $25 \mu \mathrm{M}$ (blue) of blebbistatin. Error bars: SEM. Black, red and blue curves represent the fit of Zemel's model equation. $E_{c}$ is the fitting parameter representing the Young's modulus of the cell and $R^{2}$ is the quality of the fit. (b) Representative images of stained actin in the cell. Scale bar $25 \mu \mathrm{m}$. 
A close look to the plot of the actin area of cells on various substrates (figure 5.13a), reveals that blebbistatin treatment changes actin spread area only on soft substrates. From the plot it can be seen that on gels from 0.5 to 4 $\mathrm{kPa}$, cells spread more in case of the treated cells than the control sample. Contrarily, on stiff substrates, cell area remains comparable. That result evidences that blebbistatin facilitates spreading of SAOS-2 and hMSCs only on soft substrates.

In order to examine the blebbistatin effect on other morphological parameters of the cell I analyzed the cellular aspect ratio as an indicator for cell differentiation for the set of experiments described in this section. Figure 5.14 depicts the aspect ratio of treated and non-treated hMSCs.

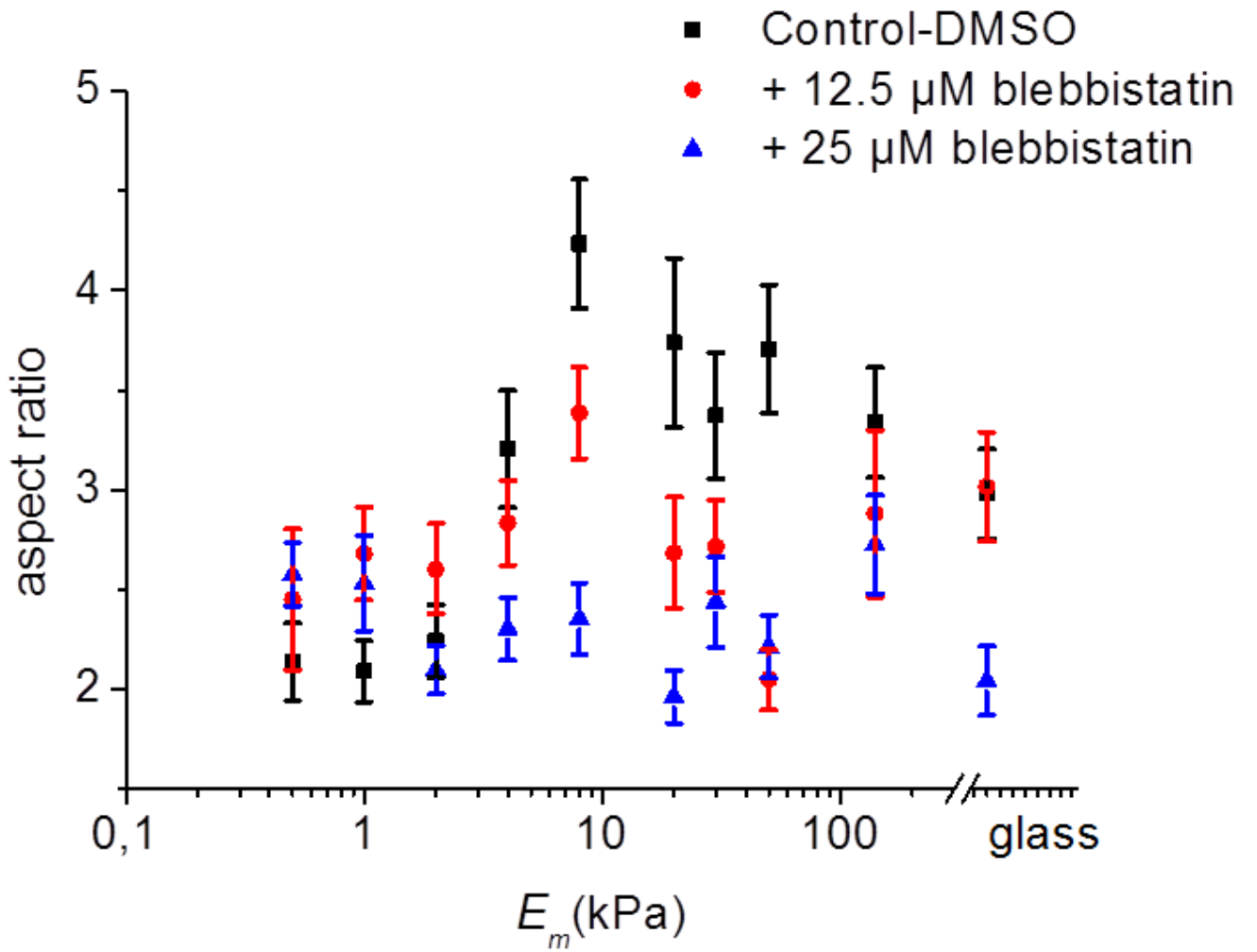

Figure 5.14. Aspect ratio of hMSCs over matrix elasticity in control medium (black) and treated with 12.5 (red) and $25 \mu \mathrm{M}$ (blue) of blebbistatin. Error bars: SEM.

In case of the control sample, cells were round on soft and stiff substrates and peaking on intermediate stiffnesses with muscle-like rigidity. This is in good agreement with the observation of Engler et al. (1). Cells treated with $12.5 \mu \mathrm{M}$ were more round in general, but the peak on $10 \mathrm{kPa}$ gel persists. Treatment with $25 \mu \mathrm{M}$ prevents any aspect ratio changes. It was shown that blebbistatin at high concentrations blocks stem cell differentiation (1). It seems 
that mild treatment also prevents stem cell morphological changes towards their shape taken after commitment.

\subsubsection{Dynamics of myosin inhibition}

The finding of an increased spreading on soft substrates raised the interest of the dynamics and mechanisms of this effect. Firstly we started with the dynamical aspect: how fast does blebbistatin affect the spreading? For that I plated hMSCs on collagen-coated PAA gel with a Young's modulus of $1 \mathrm{kPa}$. Cells were chemically fixed after several time points to analyze the actin spread area. The spread area monotonically increases over time in case of the blebbistatin treatment (figure 5.15), whereas the area of untreated cells stays at a similar value over the measured period of 24 hours. Already after 30 min of culture the area of control and $12.5 \mu \mathrm{M}$ blebbistatin treated cells was significantly different $(\rho=0.04)$.

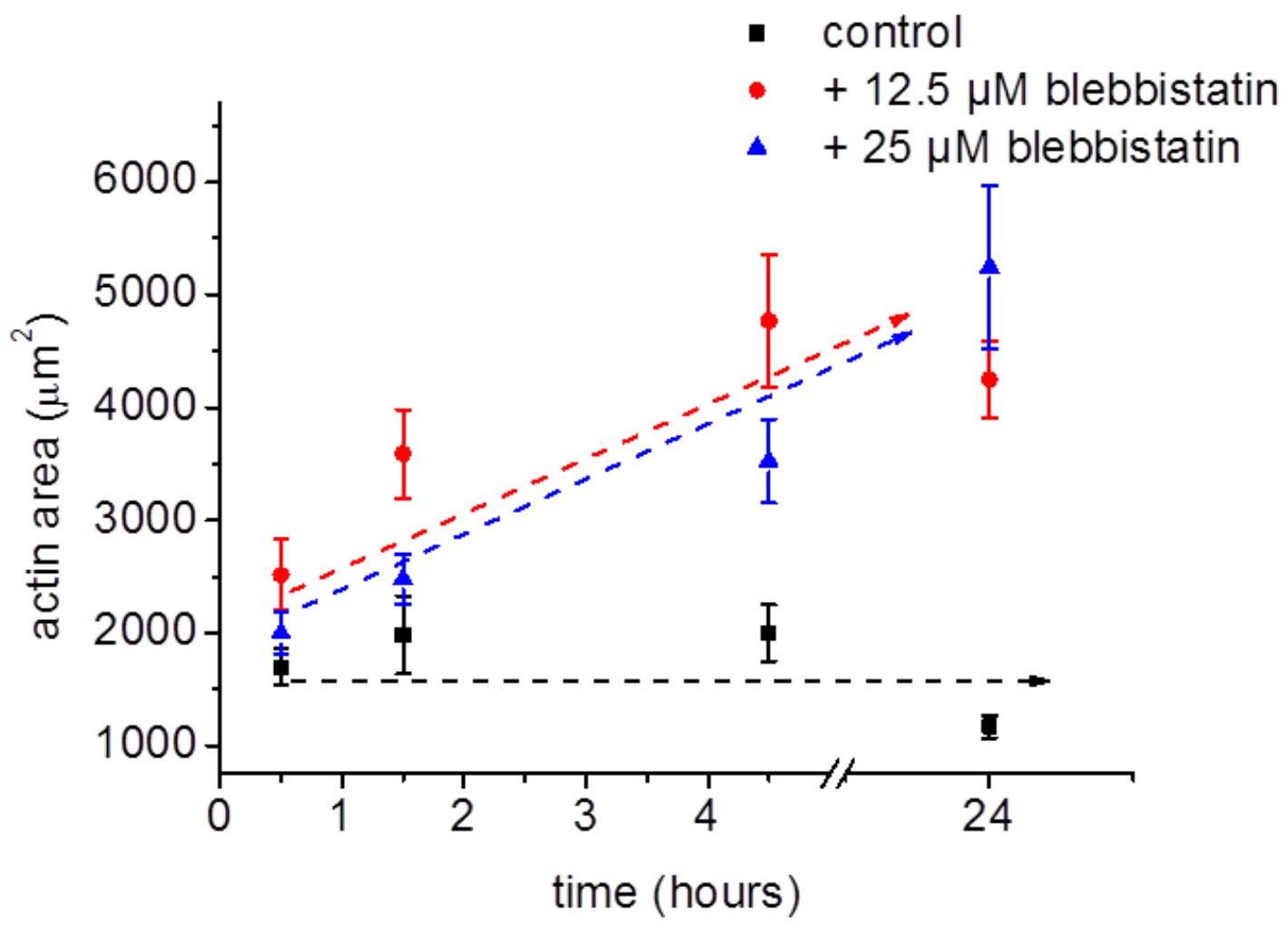

Figure 5.15. Dynamics of actin spread area over time of hMSCs on glass cultured in control medium and in medium supplemented with 12.5 and $25 \mu \mathrm{M}$ of blebbistatin. Error bars: SEM. Dashed lines guide the corresponding data trend. 
By that I could show that the mentioned area increased on soft substrates is a very fast process, which reveals morphological processes in spreading dynamics within the first hour.

Furthermore I will elaborate on an observation that I recognized while seeding cells on the gel. Following a fixed protocol, the same amount of cells was distributed on each substrate. Here I saw, that cells barely attached to the soft substrates and could be washed out easily due to the weak adhesion. This led to a low number of cells on these gels. In contrast to that, the direct addition of blebbistatin into the cell culture medium while seeding increased the number of attached cells on the soft substrate. That might indicate that the drug alters the cell cortex in suspended state and facilitates attachment and spreading.

It is clear that the process of myosin motor inhibition happens on timescales of minutes, which leads to the fast changes in the morphology. At the same time it is known that the process of myosin inhibition is reversible and washing out the drug let cells recover very fast $(41,97)$. This made me target the question, how would the spread area on soft substrates behave upon blebbistatin removal? Will the cell stay spread or will the area shrink again?

To answer this question I performed an experiment to examine the dynamics of the cell spread area on soft substrates after washing out blebbistatin. For that I prepared collagen-coated PAA gels with a Young's modulus of $1 \mathrm{kPa}$ and seeded hMSCs under the addition of blebbistatin in concentrations of 12.5 and $25 \mu \mathrm{M}$. Cells were cultured for 4.5 hours. As it was shown before that the effect of blebbistatin happens very fast and 4.5 hours is enough for a cell to spread (see figure 5.15). Then, the media containing the drug was removed and cells were rinsed with $37^{\circ} \mathrm{C}$ warm and sterile PBS to fully remove the drug. Finally, the control DMEM was added to the sample. In parallel samples with control media were incubated. Cells were chemically fixed at several time points after media exchange, stained for F-actin and the nucleus. Fluorescence images were taken of about 30 cells per condition. Figure 5.16 shows the dynamics of the cellular recovery after blebbistatin removal on the $1 \mathrm{kPa}$ gel. $30 \mathrm{~min}$ after washing out blebbistatin (concentrations 12.5 and $25 \mu \mathrm{M}$ ) the cell area remains extended (red and blue curve respectively), but already during the next few hours it decreases fast. After 20 
hours, the cell area is reduced 2.5 times. Whereas the area of untreated cells stays comparably small during the entire experiment.

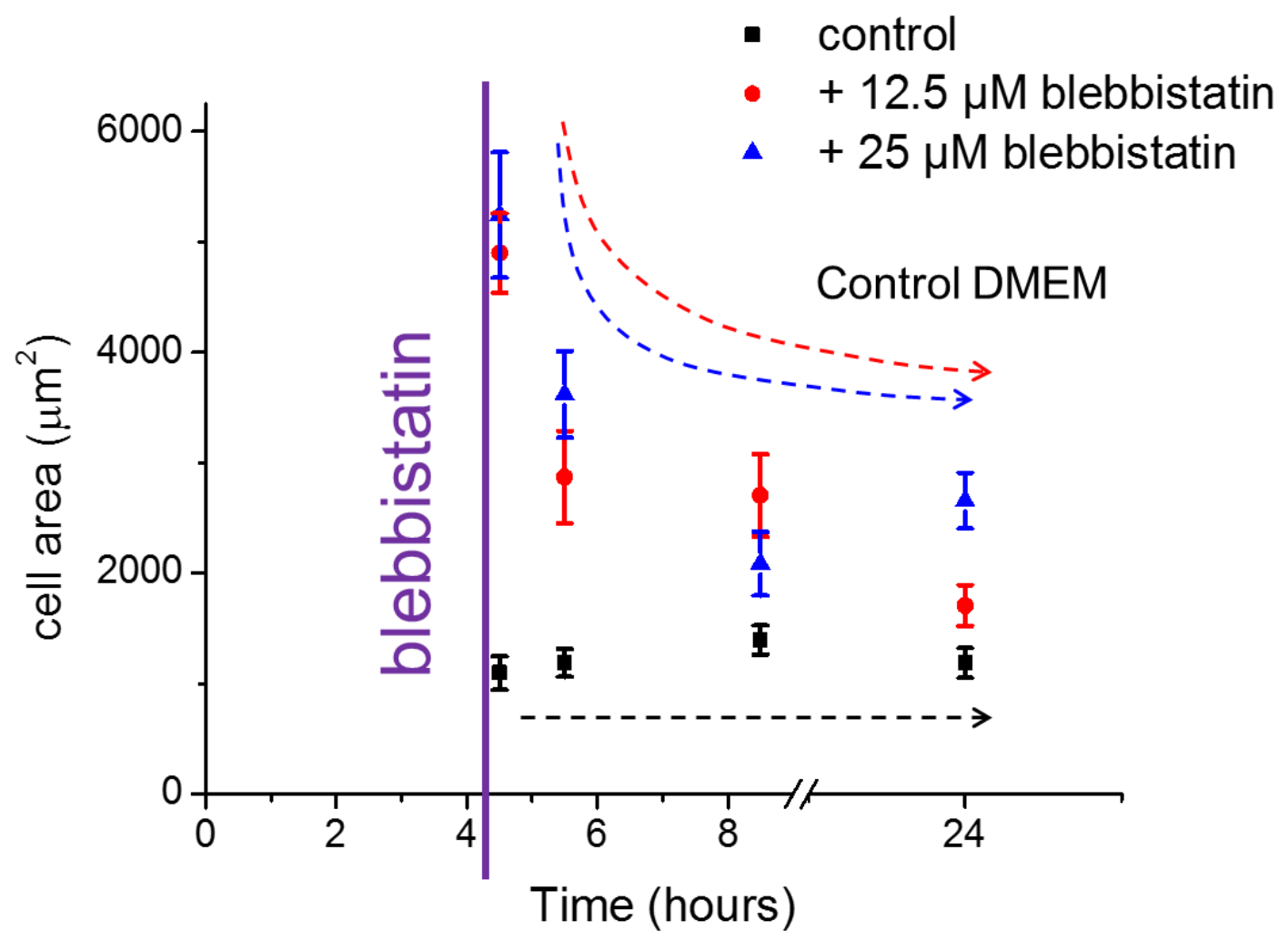

Figure 5.16. Dynamics of actin spread area vs. time of hMSCs cultured on $1 \mathrm{kPa}$ PAA gel, first in medium supplemented with 12.5 and $25 \mu \mathrm{M}$ of blebbistatin, after 4 hours the drug was washed out and control medium was added. Purple line represents the time point when blebbistatin was exchanged to control medium. In parallel, hMSCs were cultured on $1 \mathrm{kPa}$ gel in control medium. Dashed lines are shown to guide the eye to the tendency of recovery dynamics. Error bars: SEM.

To visualize the observed morphologies during spreading I present a sketch of the two mentioned cases in figure 5.17: case 1 depicts the untreated control cells and case 2 corresponds to blebbistatin treated cells seeded on a soft $1 \mathrm{kPa}$ substrate. In both cases media with suspended cells was added to the well, containing the collagen-coated gel. In the next step cells were supposed to attach to the substrate and start to spread. In case 1 cell remained small over the whole period of seeding, whereas in case 2 the spread area increased and after 4 hours of culture clear morphological changes were seen. But after blebbistatin was removed, the cell area started to shrink, while in case 1 cell area did not change drastically. 
Usually the transition between suspended and attached state takes up to 30-60 min. Blebbistatin reacts very fast, i.e. the reaction already started in the suspended state, before adhesion. It is likely that before the adhesion happens, blebbistatin already inhibits easy accessible myosin motors activity, i.e. in the cellular cortex, which is compressing the cell. As the concentration of the drug is low, molecules of blebbistatin may be enough to only inhibit myosins in the cell shell and not penetrate further in the cell. By releasing the tension in the cortex, cells can overcome the forces that compact the cell and start the cell spreading process.
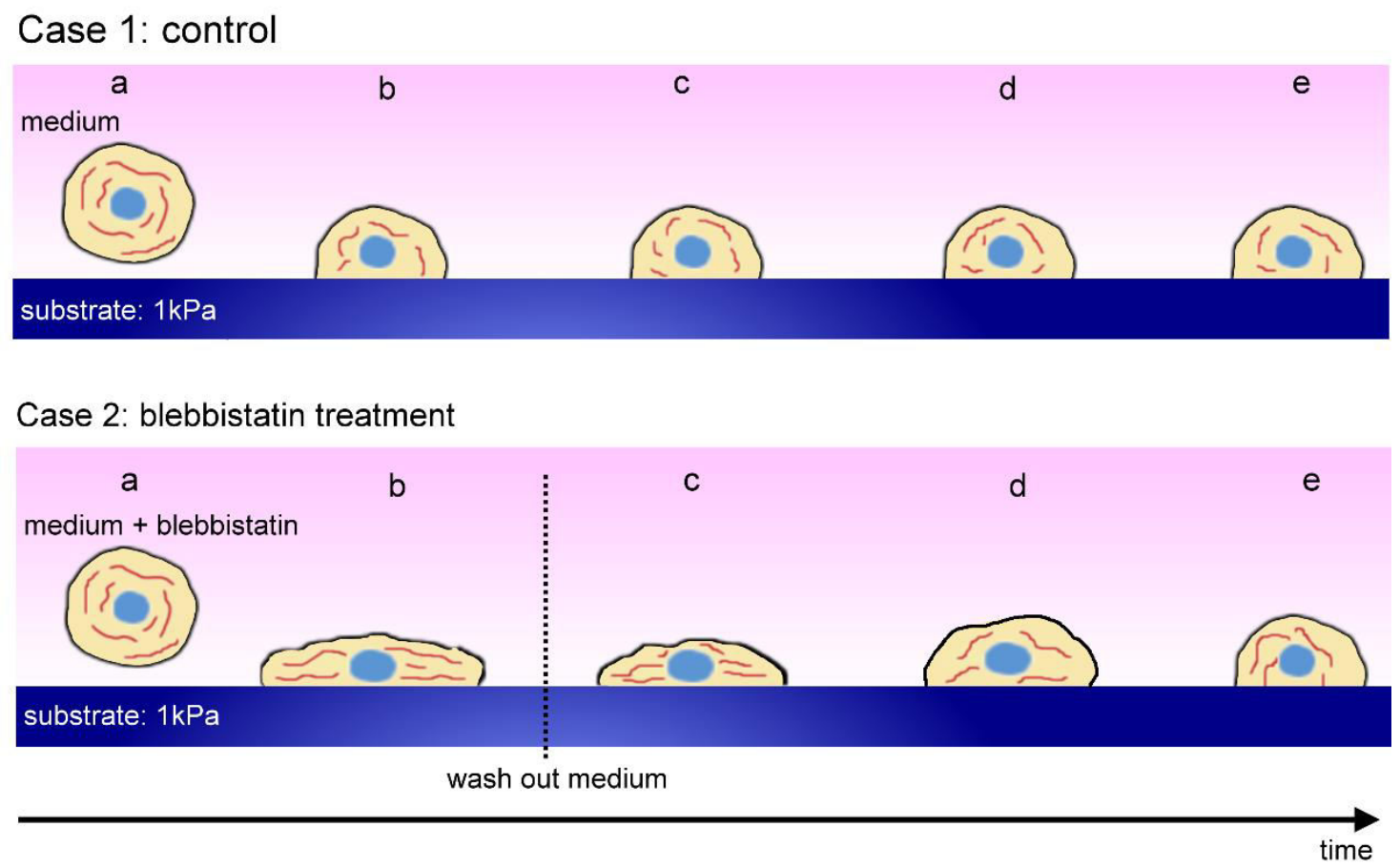

Figure 5.17. Schematic drawing of the blebbistatin treatment procedure and the observed cell shapes. (a) Cell seeding: cells placed in control suspension, case 1 , and in presence of blebbistatin, case 2. (b) Cell adhesion and spreading on a soft substrate happens. (c - e) Medium supplemented with blebbistatin is washed out and refilled with the control medium.

\subsubsection{Quantification of myosin localization}

Since I inhibited myosin motor activity, it might happened, that it prevented proper acto-myosin stress fiber formation by the drug interference. Nevertheless, treated cells spread on soft substrates and structures were observed, which looked like stress fibers, as shown in the image 5.13b. 
Interestingly, the amount of these filaments per cell unit did not change, both, on soft and stiff substrates (see the image appendix A.10).

To make sure that treated cells still could form stress fibers and focal adhesions we decided to confirm that by fluorescent staining of specific proteins. For analysis of the amount of myosin motors in the treated cells nonmuscle myosin lla was stained. To analyze fluorescence images I used the filament sensor, version $0.2 .2 \mathrm{~d}$ (71). This Java based program defines the area of the cell before tracking stress fibers inside the cell. Then the area was split into an interior and a boundary part. As "interior" a bulk body of the cell was taken, when for "boundary" - the "ring" on the cell periphery in a size of 20 pixels was taken (green area and red area respectively), as shown in the example image 5.17b. In other words, the full area of the cell consists of the bulk body of the cell and its periphery, which was considered as the cortex in 2D spread cell. The intensity distribution of myosin was analyzed in the boundary and interior part of the cell. Figure 5.18a presents the comparison of the ratios of the myosin mean intensity in the interior to boundary part. Assuming that mild concentrations of blebbistatin blocks myosin in the cortex, and in consequence, releases tension, which then again makes cells spread on soft substrates. In this case, I would expect a lower amount of myosins in the boundary part of the cell, yielding an increased ratio of the intensity of interior to boundary. From figure 5.18a it can be seen that this ratio is high when the cells were seeded on soft substrates and treated with blebbistatin. In contrast, the comparison of the ratios on stiff substrates is very similar.

To quantify the difference, the conditions were split into two groups: cells seeded on PAA gels with stiffnesses of $0.5-4 \mathrm{kPa}$ (group 1) and $10-30 \mathrm{kPa}$ and glass (group 2), figure 5.18c. In the first group the difference between all three conditions was significantly different: the significance level between the control sample and the $12.5 \mu \mathrm{M}$ blebbistatin treatment was $\rho<0.0008$ and between the control sample and the $25 \mu \mathrm{M}$ blebbistatin assay it was $\rho<10^{-10}$. Even the difference between the two treatment concentrations show significant changes with $\rho<2 \cdot 10^{-16}$. On the other hand, cells cultured in control and in blebbistatin and then seeded on stiffer gels and glass shows a similar level of myosin expression. A t-test analysis did not show any significant difference $(\rho<0.057-0.26)$. It is observed that blebbistatin in low concentrations affects only cells seeded on soft substrates. 

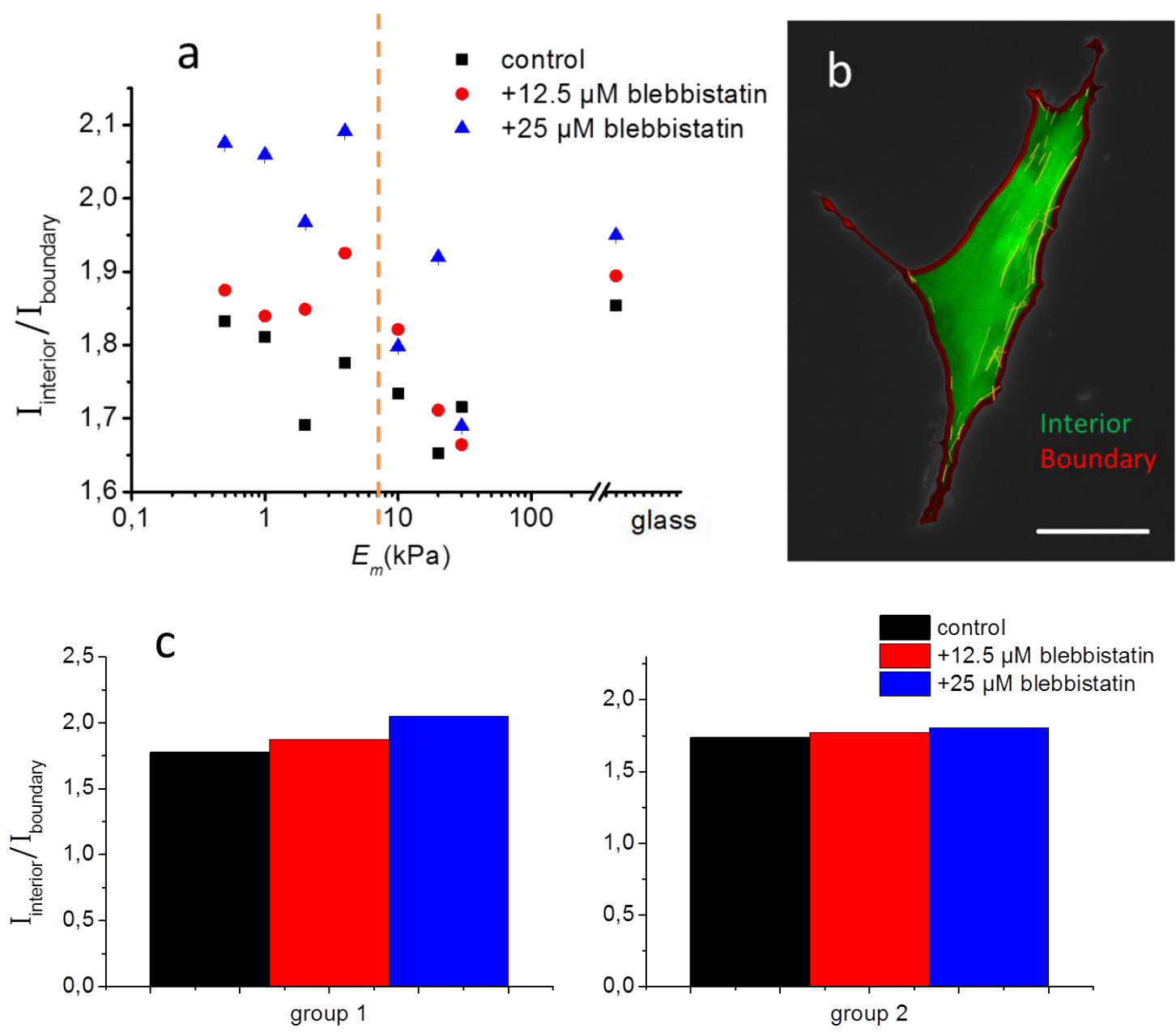

Figure 5.18. (a) Ratio of the intensities of myosin lla expression in interior to boundary parts of the cell. (b) Representative cell stained for myosin Ila. In green shown the selected interior part and in red the boundary. Scale bar $25 \mu \mathrm{m}$. (c) Ratio of intensities split into two groups: cells seeded on 0.5-4 kPa (group 1) and cells on 10-30 kPa and glass (group 2). Error bars: standard error of the mean.

\subsubsection{Analysis of focal adhesions}

Several studies showed that perturbation of myosin directly influences the formation and maturation of stress fibers and focal adhesions (FAs) (99101). I showed that low concentrations of blebbistatin facilitates spreading and does not prevent formation of SFs on soft substrates. Furthermore I saw that the amount of SFs per cell unit stays constant, i.e. unaffected by a mild blebbistatin treatment (appendix A.10). That raised our interest in how this inhibition of myosin would influence the fate of FAs. For this analysis, I stained treated and untreated cells with paxillin, which is an important cytoskeletal and 
scaffolding protein recruited by focal adhesions on early stages. It plays an essential role in FAs assembly and disassembly during cell migration (102). The procedure of staining and analysis of FAs was described in 3.8.2. A close look to the exemplary set of fluorescence images (figure 5.19) revealed that cells seeded on soft substrates form less focal adhesions after myosin motor inhibition, whereas on glass surfaces cells still do form FAs.

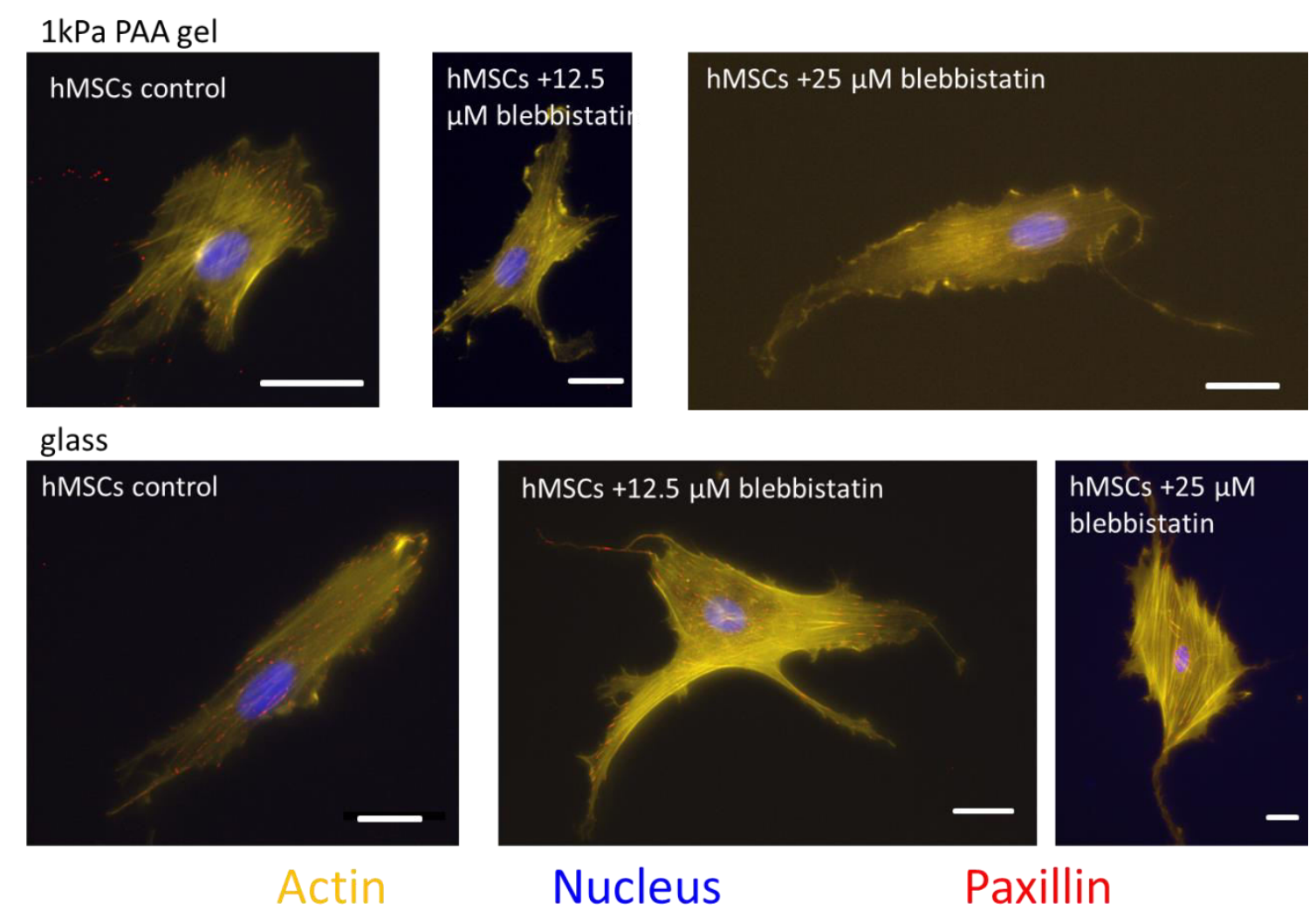

Figure 5.19. Representative images of actin (yellow), nucleus (blue) and paxillin (red) staining in control and blebbistatin treated hMSCs seeded on glass and 1 kPa PAA gel.

Scale bars $25 \mu \mathrm{m}$.

Figure 5.20 shows the number of FAs per cell area of cells cultured in control media and blebbistatin, depending on matrix stiffness underneath the adhesion. hMSCs cultured in control media turned out to have a more or less constant number of FAs per cell unit (independent of the substrate's stiffness), whereas FAs of cells cultured in blebbistatin showed a substrate dependent behavior. On soft substrates cells revealed to have less FAs per cell area, but their number increased with matrix elasticity. I also observed that on substrates in the stiffness range of $0.5-4 \mathrm{kPa}$ the difference in the number of FAs in treated and untreated cells is strongly pronounced, whereas on stiffer 
substrates no significant difference was observed. As figured out previously, the most differences in cell morphology occurred only on soft substrates and the transition between these two regimes was again in the range of 5-10 kPa.

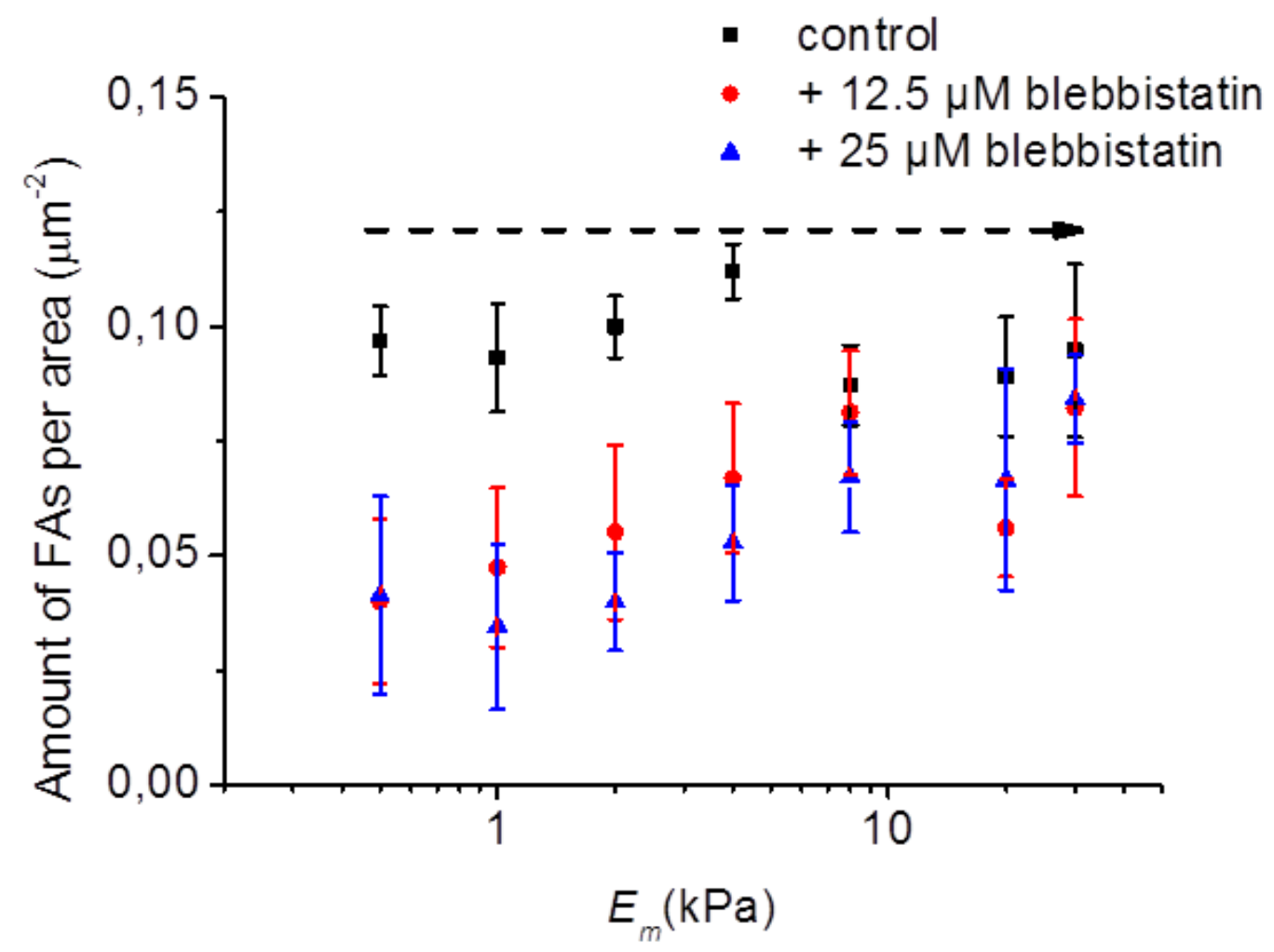

Figure 5.20. Number of FAs in hMSCs per cell area depending on the matrix elasticity cultured in control medium (black) and treated with 12.5 and $25 \mu \mathrm{M}$ of blebbistatin (red and blue respectively). Error bars: SEM. Black dashed line guides the data trend of control sample.

Interestingly, hMSCs cultured in control medium formed FAs at a similar size independent of the cell shape and matrix elasticity (see figure 5.21). The average size of FAs in control sample was $0.49 \pm 0.01{\mu \mathrm{m}^{2}}^{2}$. Unlike untreated cells, blebbistatin treated hMSCs formed FAs with an average size which correlated dependent on the substrate stiffness. In contrast to the number of FAs per area, their average size varies from cell assay to cell assay, both, on stiff and soft substrates. 


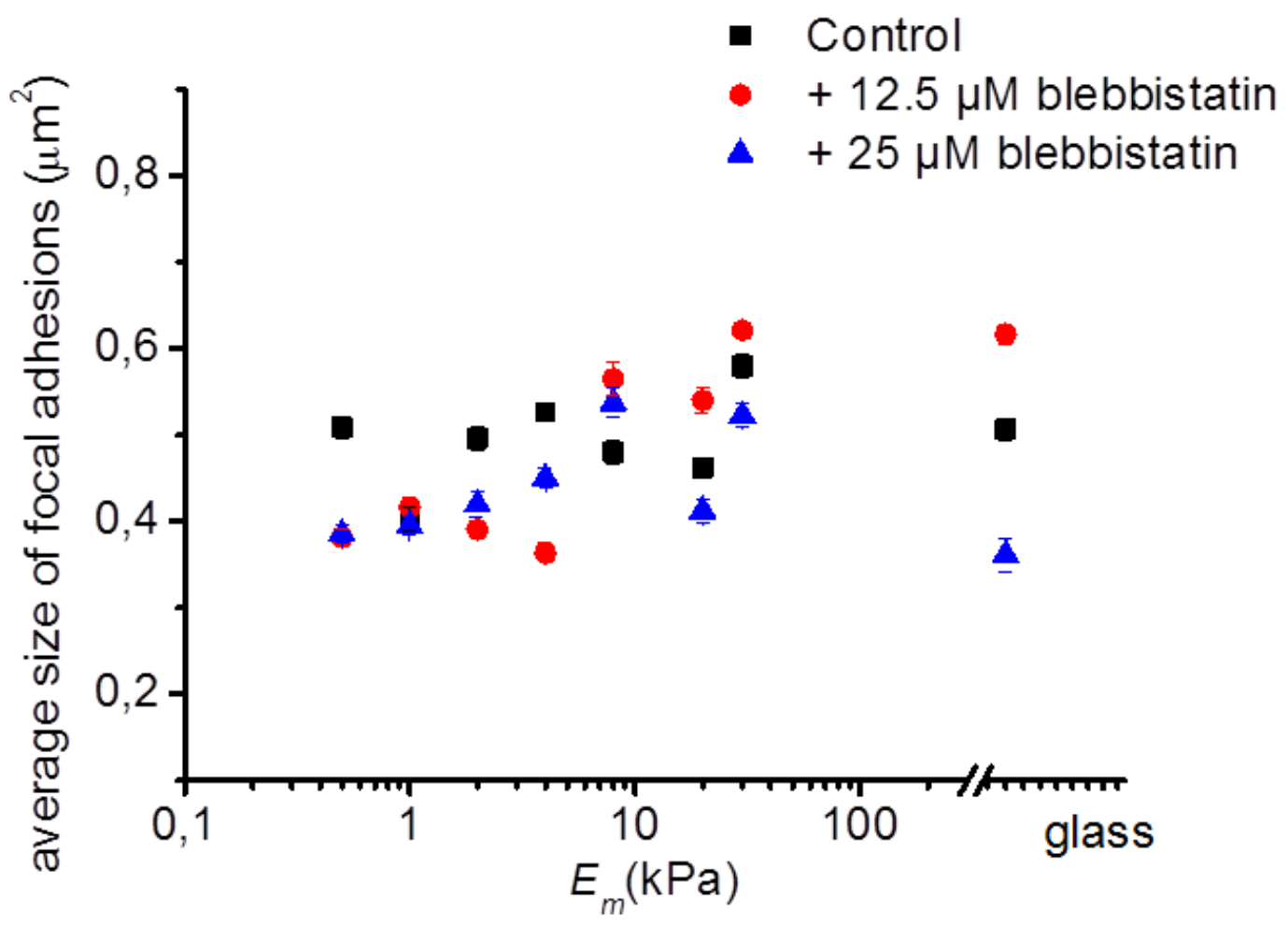

Figure 5.21. Average size of focal adhesions in $\mu \mathrm{m}^{2}$ depending on matrix elasticity in hMSCs. Error bars: SEM.

These results support the outcome of previous investigations that blebbistatin affects FAs $(99-101,103)$. Here, I showed that treated hMSCs form less FAs on soft substrates, whereas the mild concentration of blebbistatin does not affect FAs on stiff gels. At the same time the average size of FAs vary depending on the gel stiffness.

\subsection{Probing visco-elastic characteristics of blebbistatin treated cells by Atomic Force Microscopy (AFM)}

As we assumed that blebbistatin softens the cortex and by that facilitates cellular spreading on soft substrates, it was essential to analyze the viscoelastic characteristics of hMSCs treated with 12.5 and $25 \mu \mathrm{M}$ of blebbistatin. For that I have performed life-cell experiments using atomic force microscopy (AFM). Cells were seeded on collagen-coated cover glasses and cultured for about 16 hours before starting the experiment to let cells fully spread. The rigidity of the living cells were measured as described in 3.5.1. About 5-7 living cells and on each cell 5-8 points were analyzed by taking an indentation force 
curve. Figure 5.22 displays an exemplary force indentation curve of the cell seeded on glass substrate in addition of $12.5 \mu \mathrm{M}$ of blebbistatin.

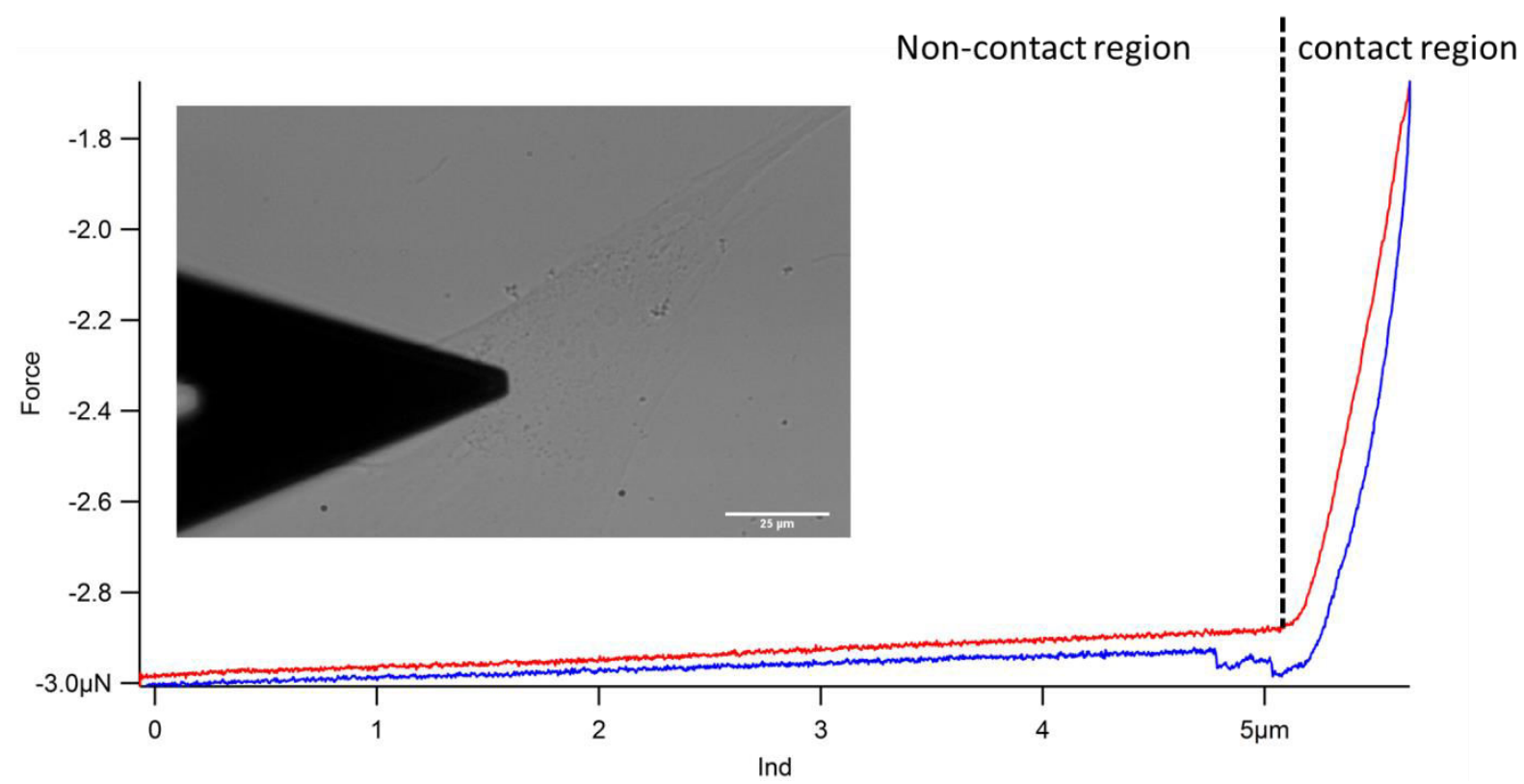

Figure 5.22. Example of a force indentation curve of a spot on a control hMSC. The red curve is the approach of the tip, the blue one the retraction. Insert: an example image of the triangular cantilever (black) probing cellular elasticity (grey shape underneath). Scale bar is $25 \mu \mathrm{m}$. Dashed line shows the point when cantilever contacts the cell.

The Hertz model (65) allows the extraction of the Young's modulus of the cell out of the force curve (see 3.5.1). In table 5.3 I present the values of the calculated Young's modulus of the cell in control medium and after addition of the myosin II inhibitor. It can be seen that the addition of the drug effectively softens the cell.

Table 5.3. Young's modulus of the cells measured by AFM.

\begin{tabular}{l|c|c} 
hMSCs on glass in & $E_{c^{\prime}}, \mathrm{kPa}$ & $\begin{array}{c}\text { Standard } \\
\text { deviation }\end{array}$ \\
\hline Control media & 4.9 & 0.9 \\
\hline $12.5 \mu \mathrm{M}$ blebbistatin & 3.4 & 0.7 \\
\hline $25 \mu \mathrm{M}$ blebbistatin & 2.5 & 1.2
\end{tabular}

These results follow the previous observations by Martens and Radmacher (104), who presented that blebbistatin at a concentration of $50 \mu \mathrm{M}$ decreases the elastic modulus of the cell more than 2 times. Moreover, using lower concentrations of blebbistatin such as $10 \mu \mathrm{M}$ was shown to decrease the 
stiffness of SFs already in the first $60 \mathrm{~min}$ (105). Though they previously verified that blebbistatin at these concentrations did not alter cell morphology on glass (106), which is in agreement with my observations. 


\subsection{Summary and Discussion}

In the first part of this chapter, I examined the static spreading properties of the five different adherent cell types. All of them followed the theoretical predictions (9) of the spreading behavior on elastic substrates, independent of their physiological function and size. Spread area increased with the matrix elasticity in all the five cases in the expected way. When fitting Zemel's model to the spreading data of the cell lines it resulted in a good fit quality, $R^{2}$ is ranging from 0.92 to 0.96 .

In contrast to the static spreading values, spreading dynamics of the individual cell types have different time constants. Cells were shown to spread on 2D substrate with different dynamics depending on their inherent cycle. Here, I presented that hMSCs require 24 hours seeding on a substrate to reach the full spreading, following the previous investigation $(1,8)$. The other cell lines such as osteoblasts and myoblasts, needed a shorter time to reach the maximum spreading on the glass substrate. Moreover, cells such as fibroblasts, extracted from the extracellular matrix, required more time to spread on $2 \mathrm{D}$ substrate.

Furthermore, though the spreading followed the theoretical prediction, the fitting of the model yielded different effective Young's moduli of the cells. It turned out that the stiffest cell type was SAOS-2. These cells also appeared to have the smallest spread area on $1 \mathrm{kPa}$ gels. The softest cell line appeared to be the HOBs line, which has the biggest spread area on glass substrate.

\section{Cellular mechano-sensitivity is altered by blebbistatin}

In the second part of this chapter, I presented the changes in cellular morphology occurring after addition of mild concentrations of the myosin II inhibitor blebbistatin. I reported that morphological changes of treated cells depend on the stiffness of the substrate: I observed no morphological changes in the cell spread area on stiff substrates compared to the control assay in both cell lines, SAOS-2 and hMSCs. Previously, a similar observation was published by Lu and co-workers (106). They reported that culture of human aortic endothelial cells in culture dishes (rigid substrate) and addition of $10 \mu \mathrm{M}$ blebbistatin did not show any differences in the spread area. 
I saw that low concentrations of blebbistatin facilitated spreading on soft substrates. Furthermore, since myosin II plays a crucial role in the recruitment of specific proteins for FAs formation $(28,29)$, its inhibition alters FAs maturation $(41,99,108)$. In this research, I have shown that mild inhibition of myosin II affects the formation of focal adhesions on soft substrates: cells form less FAs, but the size of FAs in untreated cells is independent of the substrate elasticity.

The process of enhanced spreading on soft substrates turned out to be fast: significant changes could already be seen within the first $30 \mathrm{~min}$ after the addition of the drug. After four hours of culture in the presence of the drug the cell area reached its maximum of spreading. This process is reversible, as previous experiments have shown, washing out the drug makes the cell recover within the next 24 hours $(36,41,109,110)$. Interestingly, cellular recovery happens even when culturing on soft substrates: once the drug is washed out, cell area shrank to an area close the control cell size.

Several published studies show that blebbistatin softens the cellular cortex. It was shown that the acto-myosin shell (cortex) attached to the membrane plays an important role in cell shape changes (109) and myosin inhibition affects the morphology of chinese hamster ovary $(\mathrm{CHO})$ cells, even at low concentrations down to $5 \mu \mathrm{M}$ of blebbistatin. Additionally, similar results were shown in oocytes and Dictyostelium cells, that decreasing activity of myosin motors dramatically softened the cell (111-113). Tinevez et al. showed by using micropipette aspiration, that myosin inhibition caused by blebbistatin $(50 \mu \mathrm{M})$ can lead to a decrease in cortical tension (114). Previously, blebbistatin (2.5 and $10 \mu \mathrm{M}$ ) was shown to soften drastically the cells by using optical tweezers (115). Even a very low dose of the drug $(2.5 \mu \mathrm{M})$ led to a reduction of cell surface tension by inhibition of myosin II (116). Here, we confirmed by means of AFM that the addition of the drug softens hMSCs seeded on glass, even when no obvious morphological changes could be seen. Staining nonmuscle myosin lla in the treated cell and sectioning cells into two domains (interior and boundary) resulted in different amount of myosins in cell cortex on stiff and soft substrates. I have shown that drug treated cells seeded on soft substrates shown to have fewer amounts of myosins in the cellular cortex.

These results showed the importance of myosin motors in cellular mechano-sensitivity. To explain the phenomenon of the promoted spreading on soft substrates, we suggest a model, depicted in figure 5.23 . When placed in 
suspension, cells stay spherical as a result of membrane cortical tension, which is acting against the cellular internal pressure $(34,37,38)$. When binding to a 2D surface, the cell starts to exert forces through adhesion molecules such as integrins. The forces on the early stage of the spreading several magnitudes lower than forces on the later stages $(26,27)$.

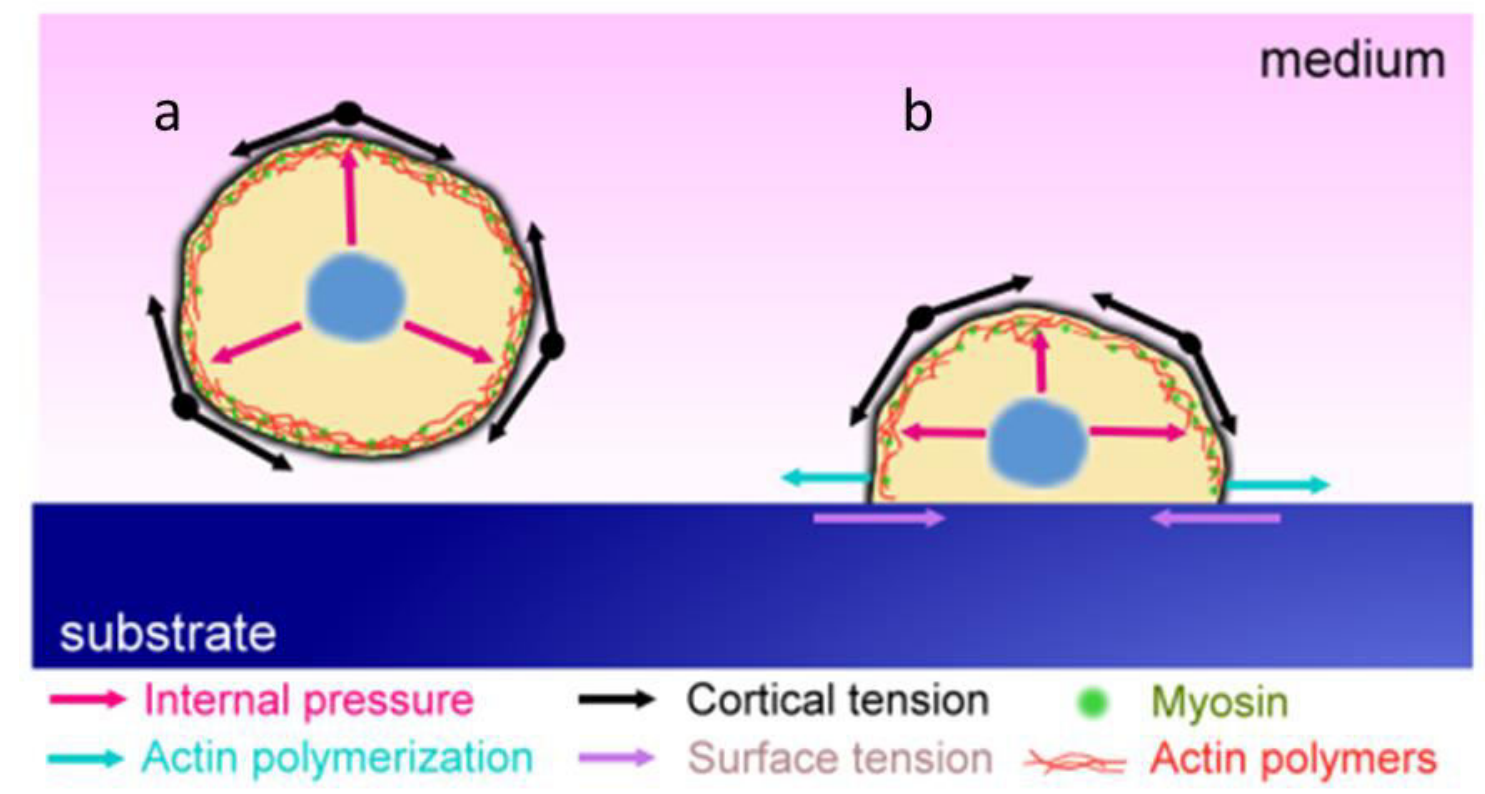

Figure 5.23. Balance of forces regulates cell shape. (a) Suspended cell shape is balanced by the outward expansion forces from the internal cell pressure (green arrows) and the counteracting contractile forces generated by the acto-myosin cortex (black arrows). This isotropic balance of forces generates a spherical cell. (b) When cells adhere to a substrate, cytoskeletal actin generates forces for further polymerization and SFs formation (red arrows). The surface tension acts against the polymerization that keeps the cell round (violet arrows).

Generation of protrusive forces at the cell periphery and formation of new adhesion sites promotes the acto-myosin polymerization. If the substrate is stiff enough for adhesive points to push and pull the substrate, spreading happens, supported by cell wetting. That means, if the acto-myosin polymerization forces are higher than the cortical tension, the cell is able to spread on the substrate. Applied to the case of soft substrates it means that if acto-myosin forces cannot overcome the cortical tension, cell area remains small. When the cortical tension in the cell is released, by inhibiting myosin activity with low concentrations of blebbistatin (in low amount of blebbistatin molecules would block corresponding number of easily accessible myosins, 
located in the cell cortex), acto-myosin forces are higher than the tension in the cortex.

We also showed that the process is reversible, since blebbistatin only blocks the activity of myosin motors with no other severe side effects in the cell. Hence, during recovery, the tension in the cortex increases again, thus the spread area is decreasing. 


\section{Chapter 6 Outlook}

In this outlook chapter I present preliminary results and describe the future potential for the experiments.

The promising results on cellular mechano-sensing call for further investigation. Fitting the theoretical model to the spreading behavior of different cell types grown on elastic substrates leads to different fitting parameters $E_{c}$, which is an effective Young's modulus of the cell. That raised our curiosity to measure cell stiffness and analyze the correlation with the fitting parameter $E_{c}$.

\section{Measuring visco-elastic properties of the cell with optical trap}

To study visco-elastic properties of the five different cell lines (hMSCs, C2C12, HOBs, SAOS-2 and 3T3 fibroblasts) I have used a dual optical trap, the setup was described previously in chapter 3.11. Figure $6.1 \mathrm{~b}$ shows representative images of the cell during the experiment.

Unfortunately, there is no exact relation between the measured effective spring constant of the cell and its Young's modulus. One of the essential parameter for such a conversion in terms of Hertzian contact mechanics is the size of the contact area between fibronectin coated beads and the cell. Assuming the cell as an elastic homogenous solid this relation was modeled and predicts linear dependence (119). However, it is obvious that the basic assumption of a homogeneous elastic material does not hold for the complex structure of a cell. Therefore we refrain from not calculating a Young's modulus and compare the relations between spring constants and fitting parameter $E_{c}$ of the given cell lines. 


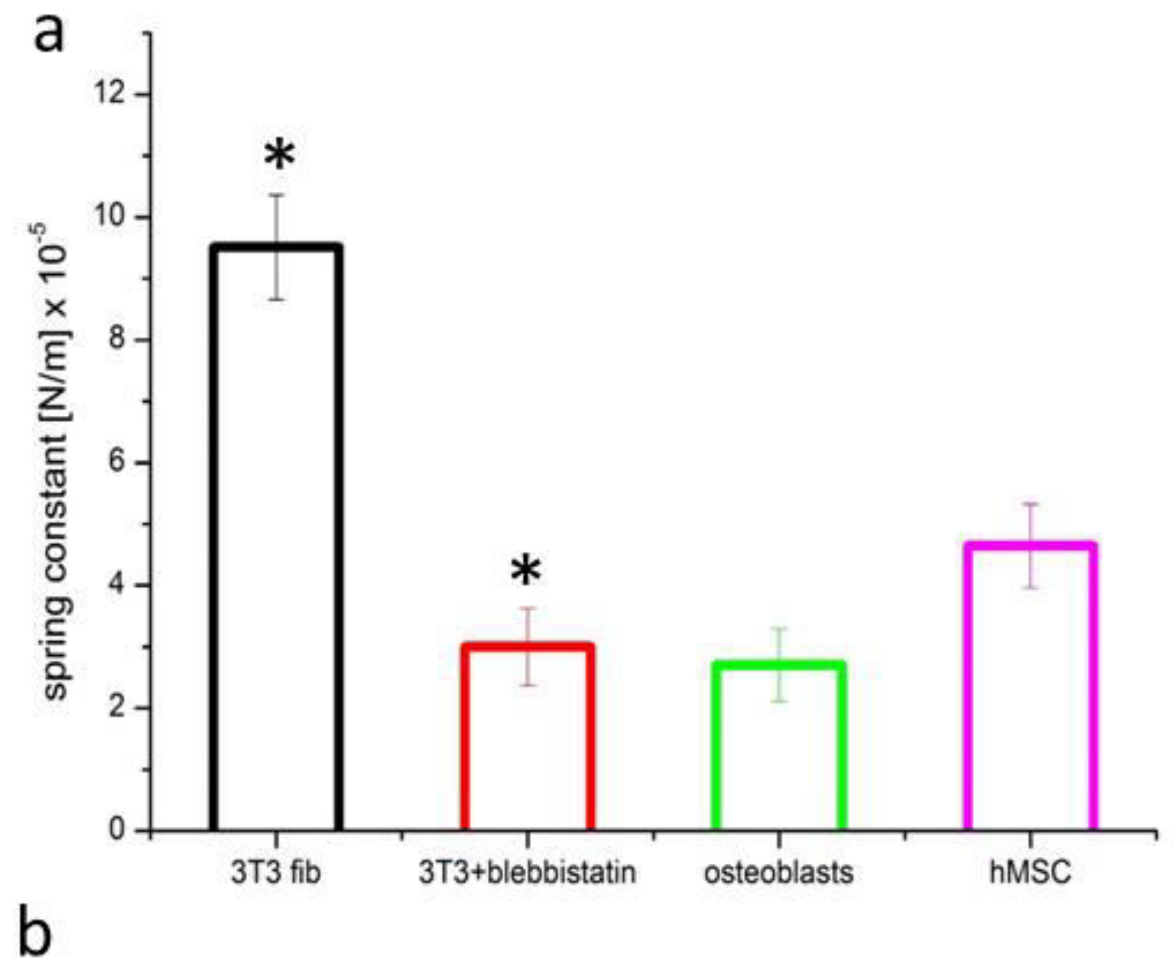

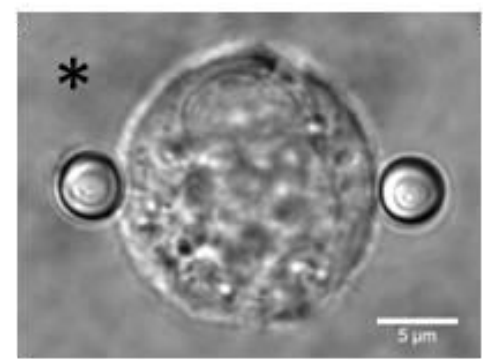

3T3 fibroblasts

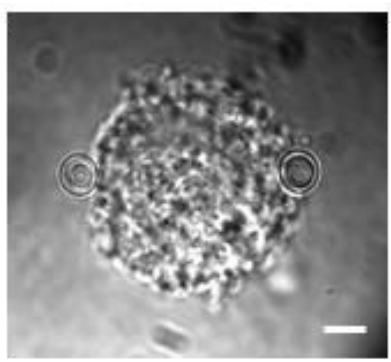

human primary osteoblasts

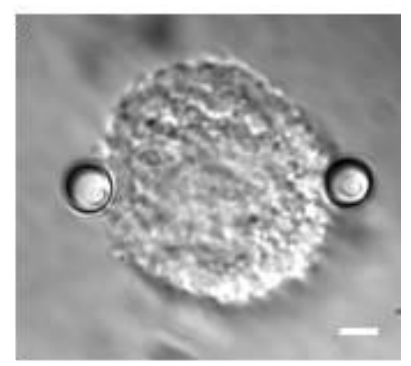

hMSCS

Figure 6.1. (a) Spring constants of $3 \mathrm{~T} 3$ fibroblasts, $50 \mu \mathrm{M}$ blebbistatin treated fibroblasts, osteoblasts and hMSCs. Error bars: standard error of the mean. (b) Representative images of trapped cells. Scale bar $5 \mu \mathrm{m}$. ( $\left.{ }^{*}\right)$ Data was made by Florian Schlosser and published in (107).

The spring constants of fibroblasts, HOBs and hMSCs are presented on the figure 6.1a. The spring constant of fibroblasts is the highest, and osteoblasts appeared to have the lowest out of the presented cell types. The same relation was extracted out of fitting the model equation 2.1 to the spread behavior of the same cell lines. In the table 6.1 I again present the fitting parameter $E_{c}$ from the chapter 5.3. Out of fitting the highest Young's modulus of the cell had $3 \mathrm{~T} 3$ fibroblasts, the same cell line had the higher spring constant. 
Table 6.1. Young's modulus of the cell extracted from the fitting model equation to the spreading behavior of different cell lines.

\begin{tabular}{c|c} 
Cell line & Fitting parameter $E_{c}, \mathrm{kPa}$ \\
\hline hMSCs & $9 \pm 2.8$ \\
\hline HOBs & $3.4 \pm 1.3$ \\
\hline 3T3 fibroblasts & $10.3 \pm 2.6$
\end{tabular}

In future research we plan to complete these experiments by also measuring the effective spring constant of SAOS-2 and $\mathrm{C} 2 \mathrm{C} 12$ cells.

\section{Measuring visco-elastic properties of blebbistatin treated cells.}

We also plan to study visco-elastic properties of blebbistatin treated cells. In the previous chapter 5.4 we discussed that the myosin drug effectively softens the cell, thus facilitates the spreading on soft substrates. I have previously shown that probing elastic properties of the cell by AFM proved that mild concentrations of blebbistatin soften hMSCs (see chapter 5.5). Also on the figure 6.1 I present the spring constant of blebbistatin treated fibroblasts, which was done by Dr. Florian Schlosser (74). It shows that addition of $50 \mu \mathrm{M}$ of blebbistatin drastically softens the cell. In further investigation, we plan to measure spring constants of hMSCs treated with mild concentration of blebbistatin (12.5 and $25 \mu \mathrm{M})$ using optical trap. 


\section{Conclusions}

This experimental $\mathrm{PhD}$ thesis gained several new insights about the interplay of the cell with its micro-environment during mechano-transduction. The obtained findings quantify spreading dynamics, confirm a formerly stated model for the cell area on different substrate and emphasize the role of myosin motors before, during and after cell attachment.

We confirmed the idea that differentiation of hMSCs directly depends on their microenvironment. Cells changed their morphology when placed in appropriate chemical or mechanical environments. I compared morphological changes of chemically and mechanically induced hMSCs, by analyzing fluorescence images of cell actin on 2D substrate and extracting cell spread area and aspect ratio of the cell. I demonstrated that the addition of TGF- $\beta 1$ to the culture triggers changes in cellular contractility already after a short time (48 hours) and causes cellular elongation. One week of culture in TGF- $\beta 1$ promoted the expression of an early myogenic marker - myogenin, indicating a differentiation into muscle cells. When seeding these chemically induced cells on elastic substrates with various elasticities we found changes in the cellular susceptibility to the matrix, precultured cells appeared to be more elongated than naive hMSCs. It indicates that cells lose their ability to adapt to new substrate elasticities. On the other hand, a week of culture of hMSCs on muscle-inducing gels resulted in cell elongation and stress fibers alignment along the long axes of the cell, comparably to what we saw for chemically induced cells. Remarkably, reseeding cells for 24 hours on gels with other stiffnesses showed that hMSCs can further adapt to another physical environment. That may indicate that a week of mechanical stimuli let these cells keep their multi-potentials.

Our investigation of the spreading process of committed cells on elastic substrates demonstrated that the spreading area increases with the substrate stiffness underneath the adhering cell, independent of cellular function, i.e. cell type and size. The findings of the spreading process follow well recently suggested theoretical predictions (9). In contrary, the cellular mechano-sensing is cell type specific. Namely, the dynamics of the spreading process depends on a cell-inherent time constant and the effective Young's modulus of the cell, extracted from fitting the theoretical model depends on the cell type. 
Additionally, this work contributed to a further understanding of the importance of myosin motors in the cellular sensing of mechanical stimuli. We demonstrated that addition of the myosin II inhibitor blebbistatin at low concentrations facilitated cell spreading only on soft substrates. This potentially might be explained by the high tension in the acto-myosin cortex, caused by myosin contraction. Thus the tension reduction promoted spreading. Moreover, morphology of cells seeded on stiff substrates was not affected. The effect of blebbistatin was shown to be fast: increased spreading was observed already after 30 minutes after addition to the cell culture. Cells seeded on soft substrates in presence of the drug exposed a larger spread area than untreated cells. Furthermore, the process was reversible: washing out the drug led to cell recovery, namely cell area shrank to the size of control cells. Due to these findings we set up a simple model which suggests that the interplay of cortical tension and the substrate stiffness dictates cell spreading behavior. Cells seeded on soft substrates have a low spreading ability due to the high cortical tension which keeps the cell round and prevents acto-myosin polymerization. The forces exerted by the cell and further acto-myosin polymerization directly depend on the stiffness of the substrate. In case of a soft substrate, actomyosin forces cannot overcome the cortical tension, thereby cell stays round. Addition of blebbistatin at low concentrations inhibits the easy accessible myosins, e.g. cortical myosins, thus release the tension. The release of the cortical tension allows acto-myosin forces to easier overcome the trigger for further polymerization.

In summary, in this PhD thesis I have contributed in understanding of the cellular mechano-sensing by proving that cells adapt their morphology to the mechanical stimuli. My results showed that molecular motors are directly in the mechano-transduction processes, pointing towards potential future investigations, which might target on the importance of the integrity of the cellular cortex on the cellular spreading, migration and proliferation. 


\section{Appendix}

\section{A.1. Cell culture protocol}

Before working under the cell culture hood the bench surface should always sprayed with $70 \%$ ethanol. All the materials have to be sterilized as well before putting in under the hood.

Every media should be warmed up in a water bath to $37^{\circ} \mathrm{C}$ before using. Needed materials:

- T75 cell culture flasks

- Cell culture medium supplemented with FBS and P/S

- PBS

- Trypsin

- $15 \mathrm{ml}$ Falcon tube

- FBS

- DMSO

- cryo-vials

- freezing box, inner box swimming in Isopropanol

- water bath, heated to $37^{\circ} \mathrm{C}$

- Incubator $\left(37^{\circ} \mathrm{C}\right.$ and $\left.5 \% \mathrm{CO}_{2}\right)$

\section{A.1.1. Thawing}

\section{Procedure:}

- Take a desired vial of cells from the liquid nitrogen tank, put the vial to the water bath for 30 seconds.

- Add $1 \mathrm{ml}$ of cell culture media to the vial and carefully pipet up and down few times.

- Fill a $15 \mathrm{ml}$ falcon tube with $12 \mathrm{ml}$ with warm culture media, transfer the content off the vial to the falcon tube.

- Centrifuge for 5 minutes at $1000 \mathrm{rpm}$.

- Carefully remove the supernatant from the falcon tube, resuspend the cell pellet in $1 \mathrm{ml}$ of media.

- Add $10 \mathrm{ml}$ of cell culture media to a T75 flask for 100000 cells. 
- Add cell suspension to the flask and genteelly shake the fflask to distribute the cells.

- Put the flask to the incubator having $37^{\circ} \mathrm{C}$ and $5 \%$ of $\mathrm{CO}_{2}$.

\section{A.1.2. Freezing cells}

\section{Procedure:}

- Remove the culture media from the flask and add $10 \mathrm{ml}$ of PBS.

- Remove PBS and add $3 \mathrm{ml}$ of trypsin. Keep in the incubator or 3 minutes.

- Gently shake the flask and check under the microscope whether the cells a detached from the surface.

- Add $5 \mathrm{ml}$ of the cell culture media to the flask.

- Transfer everything into a $15 \mathrm{ml}$ falcon tube and centrifuge for $5 \mathrm{~min}$ at $1000 \mathrm{rpm}$.

- During that time prepare the freezing solution of $90 \%$ FBS and $10 \%$ DMSO.

- When the centrifugation is over, remove the media from the tube and add $1 \mathrm{ml}$ of the freezing solution.

- In the freezing cryo-vials $100 \mathrm{k}$ cells resuspended in $1 \mathrm{ml}$ should be added.

- Put the cryo-vials into a freezing box and store at $-80 \mathrm{C}$ over night.

- Transfer vials to the liquid nitrogen vial.

\section{A.1.3. Splitting and seeding cells:}

\section{Procedure:}

- Discard culture media from the flask, add $10 \mathrm{ml}$ of PBS.

- Remove PBS and add $3 \mathrm{ml}$ of trypsin.

- Keep for 3 minutes in the incubator.

- Genteelly shake the flask and check under the microscope weather the cells a detached from the surface.

- Add $5 \mathrm{ml}$ of the cell culture media to the flask.

- Transfer everything into a $15 \mathrm{ml}$ falcon tube and centrifuge for $5 \mathrm{~min}$ at $1000 \mathrm{rpm}$.

- For seeding: sterile gels wash several times with PBS and add $2 \mathrm{ml}$ of the culture media. 
- For splitting: fill T75 culture flask with the cell culture media.

- When the centrifugation is over, remove the media from the tube and add $1 \mathrm{ml}$ of the culture media.

- Count cells. Seed 2500-3000 cells per one gel. Or transfer 100000 cells to a culture lask.

- Incubate the cells at $37{ }^{\circ} \mathrm{C}$ and $5 \% \mathrm{CO}_{2}$.

\section{A.2. Muscle Induction Medium}

Needed to have:

- Low Glucose DMEM

- $20 \%$ FBS F2442

- $1 \% \mathrm{P} / \mathrm{S}$

- 100 nM Dexamethasone (Sigma D4902)

- $50 \mu \mathrm{M}$ Hydrocortisone (Sigma H0888)

\section{$50 \mu \mathrm{M}$ Hydrocortisone}

To get $50 \mathrm{ml}$ Stock solution $0.5 \mathrm{mM}(181 \mu \mathrm{g} / \mathrm{mL})$ of Hydrocortisone: $0.036 \mathrm{~g}$ of powder dilute in $10 \mathrm{ml}$ of Ethanol. Pipet up and down.

To the $47.5 \mathrm{ml}$ of Medium [DMEM, 10\% FBS, 1\% P/S] add $2.5 \mathrm{ml}$ of Hydrocortisone in Ethanol. That will be $5 \%$ of Ethanol in solution.

Dilute stock solution 10 times.

Total amount of muscle induction medium is $500 \mathrm{ml}$, where $50 \mathrm{ml}$ should be Hydrocortisone. Percentage of ethanol $0.5 \%$.

\section{$100 \mathrm{nM}$ Dexamethasone}

Maximum solubility of Dexamethasone in Ethanol is $25 \mathrm{mg} / \mathrm{ml}$.

Preparation of stock solution, $20 \mu \mathrm{g} / \mathrm{mL}$.

$100 \mathrm{mg}$ of powder dissolve in $100 \mathrm{ml}$ of Ethanol. Vortex.

Take $100 \mu \mathrm{l}$ of Dexamethasone in Ethanol and add to the medium [DMEM, 20\% FBS, $1 \% \mathrm{P} / \mathrm{S}$ ]. Sterilize it.

To get $100 \mathrm{nM}$ in the medium, need to dilute 510 times: the total volume of the medium should still be $498.2 \mathrm{ml}, \mathrm{V}_{\text {dexamethasone }}=0.98 \mathrm{ml}$. 


\section{A.3. Polyacrylamide hydrogels:}

Based on (57)

Needed materials:

- $25 \mathrm{~mm}$ circular cover slips

- 3-aminopropyltriethoxysilane (APTES) - small chemistry lab (Sigma)

- 10 \% ammonium persulfate (APS) - freezer (solution in PBS, Fluka/Sigmaaldrich)

- Tetramethylene-diamine (TEMED) - fridge (Fluka/Sigma-aldrich)

- $40 \%$ acrylamide stock solution - fridge (Sigma)

- $2 \%$ bis-acrylamide - (Sigma) solution: fridge big chemistry lab

- $50 \mathrm{mM}$ HEPES buffer, $\mathrm{pH}=8$

- $0.4 \mathrm{mM} / \mathrm{I}$ Sulfo-SANPAH in HEPES buffer (Pierce) - freezer

- 0.5 \% gluteraldehyde in PBS of 50 \% gluteraldehyde in PBS - freezer in big chemistry lab

- dichlorodimethylsilane (DDS) - fume hood, small chemistry lab (Fluka/Sigma-Aldrich)

- dH2O from Millipore machine

- collagen I (rat tail) - fridge at cell culture (BD Biosciences)

- acetic acid (0.02\%)

- petri dishes or 6-well plates

\section{A.3.1. Coating cover glasses with glutaraldehyde}

- Put the cover slips in a cover slip plastic holder, put cover slips in a plasma cleaner for approximately $15 \mathrm{~min}$ :

o evacuate till 0-0.1 mbar

○ pump and power "ON" and set to "high"

- Place cover slips in a glass tub and add $99.8 \%$ ethanol to fully cover cover glasses ( $250 \mathrm{ml}$ ).

- Place the glass tube in ultrasound bath for $5 \mathrm{~min}$

- Discard the ethanol and refill with $250 \mathrm{ml}$ of ethanol and add $5 \mathrm{ml}$ APTES.

- Incubate in ultrasound bath for $15 \mathrm{~min}$.

- Wash 2 times with ethanol. 
- Place the glass tube to the oven at $70^{\circ} \mathrm{C}$ and cure for $30-60$ minutes.

- Wash with MiliQ water.

- Put cover slips in petri dish with pre-mixed solution of $0.5 \%$ gluteraldehyde in MilliQ water, incubate for $30 \mathrm{~min}$.

- Transfer glasses to the plastic stand, put in in the glass tube.

- Add $250 \mathrm{ml}$ of water and wash them in the ultrasound bath or 15 minutes.

\section{A.3.2. Hydrophobic cover glass treatment:}

- Work under the fume hood: Put square cover slips $(25 \times 25 \mathrm{~mm})$ into a large petri dish (9 $\mathrm{cm}$ diameter)

- Open container and place a small amount of DDS onto each cover slip. Smear it until the cover slip is completely covered by a thin layer of DDS. Close the petri dish and let it incubate for $10 \mathrm{~min}$.

- Wipe off DDS from the coverslips with a lint-free tissue and rinse with $\mathrm{dH} 20$. Carefully watch the wetting behavior of water and remember the more hydrophobic side. Set aside to dry with the more hydrophobic side up.

\section{A.3.3 Polyacrylamide hydrogel preparation:}

Table A.1. Needed concentrations of acrylamide and bis-acrylamide to obtain required gel Young's moduli.

\begin{tabular}{c|c|c|c|c|c}
$\begin{array}{c}\text { Young's } \\
\text { modulus, kPa }\end{array}$ & $\begin{array}{c}\text { Aacrylamide } \\
40 \% \text { in } 10 \mathrm{ml}, \\
\%\end{array}$ & $\begin{array}{c}\text { Bis-acrylamide } \\
2 \% \text { in } 10 \mathrm{ml}, \%\end{array}$ & $\begin{array}{c}\text { Acrylamide } \\
40 \% \text { in } 10 \mathrm{ml}, \\
\mathrm{ml}\end{array}$ & $\begin{array}{c}\text { Bis-acrylamide } \\
2 \% \text { in } 10 \mathrm{ml}, \\
\mathrm{ml}\end{array}$ & PBS, ml \\
\hline 1 & 3 & 0.20 & 0.75 & 1 & 8.25 \\
\hline 2 & 3.5 & 0.20 & 0.875 & 1 & 8.125 \\
\hline 4 & 3.8 & 0.20 & 0.95 & 1 & 8.05 \\
\hline 5 & 5 & 0.14 & 1.25 & 0.70 & 8.05 \\
\hline 8 & 6.8 & 0.10 & 1.70 & 0.5 & 7.80 \\
\hline 10 & 6 & 0.14 & 1.50 & 0.70 & 7.80 \\
\hline 16 & 6.8 & 0.20 & 1.70 & 1 & 7.30 \\
\hline 20 & 8 & 0.14 & 2 & 0.70 & 7.30 \\
\hline 32 & 8.6 & 0.30 & 2.15 & 1.5 & 6.35 \\
\hline 64 & 13.2 & 0.30 & 3.30 & 1.5 & 5.20 \\
\hline 128 & 23.6 & 0.30 & 5.90 & 1.5 & 2.60
\end{tabular}


- Mix acrylamide and bis-acrylamide to their desired concentration in PBS. Solutions do not have to be cold (but store mixed solutions in the fridge for up to four months). Mixed solutions store in the fridge.

- Prepare a wet paper towel and put it on the working bench. Try to make it as flat as possible.

- Choose an appropriate amount of acrylamide solution und place it into a $1 \mathrm{ml}$ Eppendorf tube. Add 1/100 volume of APS, vortex then add 1/1000 volume of

- TEMED to gel solution, vortex again.

- Quickly pipette $35 \mu$ l onto the circular, aminosilated cover slips (prepared in A) with the treated side up.

- Place the square, chlorosilanated cover slips on top of the polymerizing gel solution, with the treated side down.

- Allow to polymerize on wet paper towels under a petri dish or a 6-well plate for 60 minutes.

- After incubation time is over, pour MiliQ water on the paper towel. Water would help to easily remove the top cover glass.

- Place gels on cover slips in PBS in small petri dishes $(35 \mathrm{~mm}$ ) or 6-well plates.

- Incubate 2 times for 5 min in PBS on the rocker.

\section{A.3.4. Collagen coating:}

- Rinse 2 times with HEPES $=$ Remove PBS and add $2 \mathrm{ml}$ HEPES per petri dish or 6-well chamber, place it for 5 min on the rocker.

- Dry the cover slips bottom with a lint-free tissue and place them in a dry 6-well plate under the UV-lamp. Add Sulfo-SANPAH solution to the gel surface that it wets the whole gel surface but not the rest of the well. Switch on $365 \mathrm{~nm}$ UV for $10 \mathrm{~min}$.

- Rinse 3 times with HEPES.

- From here on keep everything at $0^{\circ} \mathrm{C}$. Put everything on ice.

- Prepare the needed amount of collagen I for a $0.2 \mathrm{mg} / \mathrm{ml}$ solution in HEPES. Add the same amount of acetic acid (0.02 \%) to the collagen I. Then carefully add HEPES to avoid precipitation.

- Incubate over night at $10^{\circ} \mathrm{C}$ (cool room). 
Next day:

- Rinse 2 times with PBS.

- Fill $1.5 \mathrm{ml}$ PBS in each petri dish. Put in tissue culture hood for $60 \mathrm{~min}$ under UV.

- Rince once with sterile PBS, add 2-3 ml of appropriate medium and seed cells at desired density.

\section{A.4. Immunostaining}

Based on (8)

Needed materials:

- PBS

- $10 \%$ formaldehyde in PBS

- $0.5 \%$ Triton X 100 in PBS

- $3 \%$ BSA in PBS

- Antibodies in 3\% BSA in PBS

\section{A.4.1. Cell fixation:}

- Gently remove the media from the cell culture plate / well.

- Add $2 \mathrm{ml}$ of $10 \%$ formaldehyde solution to each well and incubate for 5 min on a rocker.

\section{A.4.2. Permeabilisation:}

- Gently remove formaldehyde solution.

- Add $2 \mathrm{ml}$ of $0.5 \%$ Triton X 100 in PBS to each well and incubate for 10 min on a rocker.

- Remove Triton X solution

- Rinse once with PBS 


\section{A.4.3. Blocking:}

- Discard PBS

- Add $2 \mathrm{ml}$ 3\% BSA in PBS to each well and incubate for 30 min at RT on the rocker

- Discard BSA-solution

- Add $2 \mathrm{ml} \mathrm{0.5 \%} \mathrm{Triton} \mathrm{X} \mathrm{in} \mathrm{PBS} \mathrm{to} \mathrm{each} \mathrm{well} \mathrm{and} \mathrm{incubate} \mathrm{for} 5$ min on the rocker

- rinse once with PBS

\section{A.4.4. Primary antibody:}

- Discard PBS.

- Add $1 \mathrm{ml}$ of premixed solution of primary antibody in 3\% BSA in PBS in the desired concentration to each well.

- Put on the rocker and let incubate for at least one hour up to one day.

- Remove primary antibody solution.

- Add $2 \mathrm{ml} 0.5 \%$ Triton $\mathrm{X}$ solution to each well and incubate for $5 \mathrm{~min}$ on the rocker.

- Rinse once with PBS.

\section{A.4.5. Secondary antibody:}

- Discard PBS.

- From here on cover your samples in aluminium foil to prevent bleaching!

- Add $1 \mathrm{ml}$ of premixed solution of secondary antibody in 3\% BSA in PBS in the desired concentration to each well.

- Put on the rocker and let incubate for one or two hours.

\section{A.4.6. Actin and nucleus staining:}

- After removing secondary antibody, add $2 \mathrm{ml} 0.5 \%$ Triton $X$ solution to each well and incubate for $5 \mathrm{~min}$ on the rocker. 
- Rinse with PBS.

- Add an appropriate amount of labeled phalloidin diluted in 3\% of BSA in PBS.

- Incubate for 1-2 hours.

- Remove the staining solution. Either store it or discard.

- Add $1 \mathrm{ml}$ of Hoechst in 3\% of BSA in PBS in dilution [1:10000]. Incubate for 30-60 minutes.

\section{A.4.7. Finishing staining:}

- Check your samples on the microscope

- Rinse once with PBS

- Add $2 \mathrm{ml} 0.5 \%$ Triton $X$ solution to each well and incubate for $5 \mathrm{~min}$ on the rocker

- Rinse once with PBS

- Now either seal the container (i.e. 6-well) with parafilm and store your samples at 2

\section{A.5. DDS coating of cover slips}

Based on $(74,75)$.

$\underline{\mathrm{KOH}}$ cleaning of coverslips:

- put coverslips in a teflon holder in a glass box.

- add $6 \mathrm{~g}$ of $\mathrm{KOH}$ pellet and dissolve it with a few $\mathrm{ml}$ of MilliQ.

- fill the glass box with EtOH so that the coverslips are fully covered.

- sonicate for $5 \mathrm{~min}$.

- discard $\mathrm{KOH}$ solution and sonicate the coverslips 2x in MilliQ.

DDS coating

- $\quad$ put the $\mathrm{KOH}$ cleaned coverslips in a glass petri dish with glass beads.

- cover the coverslips with silanization solution I (DDS in heptane).

- incubate for 10-20 min.

- rinse coverslips in heptane.

- sonicate the coverslips in MilliQ.

- check if coverslips are hydrophobic and store them until usage. 


\section{A.6. Western blot of the hMSCs and C2C12 cells pre-cultured in TGF- $\beta 1$.}

These cells were pre-cultured in T TGF- $\beta 1$ for 72 hours in flasks, trypsinized and tested for the expression of myogenin using western blot. Myogenin is an early myogenic marker (approx. 34kPa), it was shown that the expression of it in $\mathrm{C} 2 \mathrm{C} 12$ cells reaches $58 \%$ and $82 \%$ after 1 and 2 days respectively of culture the differentiation media (121).

The description of the experiment:

1. hMSCs Control (negative control) ca. 100K. cells

2. hMSCs in TGF- $\beta 1$ (the sample) ca. 100K. cells

3. $\mathrm{C} 2 \mathrm{C} 12$ control (positive control) ca. 3 million cells

4. C2C12 TGF- $\beta 1$ (positive control) ca.8 million cells

$12 \%$ NuPage BisTris $1.0 \mathrm{~mm} 12$ well gel was used for this experiment.

The band of the expression was expected to be at about $40 \mathrm{kDa}$ in 3 cases: in $\mathrm{C} 2 \mathrm{C} 12$ control in TGF- $\beta 1$ and in hMSCs induced by TGF- $\beta 1$. The western blot result shown no expected band in that range, therefore no myogenin expression.

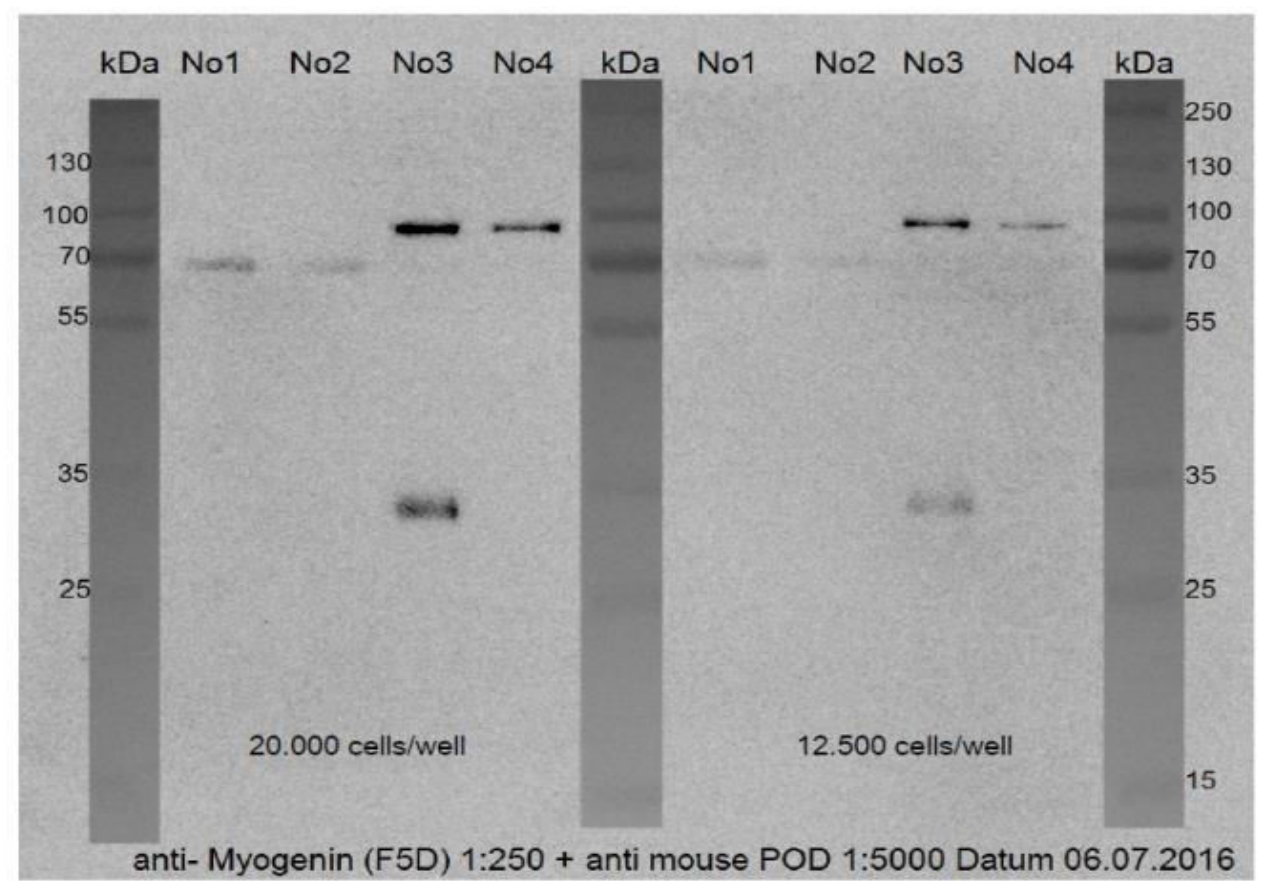

Figure A.1. Western Blot result of hMSCs and $\mathrm{C} 2 \mathrm{C} 12$ cultured in control media and in media supplemented by TGF- $\beta 1$. 


\section{A.7. C2C12 cells induced with TGF- $\beta 1$}

C2C12 cells were pre-cultured in TGF- $\beta 1$ for 48 hours in parallel with control samples. Afterwards cells were transferred on gels with different elasticities $0.5-130 \mathrm{kPa}$ for 16 hours and chemically fixed. The aspect ratio of fluorescently labeled actin was analyzed and compared. The outcome didn't show reliable result that can be seen in the aspect ratio of control, which is already expected to be higher. Basically the presented control result showed that $\mathrm{C} 2 \mathrm{C} 12$ myoblast are close to be round, what cannot be the case.

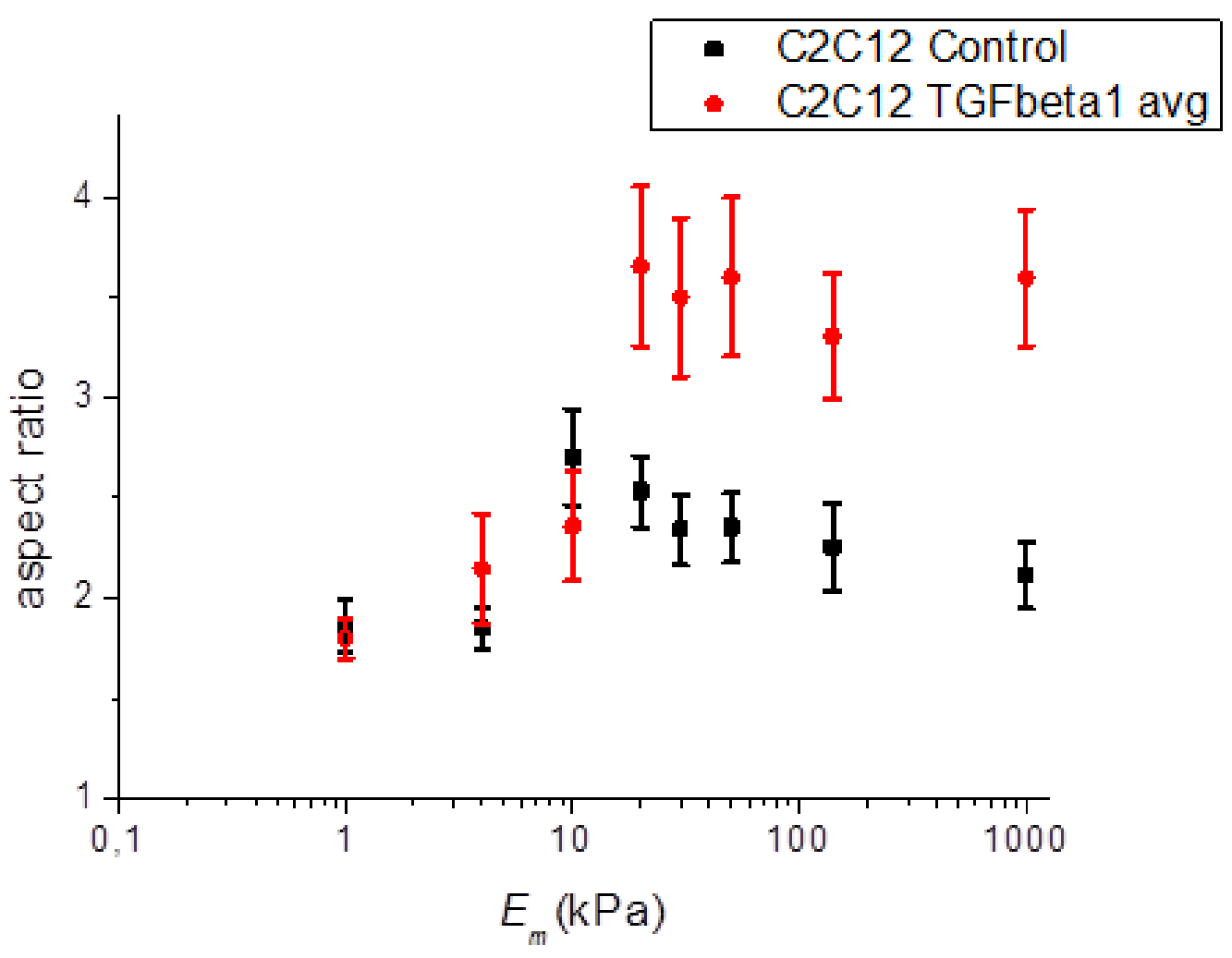

Figure A.2. Aspect ratio of $\mathrm{C} 2 \mathrm{C} 12$ cells cultured in control media and in TGF- $\beta 1$. Error bars: standard error of the mean. 


\section{A.8. Effect of ethanol on the cell culture}

Comparison of actin spread area of hMSCs cultured in control culture DMEM (black) and in addition of $5 \%$ of ethanol. From the figure A. 3 it can be seen that a low amount of ethanol does not influence cell spreading area. Table A. 2 shows the $\rho$ values of the t-test between 2 samples, out of it can be seen that that cell spread area on different substrates is not significantly altered by the addition of $5 \%$ of Ethanol.

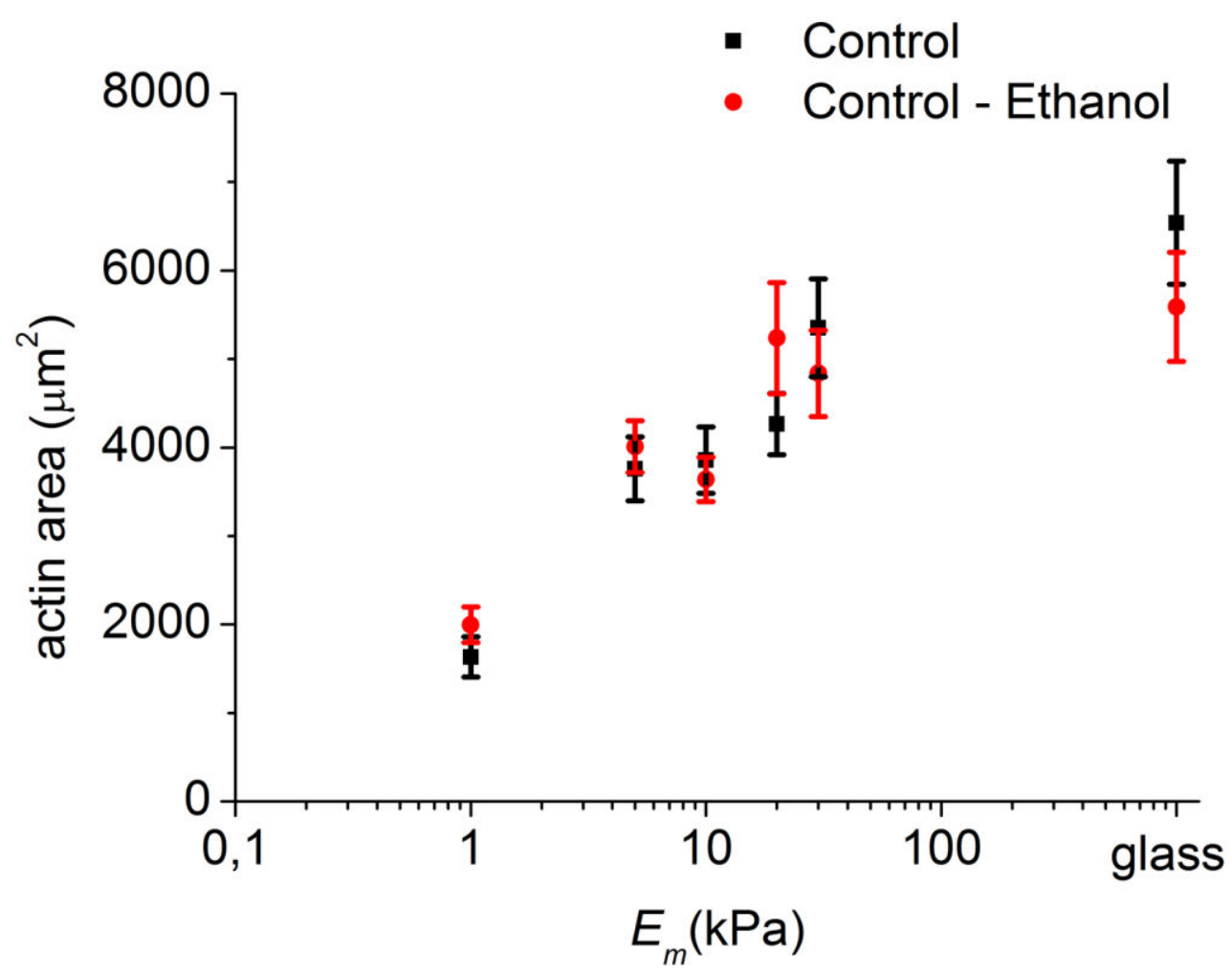

Figure A.3. Actin spread area of hMSCs cultured in control DMEM and in addition of $5 \%$ of Ethanol. Error bars: standard error of the mean. 
Table A.2. Significance test of the cell spread area on different cultures in control media or in addition of $5 \%$ ethanol.

\begin{tabular}{l|l}
$E_{m}, \mathrm{kPa}$ & $\begin{array}{l}\rho \text {-value of the t-test between control and } \\
\text { Control-Ethanol spread area }\end{array}$ \\
\hline 1 & 0.22 \\
\hline 5 & 0.41 \\
\hline 10 & 0.55 \\
\hline 20 & 0.21 \\
\hline 30 & 0.45 \\
\hline glass & 0.22
\end{tabular}

\section{A.9. Effect of DMSO on the spreading behavior of SAOS-2 cells}

Figure A.4 shows actin spread area of SAOS-2 cells cultured on different substrates in control media and in media in presence on $0.5 \%$ DMSO. The plot presents that the low amount of DMSO, in which blebbistatin is dissolved, does not influence the cell spreading area.

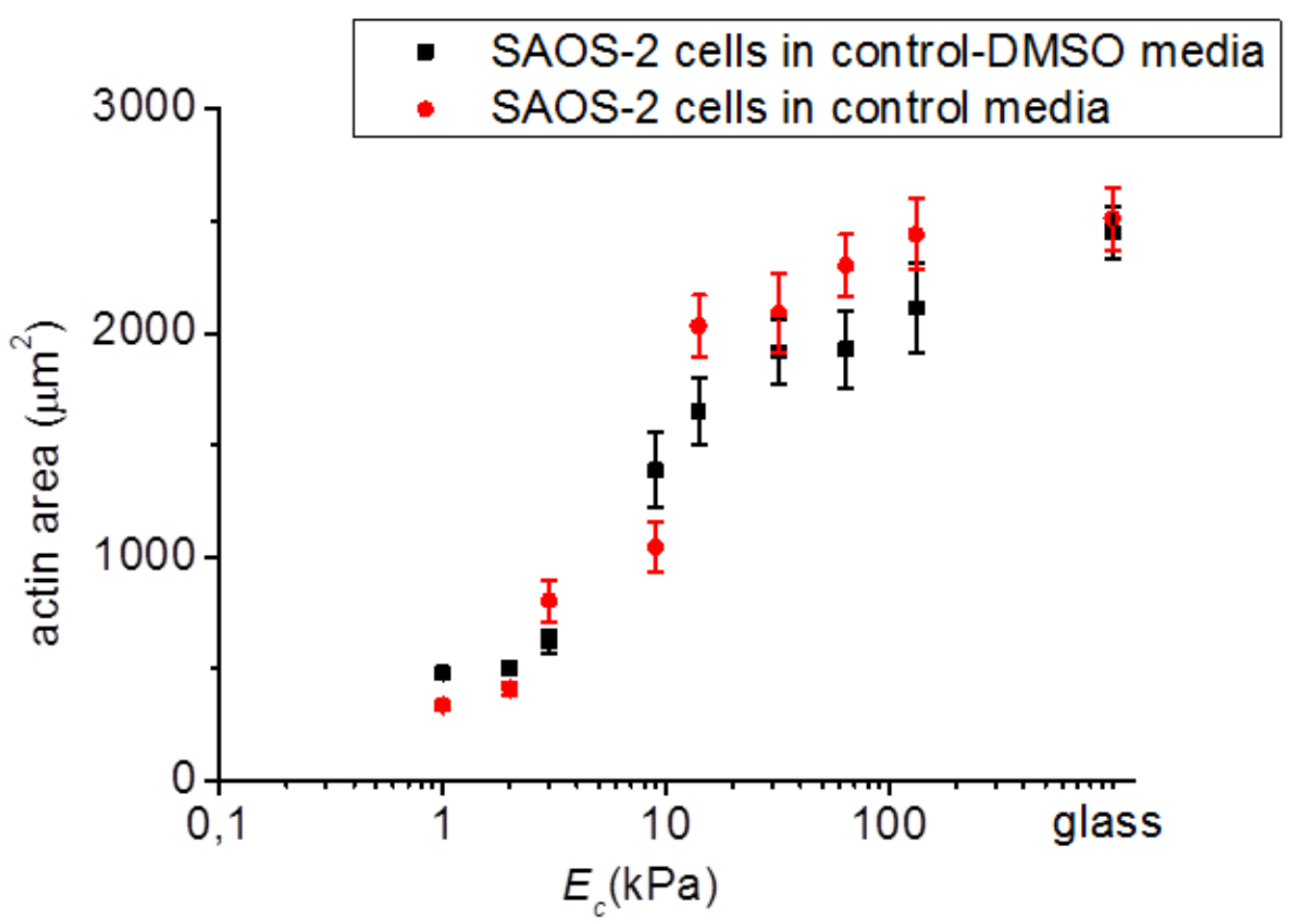

Figure A.4. Actin spread area of SAOS-2 cells cultured in control media and in addition of $0.5 \%$ of DMSO. Error bars: standard error of the mean. 


\section{A.10. Effect of blebbistatin on the amount of filaments in the cell}

Here I present the amount of stress fibers per cell area in blebbistatin treated cells. SFs were tracked with the Filament sensor (71), as was described before. Out of the figure A.5 it can be seen that blebbistatin in mild concentrations does not affect the amount off SFs in the cell.

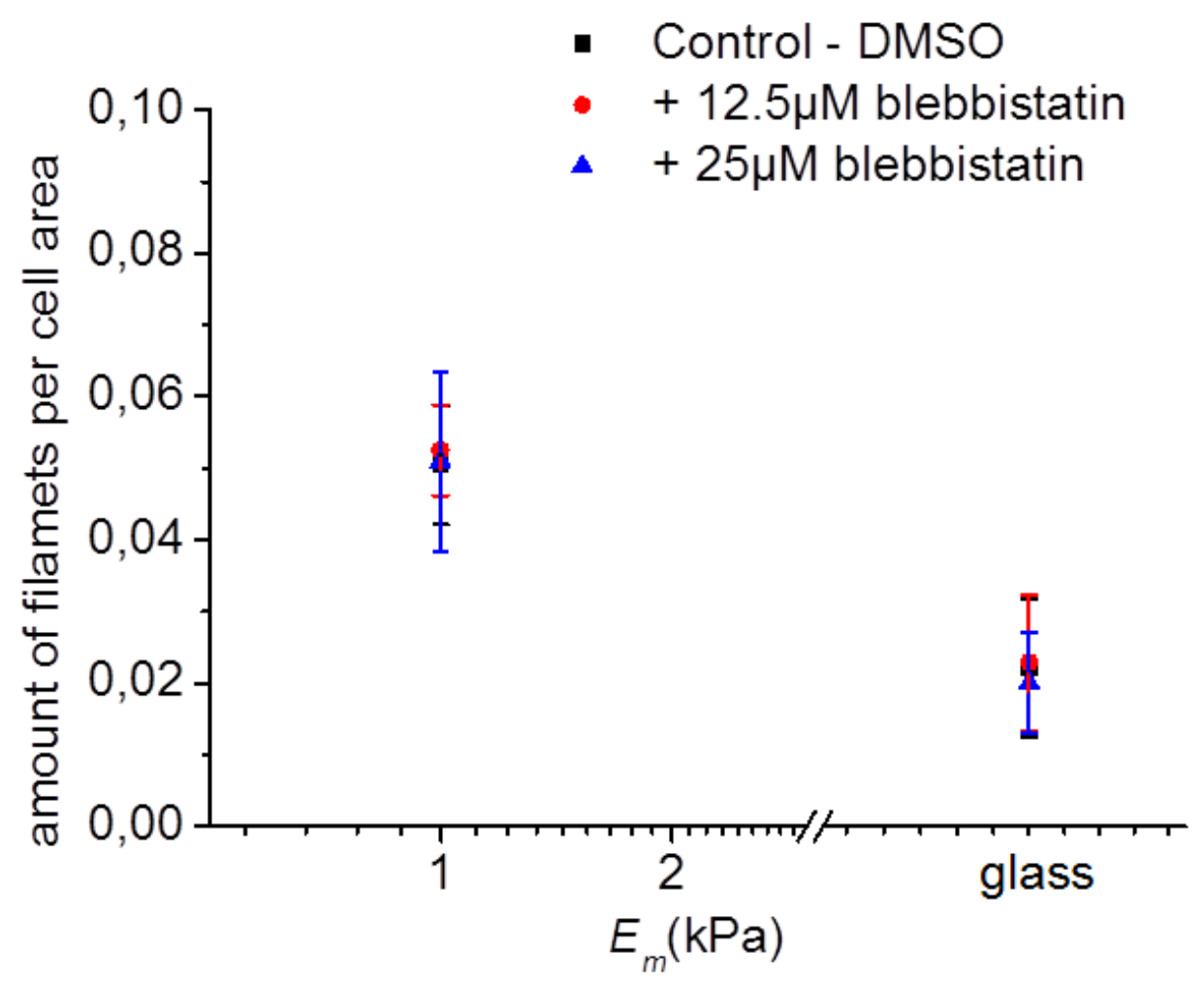

Figure A.5. Amount of stress fiber filaments per cell area depending on matrix elasticity. Error bars: standard error of the mean. 


\section{List of references}

1. Engler AJ, Sen S, Sweeney HL, Discher DE. Matrix elasticity directs stem cell lineage specification. Cell. 2006 Aug 25;126(4):677-89.

2. Rehfeldt F, Engler AJ, Discher DE. Stem Cells and Nanomedicine: Nanomechanics of the Microenvironment. In: Nanotechnology. Wiley-VCH Verlag GmbH \& Co. KGaA;

3. Geiger B, Spatz JP, Bershadsky AD. Environmental sensing through focal adhesions. Nat Rev Mol Cell Biol. 2009 Jan 1;10(1):21-33.

4. Khatau SB, Hale CM, Stewart-Hutchinson PJ, Patel MS, Stewart CL, Searson PC, et al. A perinuclear actin cap regulates nuclear shape. Proc Natl Acad Sci U S A. 2009 Nov 10;106(45):19017-22.

5. Discher DE, Janmey P, Wang Y-L. Tissue cells feel and respond to the stiffness of their substrate. Science. 2005 Nov 18;310(5751):1139-43.

6. Swift J, Ivanovska IL, Buxboim A, Harada T, Dingal PCDP, Pinter J, et al. Nuclear lamin-A scales with tissue stiffness and enhances matrix-directed differentiation. Science. 2013 Aug 30;341(6149):1240104.

7. Discher DE, Mooney DJ, Zandstra PW. Growth factors, matrices, and forces combine and control stem cells. Science. 2009 Jun 26;324(5935):1673-7.

8. Zemel A, Rehfeldt F, Brown AEX, Discher DE, Safran SA. Optimal matrix rigidity for stress fiber polarization in stem cells. Nat Phys. 2010 Jun 1;6(6):468-73.

9. Zemel A, Rehfeldt F, Brown AEX, Discher DE, Safran SA. Cell shape, spreading symmetry, and the polarization of stress-fibers in cells. J Phys Condens Matter. 2010;22(19):194110.

10. Alberts B, Johnson A, Lewis J, Raff M, Roberts K, Walter P. Molecular Biology of the Cell. 4th ed. Garland Science; 2002.

11. Lodish H, Berk A, Zipursky SL, Matsudaira P, Baltimore D, Darnell J. Myosin: The Actin Motor Protein. 2000

12. Lee S, Kumar S. Actomyosin stress fiber mechanosensing in $2 \mathrm{D}$ and $3 \mathrm{D}$. F1000Research. 2016 Sep 7 [

13. Burridge K, Guilluy C. Focal adhesions, stress fibers and mechanical tension. Exp Cell Res. 2016 Apr 10;343(1):14-20.

14. Tojkander S, Gateva G, Lappalainen P. Actin stress fibers - assembly, dynamics and biological roles. J Cell Sci. 2012 Apr 15;125(8):1855-64.

15. Burridge K. Are stress fibres contractile? Nature. 1981;294(5843):691-2.

16. Geiger B, Bershadsky A. Exploring the neighborhood: adhesion-coupled cell mechanosensors. Cell. 2002 Jul 26;110(2):139-42. 
17. Lo CM, Wang HB, Dembo M, Wang YL. Cell movement is guided by the rigidity of the substrate. Biophys J. 2000 Jul;79(1):144-52.

18. Harris AK, Wild P, Stopak D. Silicone rubber substrata: a new wrinkle in the study of cell locomotion. Science. 1980 Apr 11;208(4440):177-9.

19. Paluch EK, Nelson CM, Biais N, Fabry B, Moeller J, Pruitt BL, et al. Mechanotransduction: use the force(s). BMC Biol. 2015 Jul 4;13:47.

20. Cell Migration lab - cell adhesion.. Available from: http://www.reading.ac.uk/cellmigration/adhesion.htm

21. Zamir E, Geiger B. Molecular complexity and dynamics of cell-matrix adhesions. J Cell Sci. 2001 Oct;114(Pt 20):3583-90.

22. Puklin-Faucher E, Sheetz MP. The mechanical integrin cycle. J Cell Sci. 2009 Jan 15;122(Pt 2):179-86.

23. Rape AD, Guo W-H, Wang Y-L. The regulation of traction force in relation to cell shape and focal adhesions. Biomaterials. 2011 Mar;32(8):2043-51.

24. Carey SP, Charest JM, Reinhart-King CA. Forces During Cell Adhesion and Spreading: Implications for Cellular Homeostasis. In: Gefen A, editor. Cellular and Biomolecular Mechanics and Mechanobiology. Springer Berlin Heidelberg; 2010. p. 29-69. (Studies in Mechanobiology, Tissue Engineering and Biomaterials).

25. Galbraith CG, Yamada KM, Sheetz MP. The relationship between force and focal complex development. J Cell Biol. 2002 Nov 25;159(4):695-705.

26. Reinhart-King CA, Dembo M, Hammer DA. The dynamics and mechanics of endothelial cell spreading. Biophys J. 2005 Jul;89(1):676-89.

27. Dubin-Thaler BJ, Hofman JM, Cai Y, Xenias H, Spielman I, Shneidman AV, et al. Quantification of cell edge velocities and traction forces reveals distinct motility modules during cell spreading. PloS One. 2008;3(11):e3735.

28. Cai Y, Rossier O, Gauthier NC, Biais N, Fardin M-A, Zhang X, et al. Cytoskeletal coherence requires myosin-IIA contractility. J Cell Sci. 2010 Feb 1;123(3):413-23.

29. McGrath JL. Cell Spreading: The Power to Simplify. Curr Biol. 2007;17(10):R357-8.

30. Dubin-Thaler BJ, Giannone G, Döbereiner H-G, Sheetz MP. Nanometer analysis of cell spreading on matrix-coated surfaces reveals two distinct cell states and STEPs. Biophys J. 2004 Mar;86(3):1794-806.

31. Riveline D, Zamir E, Balaban NQ, Schwarz US, Ishizaki T, Narumiya S, et al. Focal contacts as mechanosensors: externally applied local mechanical force induces growth of focal contacts by an mDia1-dependent and ROCK-independent mechanism. J Cell Biol. 2001 Jun 11;153(6):1175-86.

32. Beach JR, Hammer JA, III. Myosin II Isoform Co-assembly and Differential Regulation in Mammalian Systems. Exp Cell Res. 2015 May 15;334(1):2. 
33. Conti MA, Kawamoto S, Adelstein RS. Non-Muscle Myosin II. 2008;223-64.

34. Kovács M, Tóth J, Hetényi C, Málnási-Csizmadia A, Sellers JR. Mechanism of Blebbistatin Inhibition of Myosin II. J Biol Chem. 2004 Aug 20;279(34):35557-63.

35. Geeves MA, Holmes KC. Structural mechanism of muscle contraction. Annu Rev Biochem. 1999;68:687-728.

36. Bond LM, Tumbarello DA, Kendrick-Jones J, Buss F. Small-molecule inhibitors of myosin proteins. Future Med Chem. 2013 Jan;5(1):41-52.

37. Li Y, Lovett D, Zhang Q, Neelam S, Kuchibhotla RA, Zhu R, et al. Moving Cell Boundaries Drive Nuclear Shaping during Cell Spreading. Biophys J. 2015 Aug 18;109(4):670-86.

38. Shu S, Liu X, Korn ED. Blebbistatin and blebbistatin-inactivated myosin II inhibit myosin II-independent processes in Dictyostelium. Proc Natl Acad Sci U S A. 2005 Feb 1;102(5):1472-7.

39. Guha M, Zhou M, Wang Y-L. Cortical actin turnover during cytokinesis requires myosin II. Curr Biol CB. 2005 Apr 26;15(8):732-6.

40. Calaminus SDJ, Auger JM, McCarty OJT, Wakelam MJO, Machesky LM, Watson SP. MyosinIIa contractility is required for maintenance of platelet structure during spreading on collagen and contributes to thrombus stability. J Thromb Haemost JTH. 2007 Oct;5(10):2136-45.

41. Liu Z, van Grunsven LA, Van Rossen E, Schroyen B, Timmermans J-P, Geerts A, et al. Blebbistatin inhibits contraction and accelerates migration in mouse hepatic stellate cells. Br J Pharmacol. 2010 Jan;159(2):304-15.

42. Dillard P, Varma R, Sengupta K, Limozin L. Ligand-Mediated Friction Determines Morphodynamics of Spreading T Cells. Biophys J. 2014 Dec 2;107(11):2629-38.

43. Gupton SL, Waterman-Storer CM. Spatiotemporal feedback between actomyosin and focal-adhesion systems optimizes rapid cell migration. Cell. 2006 Jun 30;125(7):136174.

44. Phadwal K, Watson AS, Simon AK. Tightrope act: autophagy in stem cell renewal, differentiation, proliferation, and aging. Cell Mol Life Sci. 2013 Jan;70(1):89.

45. Abdullah AI, Pollock A, Sun T. The path from skin to brain: generation of functional neurons from fibroblasts. Mol Neurobiol. 2012 Jun;45(3):586-95.

46. Gang EJ, Jeong JA, Hong SH, Hwang SH, Kim SW, Yang IH, et al. Skeletal Myogenic Differentiation of Mesenchymal Stem Cells Isolated from Human Umbilical Cord Blood. STEM CELLS. 2004 Jul 1;22(4):617-24.

47. Pittenger MF, Mackay AM, Beck SC, Jaiswal RK, Douglas R, Mosca JD, et al. Multilineage Potential of Adult Human Mesenchymal Stem Cells. Science. 1999 Apr 2;284(5411):143-7. 
48. Budasz-Rwiderska M, Jank M, Motyl T. Transforming growth factor-beta1 upregulates myostatin expression in mouse C2C12 myoblasts. J Physiol Pharmacol Off J Pol Physiol Soc. 2005 Jun;56 Suppl 3:195-214.

49. Kurpinski K, Lam H, Chu J, Wang A, Kim A, Tsay E, et al. Transforming Growth Factor- $\beta$ and Notch Signaling Mediate Stem Cell Differentiation into Smooth Muscle Cells. STEM CELLS. 2010 Apr 1;28(4):734-42.

50. Kumar S, Maxwell IZ, Heisterkamp A, Polte TR, Lele TP, Salanga M, et al. Viscoelastic retraction of single living stress fibers and its impact on cell shape, cytoskeletal organization, and extracellular matrix mechanics. Biophys J. 2006 May 15;90(10):3762-73.

51. Wang N, Ostuni E, Whitesides GM, Ingber DE. Micropatterning tractional forces in living cells. Cell Motil Cytoskeleton. 2002 Jun;52(2):97-106.

52. Griffin MA, Engler AJ, Barber TA, Healy KE, Sweeney HL, Discher DE. Patterning, prestress, and peeling dynamics of myocytes. Biophys J. 2004 Feb;86(2):1209-22.

53. Ghibaudo M, Saez A, Trichet L, Xayaphoummine A, Browaeys J, Silberzan P, et al. Traction forces and rigidity sensing regulate cell functions. Soft Matter. 2008 Aug 12;4(9):1836-43.

54. Engler AJ, Griffin MA, Sen S, Bönnemann CG, Sweeney HL, Discher DE. Myotubes differentiate optimally on substrates with tissue-like stiffness: pathological implications for soft or stiff microenvironments. J Cell Biol. 2004 Sep 13;166(6):877-87.

55. Yeung T, Georges PC, Flanagan LA, Marg B, Ortiz M, Funaki M, et al. Effects of substrate stiffness on cell morphology, cytoskeletal structure, and adhesion. Cell Motil Cytoskeleton. 2005 Jan;60(1):24-34.

56. Kurpinski K, Chu J, Wang D, Li S. Proteomic Profiling of Mesenchymal Stem Cell Responses to Mechanical Strain and TGF- $\beta 1$. Cell Mol Bioeng. 2009 Dec;2(4):606-14.

57. Chaudhuri T, Rehfeldt F, Sweeney HL, Discher DE. Preparation of collagen-coated gels that maximize in vitro myogenesis of stem cells by matching the lateral elasticity of in vivo muscle. Methods Mol Biol Clifton NJ. 2010;621:185-202.

58. Hall LD, Waterton JC. A method for determining the spatial distribution of spinlabeled organic ligands covalently bound to a noncrystalline surface: dipolar contribution to nitroxide EPR spectrum. J Am Chem Soc. 1979 Jun 1;101(13):3697-8.

59. Aplin JD, Hughes RC. Protein-derivatised glass coverslips for the study of cell-tosubstratum adhesion. Anal Biochem. 1981 May 1;113(1):144-8.

60. Pelham RJ, Wang Y 1. High resolution detection of mechanical forces exerted by locomoting fibroblasts on the substrate. Mol Biol Cell. 1999 Apr;10(4):935-45.

61. Binnig null, Quate null, Gerber null. Atomic force microscope. Phys Rev Lett. 1986 Mar 3;56(9):930-3.

62. Cappella B, Dietler G. Force-distance curves by atomic force microscopy. Surf Sci Rep. 1999 Jan 1;34(1):1-104. 
63. Ivanovska IL, de Pablo PJ, Ibarra B, Sgalari G, MacKintosh FC, Carrascosa JL, et al. Bacteriophage capsids: Tough nanoshells with complex elastic properties. Proc Natl Acad Sci U S A. 2004 May 18;101(20):7600-5.

64. Hutter JL, Bechhoefer J. Calibration of atomic-force microscope tips. Rev Sci Instrum. 1993 Jul 1;64(7):1868-73.

65. Dimitriadis EK, Horkay F, Maresca J, Kachar B, Chadwick RS. Determination of elastic moduli of thin layers of soft material using the atomic force microscope. Biophys J. 2002 May;82(5):2798-810.

66. Luxton GWG, Gundersen GG. Orientation and function of the nuclear-centrosomal axis during cell migration. Curr Opin Cell Biol. 2011 Oct;23(5):579-88.

67. Sen S, Subramanian S, Discher DE. Indentation and Adhesive Probing of a Cell Membrane with AFM: Theoretical Model and Experiments. Biophys J. 2005 Nov;89(5):3203-13.

68. Queens1 TU of, Lucia BS, Gatton Q 4072 +61 733651111 OCU, Maps UH, Queensl D (C) document write getFullYear2016 TU of. Immunofluorescence - Background http://www.di.uq.edu.au/?page $=213177 \&$ pid $=213177$

69. Abramoff MD, Magalhães PJ, Ram SJ. Image processing with ImageJ. Biophotonics international. 2004

70. Gottschlich C, Mihailescu P, Munk A. Robust Orientation Field Estimation and Extrapolation Using Semilocal Line Sensors. IEEE Trans Inf Forensics Secur. 2009 Dec;4(4):802-11.

71. Eltzner B, Wollnik C, Gottschlich C, Huckemann S, Rehfeldt F. The filament sensor for near real-time detection of cytoskeletal fiber structures. PloS One. 2015;10(5):e0126346.

72. GraphPad Curve Fitting Guide http://www.graphpad.com/guides/prism/7/curvefitting/index.htm?r2_ameasureofgoodness_of_fitoflinearregression.htm

73. Mizuno D, Head DA, MacKintosh FC, Schmidt CF. Active and Passive Microrheology in Equilibrium and Nonequilibrium Systems. Macromolecules. 2008 Oct 14;41(19):7194-202.

74. Schlosser F. Mechanics of suspended cells probed by dual optical traps in a confocal microscope.

75. Schlosser F, Rehfeldt F, Schmidt CF. Force fluctuations in three-dimensional suspended fibroblasts. Phil Trans R Soc B. 2015 Feb 5;370(1661):20140028.

76. Park JS, Chu JS, Tsou AD, Diop R, Tang Z, Wang A, et al. The effect of matrix stiffness on the differentiation of mesenchymal stem cells in response to TGF- $\beta$. Biomaterials. 2011 Jun;32(16):3921-30.

77. Nagodawithana TW, Steinkraus KH. Influence of the rate of ethanol production and accumulation on the viability of Saccharomyces cerevisiae in "rapid fermentation". Appl Environ Microbiol. 1976 Feb 1;31(2):158-62. 
78. Lennon SV, Martin SJ, Cotter TG. Dose-dependent induction of apoptosis in human tumour cell lines by widely diverging stimuli. Cell Prolif. 1991 Mar 1;24(2):203-14.

79. Topper JN. TGF-beta in the cardiovascular system: molecular mechanisms of a context-specific growth factor. Trends Cardiovasc Med. 2000 Apr;10(3):132-7.

80. Massagué J, Wotton D. Transcriptional control by the TGF-beta/Smad signaling system. EMBO J. 2000 Apr 17;19(8):1745-54.

81. Derynck R, Zhang YE. Smad-dependent and Smad-independent pathways in TGF-beta family signalling. Nature. 2003 Oct 9;425(6958):577-84.

82. Siegel PM, Massagué J. Cytostatic and apoptotic actions of TGF- $\beta$ in homeostasis and cancer. Nat Rev Cancer. 2003 Nov;3(11):807-20.

83. Meyer-ter-Vehn T, Katzenberger B, Sieprath S, Grehn F, Schlunck G. Cell

Contractility Is a Prerequisite for TGFbeta-Induced Myofibroblast Transdifferentiation. Invest Ophthalmol Vis Sci. 2006 May 1;47(13):40-40.

84. Lyon D, McKay TB, Sarkar-Nag A, Priyadarsini S, Karamichos D. Human Keratoconus Cell Contractility is Mediated by Transforming Growth Factor-Beta Isoforms. J Funct Biomater. 2015 Jun 18;6(2):422-38.

85. Uhal BD, Kim JK, Li X, Molina-Molina M. Angiotensin-TGF-beta 1 crosstalk in human idiopathic pulmonary fibrosis: autocrine mechanisms in myofibroblasts and macrophages. Curr Pharm Des. 2007;13(12):1247-56.

86. Campbell BH, Agarwal C, Wang JH-C. TGF-beta1, TGF-beta3, and PGE(2) regulate contraction of human patellar tendon fibroblasts. Biomech Model Mechanobiol. 2004 Jun;2(4):239-45.

87. Wells RG, Discher DE. Matrix Elasticity, Cytoskeletal Tension, and TGF- $\beta$ : The Insoluble and Soluble Meet. Sci Signal. 2008 Mar 11;1(10):pe13.

88. Liu XD, Umino T, Ertl R, Veys T, Skold CM, Takigawa K, et al. Persistence of TGFbeta1 induction of increased fibroblast contractility. In Vitro Cell Dev Biol Anim. 2001 Mar;37(3):193-201.

89. Tomasek JJ, Gabbiani G, Hinz B, Chaponnier C, Brown RA. Myofibroblasts and mechano-regulation of connective tissue remodelling. Nat Rev Mol Cell Biol. 2002 May;3(5):349-63.

90. Kinner B, Zaleskas JM, Spector M. Regulation of Smooth Muscle Actin Expression and Contraction in Adult Human Mesenchymal Stem Cells. Exp Cell Res. 2002 Aug $1 ; 278(1): 72-83$.

91. Frank V, Kaufmann S, Wright R, Horn P, Yoshikawa HY, Wuchter P, et al. Frequent mechanical stress suppresses proliferation of mesenchymal stem cells from human bone marrow without loss of multipotency. Sci Rep. 2016 Apr 15;6:24264.

92. Conget PA, Minguell JJ. Phenotypical and functional properties of human bone marrow mesenchymal progenitor cells. J Cell Physiol. 1999 Oct;181(1):67-73. 
93. Blau HM, Pavlath GK, Hardeman EC, Chiu CP, Silberstein L, Webster SG, et al. Plasticity of the differentiated state. Science. 1985 Nov 15;230(4727):758-66.

94. Kalinec G, Nazarali AJ, Hermouet S, Xu N, Gutkind JS. Mutated alpha subunit of the Gq protein induces malignant transformation in NIH 3T3 cells. Mol Cell Biol. 1992 Oct;12(10):4687-93.

95. Fournier B, Price PA. Characterization of a new human osteosarcoma cell line OHS-4. J Cell Biol. 1991 Aug;114(3):577-83.

96. Yarram SJ, Perry MJ, Christopher TJ, Westby K, Brown NL, Lamminen T, et al. Luteinizing hormone receptor knockout (LuRKO) mice and transgenic human chorionic gonadotropin ( $\mathrm{hCG}$ )-overexpressing mice (hCG alphabeta+) have bone phenotypes. Endocrinology. 2003 Aug;144(8):3555-64.

97. Takács B, Billington N, Gyimesi M, Kintses B, Málnási-Csizmadia A, Knight PJ, et al. Myosin complexed with ADP and blebbistatin reversibly adopts a conformation resembling the start point of the working stroke. Proc Natl Acad Sci. 2010 Apr 13;107(15):6799-804.

98. Shu S, Liu X, Korn ED. Blebbistatin and blebbistatin-inactivated myosin II inhibit myosin II-independent processes in Dictyostelium. Proc Natl Acad Sci U S A. 2005 Feb 1;102(5):1472-7.

99. Pasapera AM, Schneider IC, Rericha E, Schlaepfer DD, Waterman CM. Myosin II activity regulates vinculin recruitment to focal adhesions through FAK-mediated paxillin phosphorylation. J Cell Biol. 2010 Mar 22;188(6):877-90.

100. Even-Ram S, Doyle AD, Conti MA, Matsumoto K, Adelstein RS, Yamada KM. Myosin IIA regulates cell motility and actomyosin-microtubule crosstalk. Nat Cell Biol. 2007 Mar;9(3):299-309.

101. Schaub S, Bohnet S, Laurent VM, Meister J-J, Verkhovsky AB. Comparative Maps of Motion and Assembly of Filamentous Actin and Myosin II in Migrating Cells. Mol Biol Cell. 2007 Oct 1;18(10):3723-32.

102. Deakin NO, Turner CE. Paxillin comes of age. J Cell Sci. 2008 Aug 1;121(Pt 15):2435-44.

103. Totsukawa G, Wu Y, Sasaki Y, Hartshorne DJ, Yamakita Y, Yamashiro S, et al. Distinct roles of MLCK and ROCK in the regulation of membrane protrusions and focal adhesion dynamics during cell migration of fibroblasts. J Cell Biol. 2004 Feb $2 ; 164(3): 427-39$.

104. Martens JC, Radmacher M. Softening of the actin cytoskeleton by inhibition of myosin II. Pflüg Arch - Eur J Physiol. 2008 Apr 1;456(1):95-100.

105. Lu L, Oswald SJ, Ngu H, Yin FC-P. Mechanical Properties of Actin Stress Fibers in Living Cells. Biophys J. 2008 Dec 15;95(12):6060-71.

106. Lu L, Feng Y, Hucker WJ, Oswald SJ, Longmore GD, Yin FC-P. Actin stress fiber preextension in human aortic endothelial cells. Cell Motil Cytoskeleton. 2008 Apr;65(4):281-94. 
107. Chrzanowska-Wodnicka M, Burridge K. Rho-stimulated contractility drives the formation of stress fibers and focal adhesions. J Cell Biol. 1996 Jun;133(6):1403-15.

108. Gallegos L, Ng MR, Brugge JS. The myosin-II-responsive focal adhesion proteome: a tour de force? Nat Cell Biol. 2011 Apr;13(4):344-6.

109. Kapustina M, Elston TC, Jacobson K. Compression and dilation of the membranecortex layer generates rapid changes in cell shape. J Cell Biol. 2013 Jan 7;200(1):95108.

110. Zhang M, Rao PV. Blebbistatin, a Novel Inhibitor of Myosin II ATPase Activity, Increases Aqueous Humor Outflow Facility in Perfused Enucleated Porcine Eyes. Invest Ophthalmol Vis Sci. 2005 Nov 1;46(11):4130-8.

111. Chaigne A, Campillo C, Gov NS, Voituriez R, Azoury J, Umaña-Diaz C, et al. A soft cortex is essential for asymmetric spindle positioning in mouse oocytes. Nat Cell Biol. 2013 Aug;15(8):958-66.

112. Guo M, Ehrlicher AJ, Jensen MH, Renz M, Moore JR, Goldman RD, et al. Probing the stochastic, motor-driven properties of the cytoplasm using force spectrum microscopy. Cell. 2014 Aug 14;158(4):822-32.

113. Jay PY, Pham PA, Wong SA, Elson EL. A mechanical function of myosin II in cell motility. J Cell Sci. 1995 Jan;108 ( Pt 1):387-93.

114. Tinevez J-Y, Schulze U, Salbreux G, Roensch J, Joanny J-F, Paluch E. Role of cortical tension in bleb growth. Proc Natl Acad Sci U S A. 2009 Nov 3;106(44):18581-6.

115. Schlosser F, Rehfeldt F, Schmidt CF. Force fluctuations in three-dimensional suspended fibroblasts. Philos Trans R Soc B Biol Sci. 2015 Feb 5

116. Fischer-Friedrich E, Toyoda Y, Cattin CJ, Müller DJ, Hyman AA, Jülicher F. Rheology of the Active Cell Cortex in Mitosis. Biophys J. 2016 Aug 9;111(3):589-600.

117. Salbreux G, Charras G, Paluch E. Actin cortex mechanics and cellular morphogenesis. Trends Cell Biol. 2012 Oct;22(10):536-45.

118. Stewart MP, Helenius J, Toyoda Y, Ramanathan SP, Muller DJ, Hyman AA. Hydrostatic pressure and the actomyosin cortex drive mitotic cell rounding. Nature. 2011 Jan 13;469(7329):226-30.

119. Mizuno D, Bacabac R, Tardin C, Head D, Schmidt CF. High-Resolution Probing of Cellular Force Transmission. Phys Rev Lett. 2009;102(16):168102.

120. Schlosser F. Mechanics of suspended cells probed by dual optical traps in a confocal microscope. 2015 Dec 2; Available from: https://ediss.unigoettingen.de/handle/11858/00-1735-0000-0028-8655-D

121. Andrés V, Walsh K. Myogenin expression, cell cycle withdrawal, and phenotypic differentiation are temporally separable events that precede cell fusion upon myogenesis. J Cell Biol. 1996 Feb;132(4):657-66. 


\section{Acknowledgments}

First of all I would like to thank my supervisor Dr. Florian Rehfeldt for a great support and guidance during my thesis. The last almost four years of my $\mathrm{PhD}$ thesis were a big challenge for me both professionally and personally. I want to thank him for his patience and giving me opportunity to develop and learn.

I want to thank the other two members of my thesis committee: Prof. Tim Salditt and Prof. Annette Zippelius for their kindness and fruitful discussions during my thesis committee meetings. Moreover, I want to thank Prof. Christoph Schmidt for useful comments on Friday seminars and cell clubs.

The project I was working on first three years was funded from IsraelNiedersachsen cooperation. This project was done in collaboration with Dr. Assaf Zemel from The Hebrew University of Jerusalem, that is why I want to thank him as well for his help. For me it was a pleasure to work on such an interesting project. Additionally I want to thank SFB 937 for letting me finish my thesis and funding the last year of my PhD. Thank you for granting my attendance at the interesting conferences. I also want to thank the GGNB program for guidance and very useful courses.

It has been a great time working in DPI, I have learned a lot during last 4 years. What is very important for me that I have met very nice people, who I hope to stay in touch with. Especially I want to thank Carina for her patience while teaching me in the beginning and supporting me during the whole time. Many thanks to Alok for being my best friend, always helping, teaching and giving many comments. Minu, my choco-vanilla partner in the small-crime activities, thank you for being rational and keeping me calm in crisis. Thanks Andre (Dr. Düsy) Düselder for whining and at the same time giving wise advices, such as "when you don't know where to go or what to do, always follow THE Flo". I thank "THE Flo" Schlosser himself for teaching and forwarding to the rational route. Additionally, I want to thank Miquel, for keeping the group spirit and organizing many events; after you left the lab atmosphere would never be the same. Many thanks to Daniel Meyer for a good friendship and a nice company during the bench work. A big thank I send to Abhinav Sharma, he was a great teacher, explaining me all the theoretical basis, and became a good friend. I also want to thank Sam, Christina CJ, Renata for being 
very friendly and kind to me. There are of course many others I would like to thank: our T.As Kerstin, Ulrike and Tanja; Dieter Klopfenstein, Achintya Prahlad, Paula Sánchez, Chris Battle, Jennifer Radwitz, Knut Heidemann, Benjamin Eltzner, Ulrich Fromme, Eugenia Butkevich, Alice Wiesbaum, Mitja Platen, Frederike Derksen, Til Driehorst, Philipp Linke, Susanne Karsch, Gabriele Straaß, Kengo Nishi, Constantin Kohl, Max Scheu and everyone else I have forgotten here. Thank you very much to many of you who had time to proofread my thesis!

Furthermore, I thank Luda Osipova for a great friendship, support and being the best flatmate. In the end, the biggest thank goes to my family: my mom Nadezhda Kudryasheva, my father Alexander Kudryashev and my brother Misha Kudryashev for all the support and criticism, for the inspiration and being the good example for me. A great thank I send to my granny, who definitely will not understand what I wrote in English, she is a great grandma and a dangerous food terrorist :)

\section{Thank you!}




\section{Curriculum Vitae}

\section{Personal information}

Name:

Affiliation:

Address:

Date of birth

Place of birth

Tel.

E-mail
Galina Kudryasheva

Third Institute of Physics - Biophysics, Georg August University, Goettingen

Turmstrasse 1, 37073 Goettingen, Germany

21.09.1989

Krasnoyarsk, Russia

+4915731621520

galina.kudryasheva@phys.uni-goettingen.de

\section{Research experience}

03.2013 - present

$09.2011-12.2012$

$09.2006-07.2011$
PhD student in biophysics

Third Institute of Physics - Biophysics, Georg August

University Goettingen, Germany

Supervision by Dr. Florian Rehfeldt

Thesis title: Acto-myosin based mechano-sensitivity of cells - comparing human mesenchymal stem cells and differentiated cells

Academic researcher

University of Bayreuth, Germany

Boehringer Ingelheim Fonds funded research

Research title: kinetics of bimolecular interactions of glutathione reductase

Diploma in physics (equivalent to M.Sc)

Siberian Federal University, Krasnoyarsk,

Russia

Thesis title: Halogenated anthracenes:

spectral characteristics and their effects on

bioluminescent reaction

Supervisor: Dr. Elena Nemtseva 


\section{Publications}

E. Paluch, C. Nelson, N. Biais, B. Fabry, J. Moeller, B. Pruitt, C. Wollnik, G.

Kudryasheva, F. Rehfeldt, and W. Federle. (2015) Mechanotransduction: use the force(s). BMC Biol. 13: 47.

February $3^{\text {rd }}, 2017$ 